\title{
Test Plan for the Remote Conveyance and Innovative End Effector Demonstration
}

Phil Rice, EG\&G Idaho, Inc.

Ann Marie Smith, EG\&G Idaho, Inc.

Randy Peterson, RAHCO International

Published August 1994

Idaho National Engineering Laboratory

EG\&G Idaho, Inc.

Idaho Falls, Idaho 83415

Prepared for the

U.S. Department of Energy

Office of Environmental Management

Under DOE Idaho Operations Office

Contract No. DE-AC07-76ID01570 


\section{DISCLAIMER}

This report was prepared as an account of work sponsored by an agency of the United States Government. Neither the United States Government nor any agency thereof, nor any of their employees, make any warranty, express or implied, or assumes any legal liability or responsibility for the accuracy, completeness, or usefulness of any information, apparatus, product, or process disclosed, or represents that its use would not infringe privately owned rights. Reference herein to any specific commercial product, process, or service by trade name, trademark, manufacturer, or otherwise does not necessarily constitute or imply its endorsement, recommendation, or favoring by the United States Government or any agency thereof. The views and opinions of authors expressed herein do not necessarily state or reflect those of the United States Government or any agency thereof. 


\section{DISCLAIMER}

Portions of this document may be illegible in electronic image products. Images are produced from the best available original document. 


\section{Test Plan for the \\ Remote Conveyance and \\ Innovative End Effector Demonstration}

EGG-WTD-11185

Prepared by

M. M. M

P. M. Rice, Principal Investigator

Mechanical Engineering
$8-15-94$

Date

Reviewed by

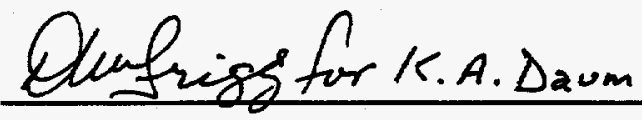

K. A. Daum, Senior Scientist

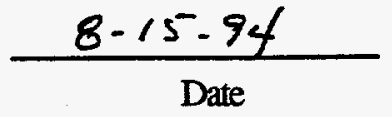

Environmental Restoration Program

Approved by

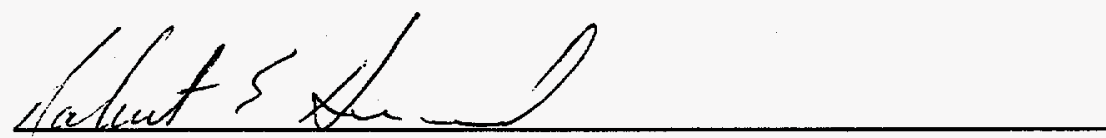

R. E. Heard, Program Manager

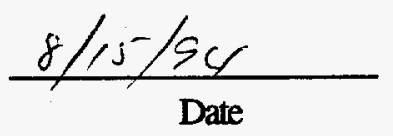

Buried Waste Integrated Demonstration

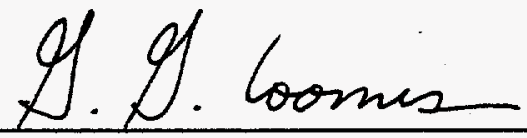

G. G. Loomis, Technical Liaison

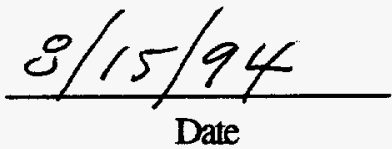

Buried Waste Integrated Demonstration 


\section{ABSTRACT}

This test plan describes the demonstration of innovative equipment and processes specifically designed to be superior to currently employed technology for buried waste retrieval.

The dumping of dry soil into a funnel/dumpster arrangement has been found to be the primary mechanism for dust generation during the retrieval of buried transuranic waste. The primary goal of the innovative end effector is to reduce dust generation and the potential spread of airbome contaminants during the dumping operation. In addition, regardless of the excavation technique, exhumed waste will have to be conveyed away from the retrieval area to a packaging area or directly to a treatment facility. The remote conveyance system is aimed at developing an remotely controlled vehicle to convey retrieved waste that will operate on variable terrain and remove workers from the hazardous zone.

To demonstrate the remote conveyance system and the innovative end effector, the Buried Waste Integrated Demonstration (BWID) Program has subcontracted with RAHCO International to provide equipment and services to perform a demonstration of the technologies. The demonstration will be performed in two phases. In Phase I, the subcontractor will perform a full scale demonstration to assess the ability of the innovative end effector to control dust generation and the potential spread of contamination during dumping operations. Phase II includes performing a retrieval/conveyance demonstration. This demonstration will excavate, dump, and convey simulated waste to demonstrate the functionality of the system (e.g., maneuverability, retrieval rates, and system integration). Phase II of the demonstration will include all elements of the remote conveyance and end effector system.

This test plan will describe the demonstration objectives, data quality objectives, equipment operation, and methods for collecting data during the demonstration. 


\section{SUMMARY}

This test plan describes a remote conveyance and innovative end effector demonstration that is being performed for the Idaho National Engineering Laboratory (INEL) as part of the U.S. Department of Energy's Office of Technology Development Buried Waste Integrated Demonstration (BWID) Project under the Retrieval Related Technologies Technical Task Plans ID1-4-20-06 and ID1-4-20-07. BWID examines promising, innovative technologies for demonstration purposes and also develops new technologies for application to DOE sites' waste problems.

To accomplish the task, a competitive procurement for a fixed price contract was initiated in fiscal year 1994 to private industry to solicit proposals for innovative equipment and processes for performing the demonstration. RAHCO Intemational, of Spokane, Washington, in conjunction with Spar Aerospace Ltd., of Brampton, Ontario, submitted the winning proposal and was awarded the contract to perform the demonstration, scheduled for the summer of 1994.

The overall objective of the demonstration is to explore the effectiveness of methods and equipment to remotely transport buried waste away from the digface and control dust generation and contamination spread while dumping retrieved waste. To achieve this goal, RAHCO will develop the system and conduct the demonstration as follows:

\section{Phase I Demonstration:}

Phase I will consist of a full-scale demonstration to assess the ability of the innovative end effector to control dust generation and the potential spread of contamination during dumping operations.

The specific objectives for Phase I of the demonstration are:

- Determine the amount of dust generated and contamination spread during the test

- Evaluate the capability of the system to excavate buried waste.

The Phase I test will be performed in Spokane, Washington, at RAHCO's facility under controlled environmental conditions (such as would occur inside a retrieval containment structure). The demonstration will include, at a minimum, the digging and dumping operations of the system and test the ability of the system to reduce the generation and spread of dust during the dumping operation. Simulated waste and dry INEL soils will be used as the test media.

\section{Phase II Demonstration:}

Phase II will consist of a full-scale retrieval/conveyance demonstration. The demonstration will include all elements of the waste conveyance and end effector system. The Phase II demonstration will also take place at RAHCO's facility but will be performed outdoors. The demonstration will excavate, dump, and convey simulated waste to demonstrate the functionality of the system (e.g., maneuverability and retrieval rates). 
The specific objectives for Phase II of the demonstration are:

- Determine the rate of waste removal using the selected end effector and/or dust free dumping system (the goal is $80 \mathrm{yd}^{3} /$ day).

- Determine the capability of the end effector to handle the various objects that could be encountered in an actual operation.

- Establish a probable rate for conveyance of waste from the digface based on use of the selected equipment and technologies. A goal of $80 \mathrm{yd}^{3} / \mathrm{day}$ in an 8-hour shift will be used for design of the demonstration system. Each conveyed waste container will be allowed to hold a maximum of approximately $1.4 \mathrm{yd}^{3}$ of simulated buried waste.

- Demonstrate the effectiveness of the conveyance vehicle telerobotic control system.

- Determine the maneuverability and ability of the conveyance system to operate on rugged terrain.

- Evaluate the capability of the system for operation in a transuranic contaminated environment (including deployment, maintenance, reparability, reliability, and operating cost).

- Demonstrate the smooth integration of the innovative end effector and the remote conveyance system.

Work done under the BWID remote conveyance and innovative end effector demonstration project will provide data required by the Comprehensive Environmental Response, Compensation, and Liability Act for evaluating the application of these technologies as alternates to existing conventional methods for the retrieval of buried transuranic waste at the INEL and other DOE facilities. This information will be factored into a remedial investigation/feasibility study leading to a final record of decision for disposition of the buried transuranic waste. 


\section{CONTENTS}

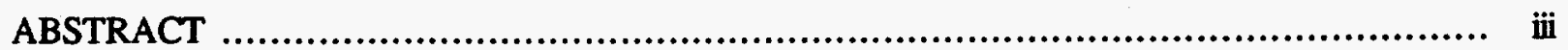

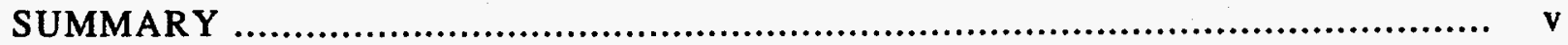

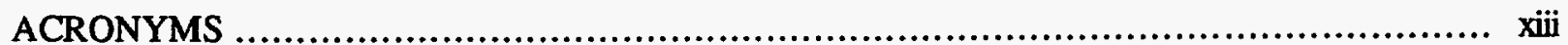

1. INTRODUCTION ............................................................................ 1

1.1 Technology Description and Background ................................................... 1

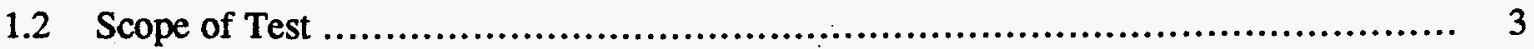

1.2.1 Phase I Demonstration-Dust and Contamination Spread ........................ 3

1.2.2 Phase II Demonstration-Retrieval and Conveyance ............................. 4

1.3 Test Objectives and Data Quality Objectives ....................................... 5

1.3.1 Phase I Demonstration-Dust and Contamination Spread ........................ 6

1.3.2 Phase II Demonstration-Retrieval and Conveyance .......................... 10

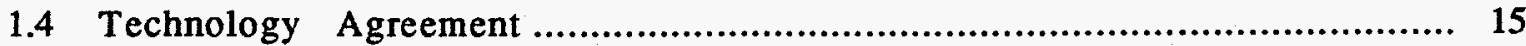

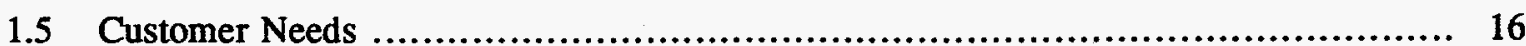

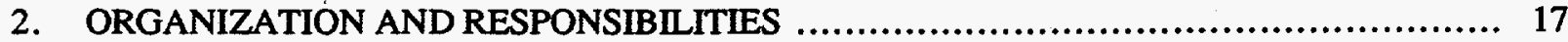

2.1 Buried Waste Integrated Demonstration Program .......................................... 17

2.2 Organizational Responsibilities ......................................................... 17

2.2.1 Programmatic Responsibilities ............................................... 17

2.2.2 Delegation of Authority for Conducting the Test ............................... 19

2.3 Personnel Support Requirements ................................................ 19

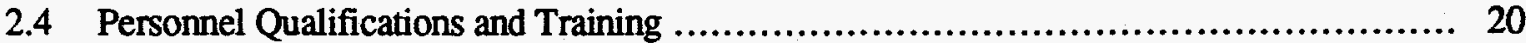

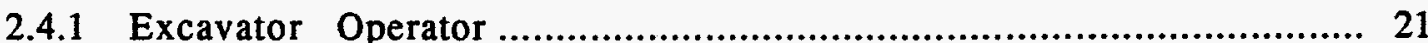

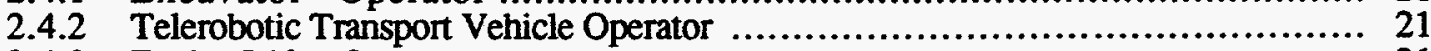

2.4.3 Fork Lift Operator ......................................................... 21

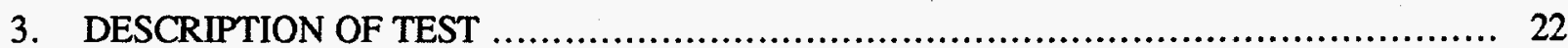

3.1 Key Input and Output Parameters ....................................................... 22

3.1.1 Phase I Demonstration ............................................................ 22

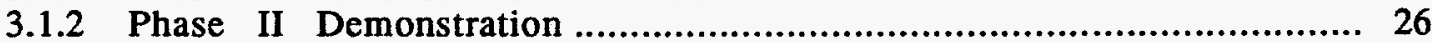

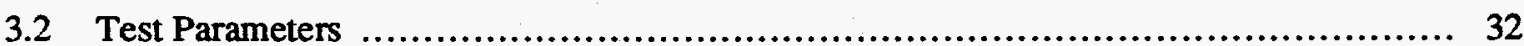

3.2.1 Number of Tests ............................................................... 32

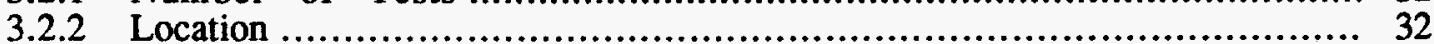

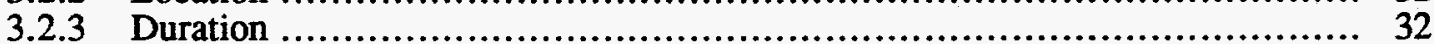

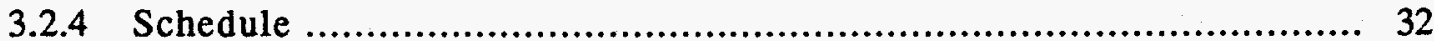

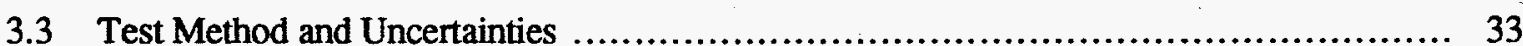




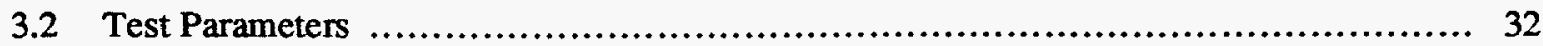

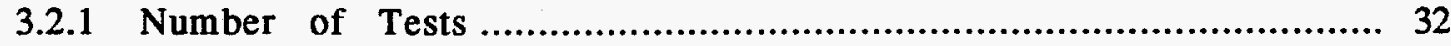

3.2.2 Location .................................................................... 32

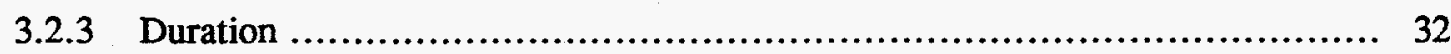

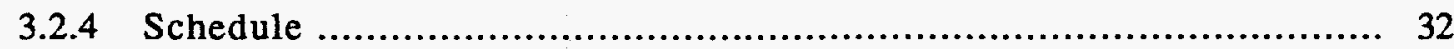

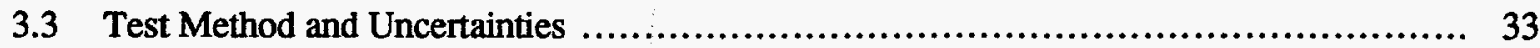

$3.4 \quad$ Procedures to Conduct the Test........................................................ 33

3.5 Contingency Plans ............................................................ 33

3.6 Performance Objectives.............................................................. 33

3.6.1 Innovative End Effector System Performance Objectives .......................... 33

3.6.2 Performance Objectives for the Remote Waste Conveyance System.................... 36

3.7 Customer Needs..................................................................... 38

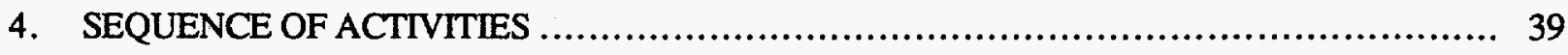

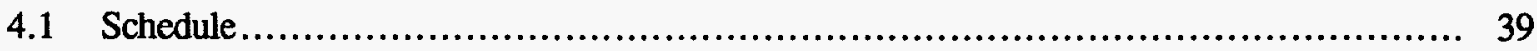

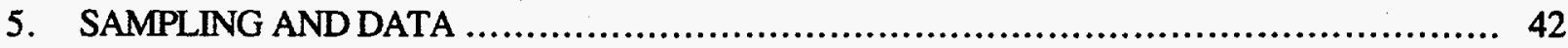

5.1 Relationship of Data to CERCLA Criteria ...................................... 42

5.1.1 Overall Protection of Human Health and the Environment ........................ 42

5.1.2 Long-Term Effectiveness and Permanence.................................. 42

5.1.3 Reduction of Toxicity, Mobility, and Volume Through Treatment................ 42

5.1.4 Short-Term Effectiveness....................................................... 42

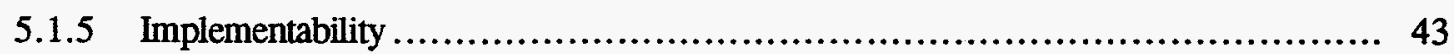

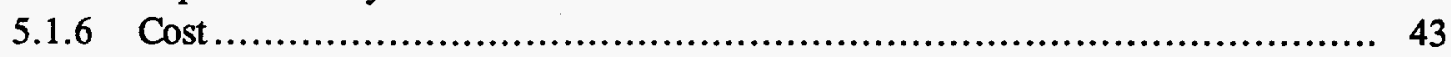

$5.2 \quad$ Data Collection Techniques ........................................................ 43

5.2.1 Particulate Sample Filters ................................................ 43

5.2 .2 Mass Measurements....................................................... 43

5.2.3 Maneuverability (Precision and Accuracy) Evaluation ........................ 44

5.2.4 Operational Evaluation ......................................................... 45

5.3 Sampling and Data Collection Procedures......................................... 45

5.3.1 Particulate Sample Filters.................................................... 45

5.3.2 Precision and Accuracy of Remote Operations.................................... 47

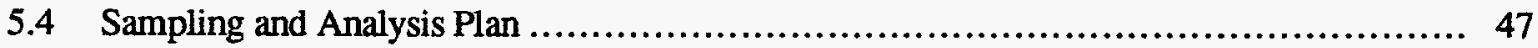

5.4.1 Chain of Custody ............................................................ 47

5.4 .2 Management of Samples..................................................... 47 
5.4.3 Analysis of Samples.......................................................................... 48

5.4.4 Data Reduction, Validation, and Verification.............................................. 48

5.4.5 Data Analysis........................................................................ 48

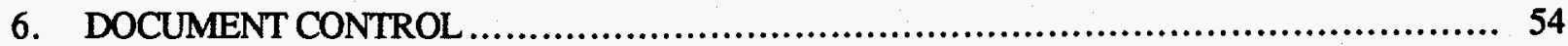

6.1 BWID Requirements..................................................................... 54

6.1.1 Management of Electronic Data .................................................... 54

6.1.2 Management of Reports................................................................. 54

6.1.3 Management of Log Books............................................................... 54

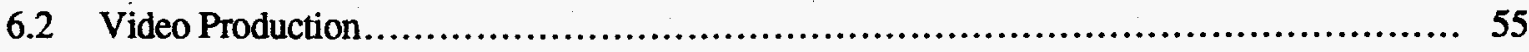

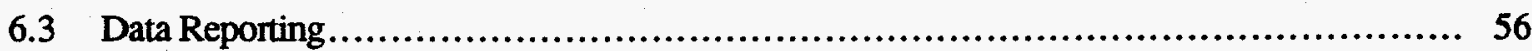

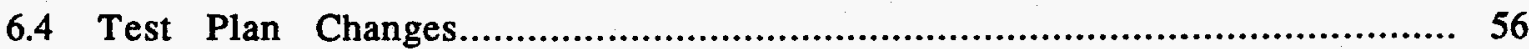

7. ANALYTICAL PROCEDURES.................................................................... 57

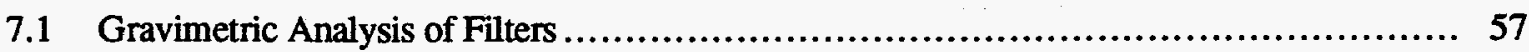

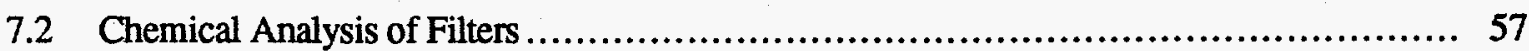

8. DATA REDUCTION, VALIDATION, AND VERIFICATION .................................... 58

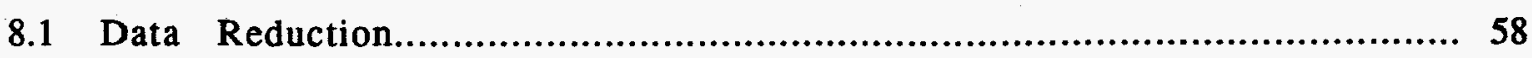

8.1.1 Dust Measurement Data Reduction .................................................. 58

8.1.2 Rare Earth Tracer Data Reduction ................................................... 59

8.1.3 Other Data Reduction Methods............................................................. 62

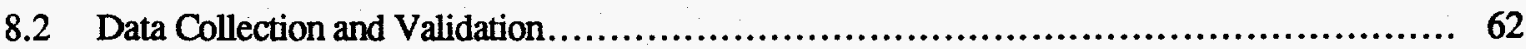

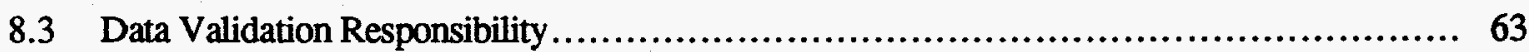

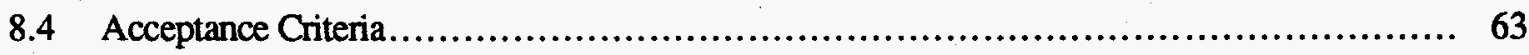

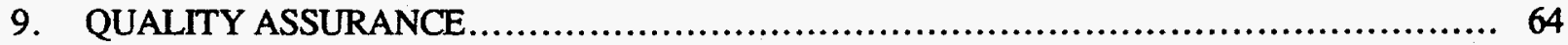

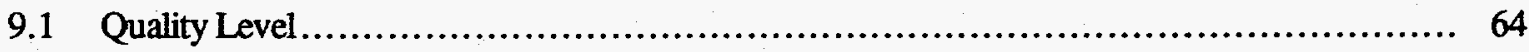

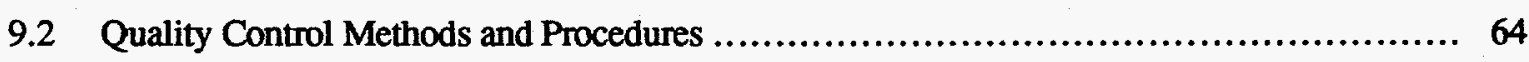

9.3 Precision and Accuracy of Measured Data.......................................................... 65

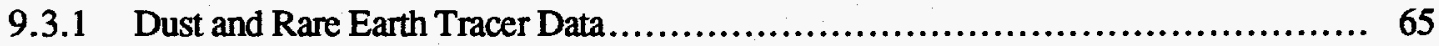

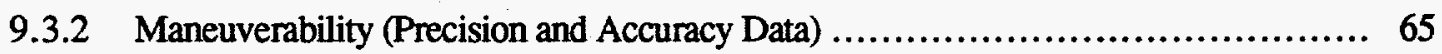

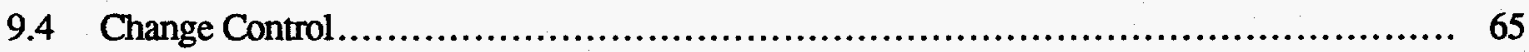

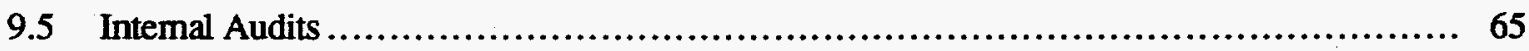




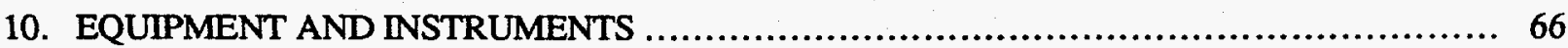

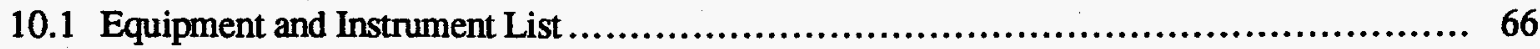

10.2 Instrument Requirements..................................................... 67

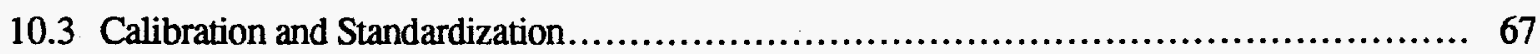

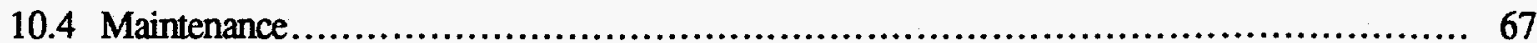

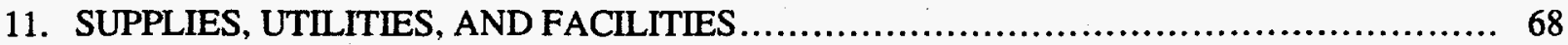

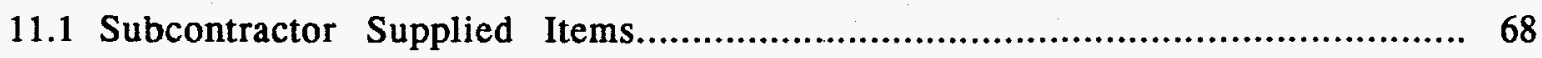

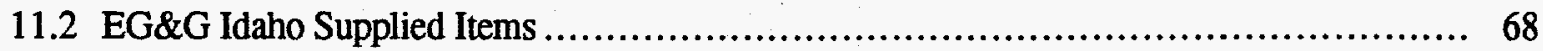

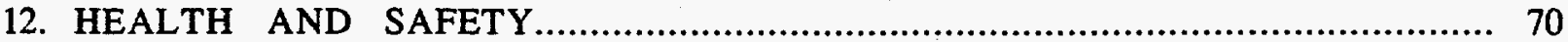

12.1 Radiological Safety Training .................................................... 70

12.2 Laboratory Safety Training............................................................. 70

12.3 Waste Management Practices and Training................................................. 70

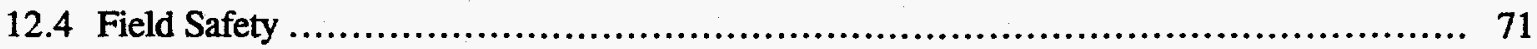

12.4.1 Environmental Conditions................................................ 71

12.4.2 Telerobotic Transport Vehicle ............................................ 72

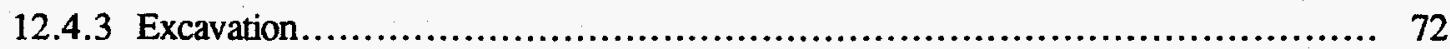

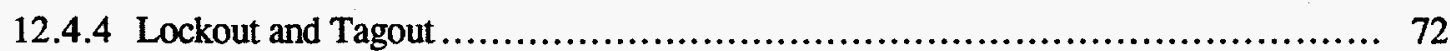

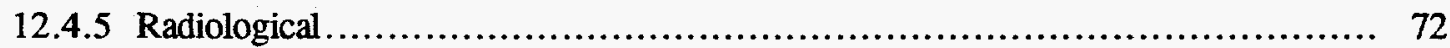

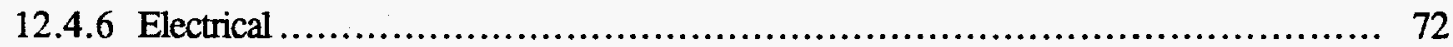

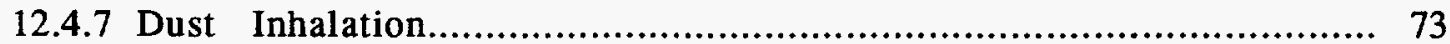

13. RESIDUALS MANAGEMENT ......................................................... 74

13.1 Phase I Demonstration-Dust and Contamination Spread.................................. 74

13.2 Phase II Demonstration-Retrieval and Conveyance ................................. 74

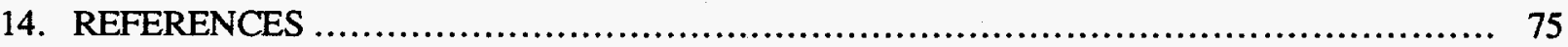

Appendix A-Basis for Dust Level ........................................................... A

Appendix B-Test Procedures...................................................................... B-1

\section{FIGURES}

1. Process diagram showing a portion of the waste retrieval process ............................ 3

2. The Phase I test will be conducted in an enclosed structure to ensure controlled environmental conditions 
3. The Phase II test will involve exhumation of simulated buried TRU waste and will be conducted at the subcontractor's facility

4. Innovative end effector and waste conveyance demonstration organization chart

5. The innovative end effector is highly integrated with the excavator and the conveyance system.

6. The multipurpose end effector integrates innovative features with proven excavation and retrieval technology.

7. The ITM is a detachable loading, handling, and conveyance bucket

8. The waste transport container carries the ITMs and can be used to transport large objects including intact $4 \times 4 \times 8$ - $\mathrm{ft}$ waste boxes.

9. The TTV mechanical subsystem consists of a track assembly, main frame, diesel power plant, hydraulic system, and ITM cradle

10. The mechanical subsystem uses existing, state-of-the-art, mobile equipment components

11. Detailed schedule for Phases I and II of the demonstration.

12. Project schedule

13. Cross-sectional view of the HI-VOL air sampler

14. TTV maneuverability evaluation measurements

15. Sample dust measurement collection sheet.

16. Sample filter weight data collection sheet.

17. A simple bar chart will be used to display the dust measurement data.

18. A simple bar chart will be used to display the rare earth tracer data

\section{TABLES}

1. Supporting personnel for the demonstration

2. Risk mitigation.

3. Contingency plans for items most likely to interrupt or delay the demonstration have been identified..... 
4. Detailed breakdown of the schedule milestones arranged by task element code..................... 40

5. Detailed breakdown of the schedule milestones arranged in chronological order................ 41

6. The data and analysis for dust measurement will be published in tabular form for each test run similar to the table shown............................................................

7. The data and analysis for rare earth tracers will be published in tabular form for each test

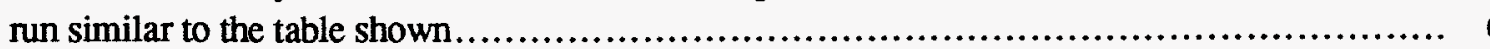

8. Air sampling equipment, laboratory equipment, and consumables (filters) are required to determine the contamination spread and dust generation for Phase I of the demonstration........ 66

9. Primary equipment needed to support the Phase I demonstration ........................... 66

10. Primary equipment needed to support the Phase II demonstration..................................... 66 


\section{ACRONYMS}

BWID Buried Waste Integration Demonstration

CERCLA Comprehensive Environmental Response, Compensation, and Liability Act

COC Chain of Custody

DOE U.S. Department of Energy

DOE-ID U.S. Department of Energy Idaho Operations Office

DQO Data Quality Objective

ECL Environmental Chemistry Laboratory

FY Fiscal year

HI-VOL High-volume air sampler

ICP-MS Inductively Coupled Plasma-Mass Spectrometry

IDC Integrated Demonstration Coordinator

INEL Idaho National Engineering Laboratory

ITM Integrated Transfer Module

OTD Office of Technology Development

PI Principal Investigator

PM Project Manager

PPG Program Planning Group

RF Radio Frequency

RWMC Radioactive Waste Management Complex

ROD Record of Decision

SDA Subsurface Disposal Area

SOP Standard Operating Procedure

SOW Statement of Work

TL Technical Liaison

TRU Transuranic

TSG Technical Support Group

TTP Technical Task Plan

TTV Telerobotic Transport Vehicle

QPP Quality Program Plan

VARSA Vehicle Acoustic Ranging System Array 


\section{Test Plan for the Remote Conveyance and Innovative End Effector Demonstration}

\section{INTRODUCTION}

This test plan outlines the methods that will be used to evaluate the remote conveyance system, and the innovative end effector. These technologies will be demonstrated during fiscal year (FY) 1994. Both phases of the demonstration will be conducted at RAHCO International's facility in Spokane, Washington. The purpose of this demonstration is to explore the effectiveness of methods and equipment to remotely transport buried waste away from the digface and control dust generation and contamination spread while dumping retrieved waste.

This test plan provides the background information for the demonstration, discusses the organizational structure, outlines the objectives of the tests to be conducted, describes the methods and apparatus used to conduct the tests, and details the quality and safety requirements for these tests.

In compliance with Buried Waste Integrated Demonstration's (BWID's) direction and funding availability, the scope of this project was limited to development and testing of one integrated system to control dust and contamination spread. Exploration into other alternatives and/or improvements in the FY-94 system may be pursued under subsequent BWID programs.

\subsection{Technology Description and Background}

Between 1952 and 1970, over two million cubic feet of transuranic (TRU) mixed waste was buried in shallow pits and trenches in the Subsurface Disposal Area (SDA) at the Idaho National Engineering Laboratory's (INEL's) Radioactive Waste Management Complex (RWMC). Commingled with this two million cubic feet of waste is up to 10 million cubic feet of fill soil (Arrenholz and Knight, 1991). Approximately $6 \mathrm{ft}$ of clean overburden soil has been placed on top of the buried waste pits and trenches to isolate the waste from surface water runoff and wind erosion. The pits and trenches were constructed similarly to municipal landfills with both stacked and random dump waste forms such as barrels and boxes. The barrels are typically 55-gal drums made of metal. The boxes are typically $4 \times 4 \times$ $8 \mathrm{ft}$ and constructed of plywood. The drums and boxes contain wastes such as paper, sludge, metal, tools, cloth, wood, asphalt, concrete, and glass. There could also be large objects including storage tanks, vehicles, pipes, beams, and glove boxes. The main contaminants are micron-sized particles of plutonium and americium oxides, chlorides, and hydroxides (Meyer, 1990). Retrieval, treatment, and disposal is one of the options being considered for the waste. As an aggregate, the retrieved waste will average above $10 \mathrm{nCi} / \mathrm{g}$ for the TRU elements. The waste also contains volatile organics such as trichloroethylene and carbon tetrachloride and cutting oils such as REGAL oil. The waste containers are assumed to be severely deteriorated to the point that many containers are breached, leaking, or even unrecognizable due to deterioration. 
The configuration of waste described above and located at the SDA is similar to other buried waste located at U.S. Department of Energy (DOE) sites throughout the United States. In response to the need to remediate these sites the DOE's Office of Technology Development (OTD) has initiated a comprehensive program to develop and demonstrate advanced remediation technologies that support DOE's environmental restoration objectives. Further, OTD has initiated the BWID program at the INEL to investigate the feasibility of new and existing technologies for the effective in situ treatment, removal, and treatment after removal of buried wastes. BWID will address the complex problems associated with buried waste by initially focusing on buried waste located at the INEL. Technologies that are successfully developed within the BWID Program will result in the transfer of scientifically sound, demonstrated technologies that can be deployed in various Environmental Restoration programs throughout the DOE complex.

The waste conveyance system and innovative end effector are major components of the retrieval related technologies. These technologies directly affect the digging, dumping, and transport processes of the retrieval (see Figure 1).

Previous experiments conducted at the INEL have used both misting systems and directed airflow to control the spread of dust during dumping operations into a funnel. Misting and directed airflow, while practical, require more maintenance and downtime for repair and are cumbersome to deploy, maintain, and move. It is desirable to avoid directed airflow and/or misting systems if possible. Neither of these approaches were ideal because in both cases dust escaped regardless of airflow or misting rate. In addition, the dust that does escape is the respirable fraction thought to carry the plutonium/americium particles. The dumping of dry soil into a funnel/dumpster arrangement has been found to be the primary mechanism for dust generation during the retrieval process. Therefore, improving the method of dumping soil and debris and thereby limiting the spread of dust and contaminants is mandatory.

Regardless of the excavation technique, exhumed waste will have to be conveyed away from the retrieval area to the packaging area or directly to the treatment facility. Conveyance of the retrieved waste from the digface during the FY-93 demonstration was performed by an integrated tool carrier (Caterpillar IT-28) with a forklift attachment. Although the vehicle used in the demonstration was effective in traversing the terrain and lifting the loads, it is not remotely controlled as will be required in a radioactive (hot) retrieval.

The innovative end effector system and remotely operated conveyance system need to be developed in close coordination with one another to ensure a systems design approach that maximizes the effectiveness of the combined technologies. The following describes the relationship between the proposed demonstrations and the envisioned actual operation:

- The demonstration will be limited in the types of waste materials that can and will be included in the excavation process whereas the actual operation would have a full range of waste items and materials that would be encountered.

- The demonstration will be performed in a cold environment as opposed to a hot or radioactive environment found in an actual operation. This will prevent unnecessary delays or downtime for extensive decontamination during maintenance and possible retooling. 


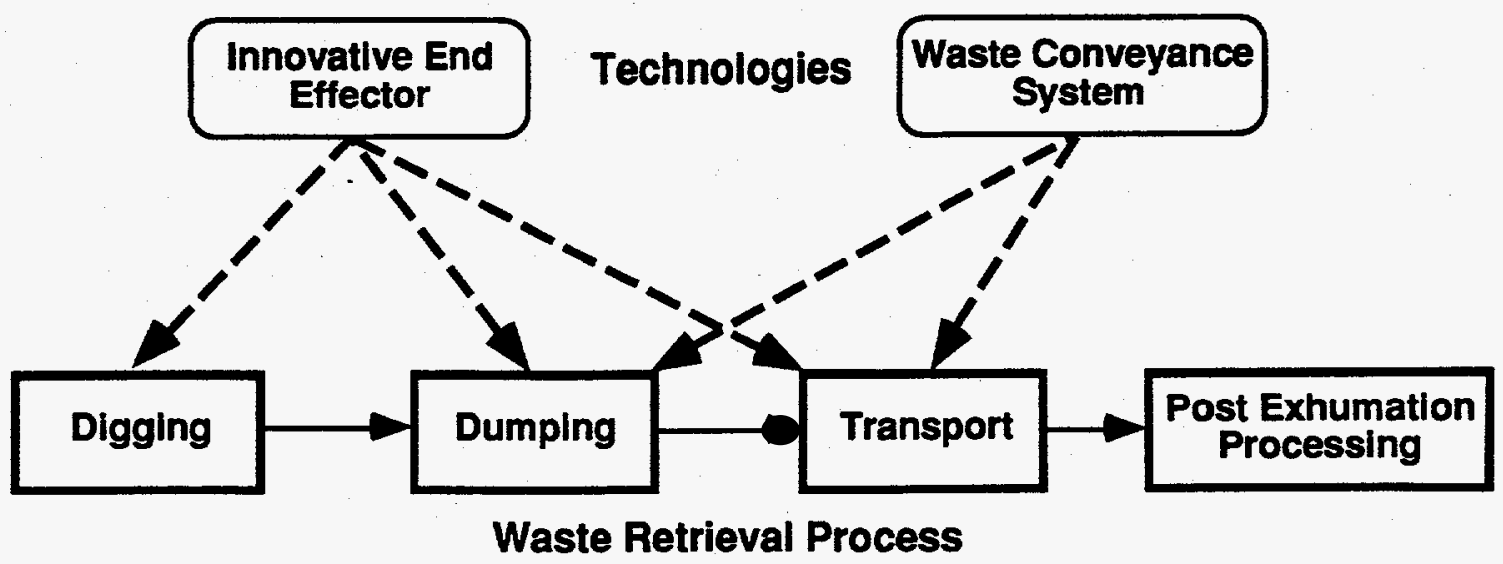

Figure 1. Process diagram showing a portion of the waste retrieval process. Waste conveyance and innovative end effector technologies affect several stages of the retrieval process.

- The actual system shall be designed so that personnel exposure to radiation will comply with DOE Order 5480.11 "Radiation Protection for Occupational Workers." Radiation exposure limits do not apply to this demonstration because no radioactive materials will be involved.

\subsection{Scope of Test}

\subsubsection{Phase I Demonstration-Dust And Contamination Spread}

The Phase I demonstration consists of a full-scale test to assess the ability of the innovative end effector to control dust generation and the potential spread of contamination during dumping operations. The test will be performed at RAHCO's facility under controlled environmental conditions (such as would occur inside a retrieval containment structure). The demonstration will include, at a minimum, both digging and dumping operations; however, the primary objective is to test the ability of the system to reduce the generation and spread of dust during the dumping operation.

This demonstration will consist of digging and dumping dry, INEL soils mixed with simulated waste using the RAHCO-designed innovative end effector. The demonstration will be performed in an indoor facility where environmental conditions (especially air circulation) can be controlled so that effective dust and rare earth tracer measurements can be taken. Figure 2 is an illustration showing the general arrangement for the Phase I test. The digging and dumping operations must be separated so that the dust generated from the digging does not affect the dumping portion of the test (since it is the dust generated during dumping that is of interest). Because the subcontractor has elected to develop an end effector instead of a dust free dumping system, the test would consist of the digging phase and whatever actions are required to deposit the end effector for the conveyance system to remove. The demonstration will consist of a series of digging and dumping actions from a pile of approximately $66 \mathrm{yd}^{3}$ of mixed soil and simulated waste. The soil and waste shall be spiked with a rare earth tracer (a rare, nonhazardous, nonradioactive element) to provide an easy method to analyze and evaluate samples. Dust measurements 


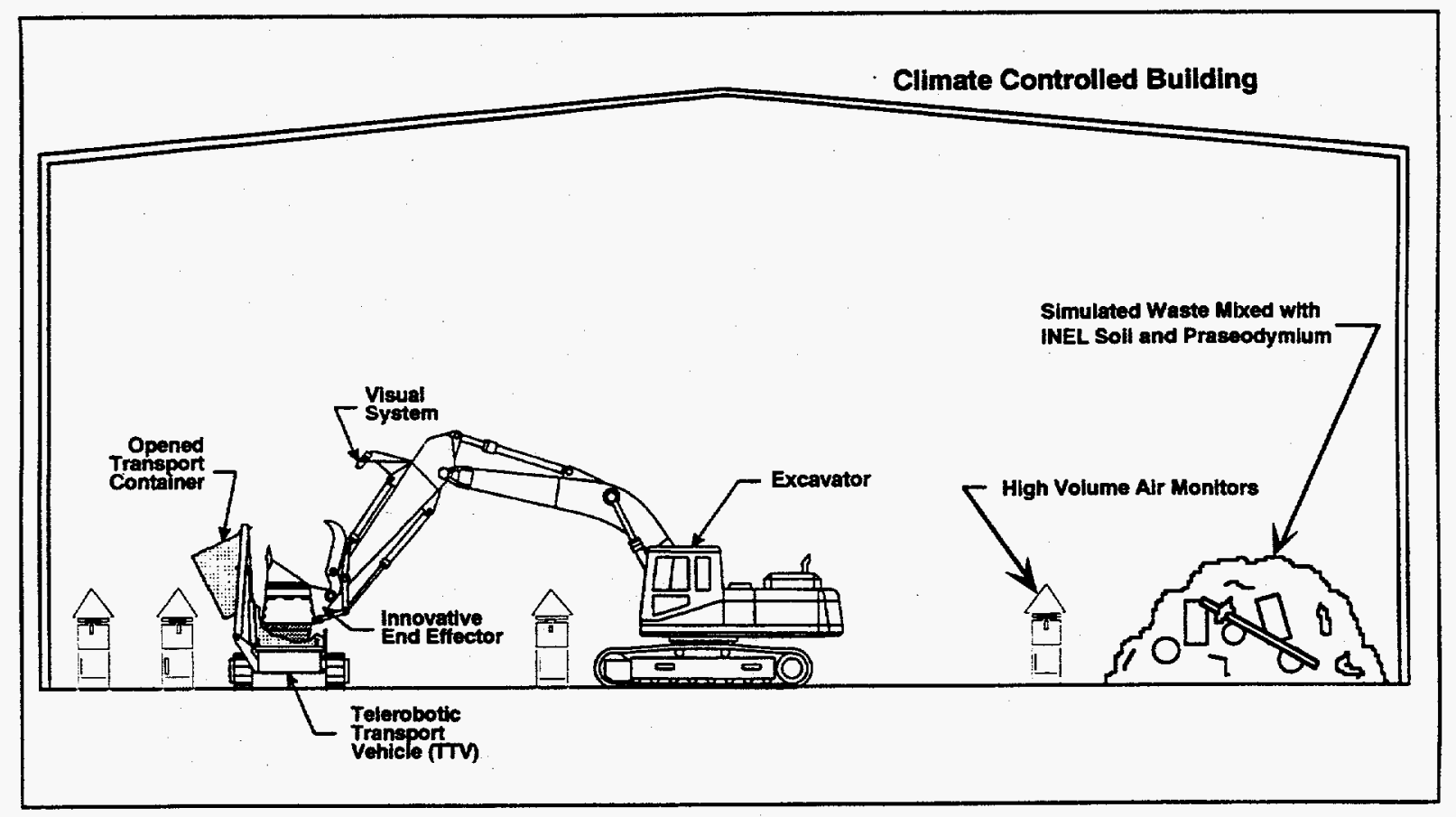

Figure 2. The Phase I test will be conducted in an enclosed structure to ensure controlled environmental conditions. The primary purpose of the Phase I test is to determine the amount of dust generated during waste dumping and level of potential contamination spread.

will be made by EG\&G Idaho, Inc. The samples will be analyzed to determine the ability to minimize the generation and suspension of dust during the dumping operations.

\subsubsection{Phase II Demonstration-Retrieval And Conveyance}

The Phase II demonstration consists of a full-scale retrieval of simulated buried waste using an excavator to assess the ability of the end effector and the waste conveyance system to effectively handle, dump, and transport the waste from the digface. This phase of the demonstration will also be performed at RAHCO's facility. The demonstration shall include all elements of the waste conveyance and end effector systems. The demonstration will excavate, dump, and convey simulated waste from the test arena to demonstrate the functionality of the system (e.g., maneuverability and retrieval rates). Figure 3 is an illustration showing the general arrangement for the Phase II test. During the retrieval activities, observations and measurements will be performed to determine how efficiently the equipment excavates the waste, works around or handles large objects, and conveys the waste from the excavation site. The baseline for the excavation (e.g., ability to handle large objects) will be the Balderson thumb. The Balderson thumb has been shown to be very effective and versatile in previous demonstrations. Assessment of the maneuverability, precision, accuracy, flexibility of the conveyance system, and an assessment of the remote control system shall be made. Observations will be made regarding the system integration between the remote conveyance system and the innovative end effector and the affect that system integration has on overall system performance. No dust measurements will be made during this demonstration; however, qualitative data will be gathered on the ability of the system to control dust generation during these operations. 


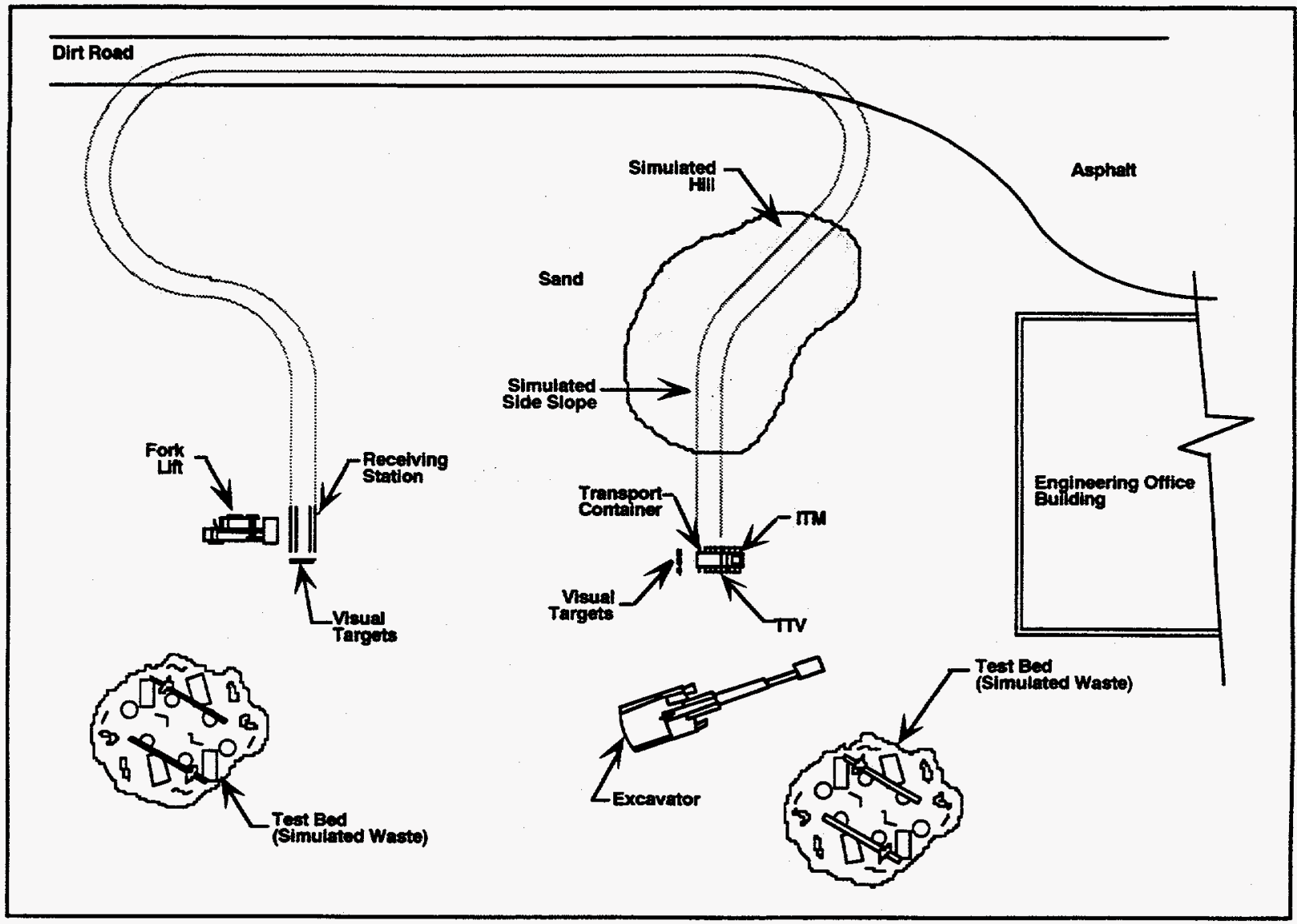

Figure 3. The Phase II test will involve exhumation of simulated buried TRU waste and will be conducted at the subcontractor's facility. The primary purpose of the Phase II test is to demonstrate the remote conveyance system and examine the integration between the innovative end effector and conveyance systems.

\subsection{Test Objectives and Data Quality Objectives}

The overall objective of the demonstration is to explore the effectiveness of methods and equipment to remotely transport buried waste away from the digface and control dust generation and contamination spread while dumping retrieved waste. The data will eventually be used by Environmental Restoration during the feasibility study for parts of the RWMC and possibly by additional remediation efforts in other DOE locations and U.S. Superfund Sites. Data will also be used by Environmental Restoration to project additional technology needs for BWID out year planning.

Data will be obtained with the best available instrumentation within the budget of the project. All instrumentation will operate within the stated calibration range, with total uncertainty as stated in Sections 1.3.1 (Phase I Demonstration-Dust And Contamination Spread) through 1.3.2 (Phase II Demonstration-Retrieval And Conveyance).

Details of the analytical procedures, including gravimetric analysis of the filters, chemical analysis of the filters, and calculation procedures are detailed in Section 7, "Analytical Procedures," of 
this test plan. Section 8, "Data Reduction, Validation, and Verification," describes the procedures for reduction, validation, and recording of the data.

The following discussion of the test objectives includes a statement of the test objective, the data quality objective (DQO) for that test objective, and a statement of the uncertainty for the measurements to be taken to meet the DQO with a short discussion of how each uncertainty specification was derived. In some cases, a description of how the data and final analysis will be presented is given. Some of the data to be collected (e.g., soil moisture, humidity) may not be used directly in the analysis but are being collected out of convenience and in anticipation of its future value.

\subsubsection{Phase I Demonstration-Dust and Contamination Spread}

Phase I will consist of a full-scale demonstration to assess the ability of the innovative end effector to control dust generation and the potential spread of contamination during dumping operations.

The specific objectives for Phase I of the demonstration are as follows.

\subsubsection{Dust Measurement.}

Test Objective: Demonstrate the ability of the equipment and processes to control the generation of dust during dumping operations to a level of $1.1 \times 10^{-4} \mathrm{~g} / \mathrm{L}$ of air above background levels. This level $\left(1.1 \times 10^{-4} \mathrm{~g} / \mathrm{L}\right)$ represents a contaminated dust level that will allow bubble suit entry into a retrieval zone with an airborne concentration level of $<10 \mathrm{nCi} / \mathrm{g}$. The derivation of the dust level can be found in Appendix A.

Data Quality Objective: Determine with a $95 \%$ confidence level if dust at $1.1 \times 10^{-4} \mathrm{~g} / \mathrm{L}$ of air above background levels was detected.

Uncertainty: The following total uncertainty specifications apply for the measurements:

- Airflow measurements through the particulate samplers: Maintained within $10 \%$ of calibrated value.

The $10 \%$ flow total uncertainty was derived from the accuracy of calibration of the instruments used in this test for particulate air sampling.

- Mass measurements of the air sampler filters within $0.0001 \mathrm{~g}$.

The $0.0001 \mathrm{~g}$ total uncertainty was derived from the accuracy of calibration of the instruments used in this test for weighing the particulate air sample filters.

- Soil moisture measurements: Uncertainty will be reported with the data.

Soil moisture is determined by weighing and drying a soil sample. Soil samples are weighed to the nearest $0.0001 \mathrm{~g}$ before and after desiccation. 


\subsubsection{Tracer Measurement.}

Test Objective: Demonstrate the ability of the equipment and processes to control the spread of contamination.

Data Quality Objective: Determine with a $95 \%$ confidence level if rare-earth tracer (praseodymium) was detected above background levels.

Uncertainty: The following total uncertainty specifications apply for the measurements:

- Airflow measurements through the particulate samplers: Maintained within $10 \%$ of calibrated value.

The $10 \%$ flow total uncertainty was derived from the accuracy of calibration of the instruments used in this test for particulate air sampling.

- Mass measurements of the air sampler filters within $0.0001 \mathrm{~g}$.

The $0.0001 \mathrm{~g}$ total uncertainty was derived from the accuracy of calibration of the instruments used in this test for weighing the particulate air sample filters.

- Soil moisture measurements: Uncertainty will be reported with the data.

Soil moisture is determined by weighing and drying a soil sample. Soil samples are weighed to the nearest $0.0001 \mathrm{~g}$ before and after desiccation.

Analytical Variation: For rare earth tracer praseodymium,

Instrument Detection Limit- $0.032 \mu \mathrm{g} / \mathrm{L}$

Standard Concentration $\quad=\quad 0.200 \mu \mathrm{g} / \mathrm{L}$

Measured 7 Aliquots (3 Reps Each) On 3 Separate Days:

$\begin{array}{lll}\text { Average Value } & = & 0.2424 \mu \mathrm{g} / \mathrm{L} \\ \% \text { Recovery } & = & 121.2 \% \\ \text { Standard Deviation } & = & 0.0107 \mu \mathrm{g} / \mathrm{L}\end{array}$

Method accuracy and variation example for praseodymium previously used as a surrogate spike:

High Volume (HI-VOL) Air Sampler (1 set of digestions and analysis)

$\begin{array}{lll}\text { Actual } & = & 100 \mu \mathrm{g} / \mathrm{L} \\ \text { Average } & = & 104.77 \mu \mathrm{g} / \mathrm{L} \\ \text { Standard Deviation } & = & 3.896 \mu \mathrm{g} / \mathrm{L} \\ \text { Minimum } & = & 98.87 \mu \mathrm{g} / \mathrm{L} \\ \text { Maximum } & = & 110.95 \mu \mathrm{g} / \mathrm{L}\end{array}$


Previous studies performed at the INEL show that rare earth tracer can act as a surrogate for plutonium to evaluate the spread of contamination (Meyer, et al, 1994).

The rare earth tracer praseodymium was chosen for several reasons: (1) of the lanthanide series rare earth elements, praseodymium's typical earth crust level (parts per million) is only exceeded by cerium and neodymium, making it relatively easy to detect, (2) for the analytical measurements, there are no interfering ions for praseodymium 141 , and (3) praseodymium is relatively inexpensive compared to other rare earth tracers.

The praseodymium will be spiked in the soil and simulated waste at approximately 5 times background level. Natural background level for praseodymium in the earth's crust is approximately $6 \mathrm{ppm}$. To achieve a level of $30 \mathrm{ppm}(\mu \mathrm{g} / \mathrm{g})$, a total of $2 \mathrm{~kg}$ of praseodymium will be added to the soil/waste mixture. The following is the calculation for the praseodymium spike:

$\begin{array}{lll}\text { Total Soil } & = & 50 \mathrm{yd}^{3} \\ \text { Total Waste } & = & 16 \mathrm{yd}^{3} \\ \text { Total Waste Volume } & = & 66 \mathrm{yd}^{3}\end{array}$

Consider only the soil volume for the purposes of calculating the rare earth tracer spike

$\left(50 \mathrm{yd}^{3}\right) \times\left(27 \mathrm{ft}^{3} / \mathrm{yd}^{3}\right) \times\left(105 \mathrm{lb} / \mathrm{ft}^{3}\right) \times(454 \mathrm{~g} / \mathrm{lb})=64,354,500 \mathrm{~g}$ of soil.

To achieve $30 \mu \mathrm{g} / \mathrm{g}$

$(64,354,500 \mathrm{~g}$ of soil $) \times(30 \times 10-6 \mathrm{~g}(\mathrm{Pr}) / \mathrm{g}$ of soil $)=1,930 \mathrm{~g}(\mathrm{Pr})$

The praseodymium is purchased in even quantities so round up and use $2,000 \mathrm{~g}$ to spike the soil/waste mixture.

A "mini-test" was run to determine if the soil spike at 5 times background could be easily detected on the filters (i.e., was high enough to be detected above background), and to determine if the assumption that a 1:1 correlation between dust and tracer was reasonable. An EG\&G Idaho letter report AMS-23-94a was issued to document this test. Summary results indicated that (probably due to the micron sized particles of praseodymium) the praseodymium was detected at levels approximately 100 times background. This indicates that the 1:1 correlation assumption is very conservative and that the $30 \mathrm{ppm}$ spike level should be quite sufficient to provide detection on filters that collect an adequate amount of dust.

a. EG\&G Idaho, Inc., Letter Report, Ann Marie Smith, "Basis for Dust Level," AMS-23-94. 


\subsubsection{Operational Evaluation.}

Test Objectlve: Evaluate the capability of the system.

Data Quality Objective: Observe the operations of the innovative end effector system and record information concerning: spillage, ability to handle the waste forms, visual estimate of dust generation, reliability, ease of use, ease of maintenance, and any other operational parameters that could be used to determine the system's capability. Documentation shall include photographs, videotape, and log book entries. Specific items to document include:

- Volume of waste removed per excavation cycle

- Waste spillage volume measurements

- Observations on system excavation effectiveness and ability to handle waste forms

- Visual observations of dust generated during the complete excavation and dumping cycle

- Ease of use of the end effector system, including Integrated Transfer Module (ITM) attachment/detachment to end effector, ITM placement into transport container

- Anomalous conditions

- Overall reliability of end effector system

- Frequency and type of maintenance required during the demonstration, both scheduled and unscheduled

- Length of time required for maintenance activities.

Uncertainty: The following total uncertainty specifications apply for the measurements:

- The volume of waste removed per cycle: $10 \%$ of end effector capacity.

The $10 \%$ total uncertainty was derived using engineering judgment. The excavator bucket is capable of holding $1.4 \mathrm{yd}^{3}$. Allowing for judgment by field personnel of how full the bucket is, it was determined that this was an achievable goal and would adequately satisfy the DQO.

- Waste spillage volume measurements: $0.0002 \mathrm{yd}^{3} / \mathrm{cycle}^{2}$

The $0.0002 \mathrm{yd}^{3} /$ cycle was derived using engineering judgment. It is based on the assumption that measurements of spillage volume can be made to this accuracy by following the specified spillage data gathering procedure. This procedure involves gathering the spilled waste and placing it into a calibrated container. 


\subsubsection{Effectiveness on Various Waste Forms.}

Test Objective: Determine the capability of the end effector to handle the various objects that could be encountered in an actual operation.

Data Quality Objective: Document the various waste forms encountered and the ability of the system to move these objects through the entire excavation and transport process using photographs, videotape, and log book entries. Document the affect the waste type has on spillage, equipment jams or failure, and on the rate of retrieval for the entire system using photographs, videotape, and log book entries.

Uncertainty: Not applicable.

1.3.1.5 Overall Phase I Demonstration Success. This phase of the demonstration can be deemed a success if sufficient data and operations experience are gained to assess the capability of this technology to accomplish its goals and if Environmental Restoration is provided with data to perform the feasibility studies. This determination will be made based on the following:

- Collection of sufficient quantitative data to make a determination on the spread of contamination resulting from the application of the equipment and processes

- Collection of sufficient quantitative data to make a determination on the amount of dust generation resulting from the application of the equipment and processes

- Observations regarding overall system performance including: spillage, ability to handle the waste forms, visual estimate of dust suppression, reliability, ease of use, ease of maintenance, and any other operational parameters are made and recorded for future reference.

\subsubsection{Phase II Demonstration-Retrieval And Conveyance}

Phase II will consist of a full-scale retrieval/conveyance demonstration. The demonstration will include all elements of the waste conveyance and end effector system. The demonstration will excavate, dump, and convey simulated waste from the test arena to demonstrate the functionality of the system (e.g., maneuverability and retrieval rates).

The specific objectives for Phase II of the demonstration are as follows.

\subsubsection{Throughput.}

Test Objective: To measure the production rate for dumping and conveyance of waste from the digface based on use of the selected equipment and technologies. A goal of $80 \mathrm{yd}^{3} / \mathrm{day}$ in an 8-hour shift will be used for design of the demonstration system. Each conveyed waste container or end effector will be allowed to hold a maximum of approximately $1.4 \mathrm{yd}^{3}$ of simulated buried waste in the form of waste mixed with soil. Note that some large objects or intact waste boxes may be larger than $1.4 \mathrm{yd}^{3}$. 
Data Quality Objective: Document the rate of waste removal and transport as performed during the demonstration by measuring the time of actual excavation operations and number of cubic yards of soil removed and conveyed.

Uncertainty: The following total uncertainty specifications apply for the measurements:

- The volume of waste removed and transported per cycle: $10 \%$ of end effector capacity.

The $10 \%$ total uncertainty was derived using engineering judgment. The excavator bucket is capable of holding $1.4 \mathrm{yd}^{3}$. Allowing for judgment by field personnel of how full the bucket is, it was determined that this was an achievable goal and would adequately satisfy the DQO.

- The time required: .25 minute per cycle.

The .25 minute total uncertainty was derived using engineering judgment. This time accuracy was selected because it is easy to measure and provides sufficient accuracy to satisfy the DQO.

\subsubsection{Effectiveness on Large Objects.}

Test Objective: Determine the capability of the end effector to handle the various typical selected large (large being greater than 55-gal drum) waste forms that could be encountered in an actual operation.

Data Quality Objective: Document the type of large objects encountered and the ability of the system to selectively retrieve, lift, and set these objects to the side of the excavation area using photographs, videotape, and log book entries. Document the number and type of large objects dropped and the amount of slip for objects successfully moved using photographs, videotape, and log book entries. Estimate and document in log book entries the percentage that operator skill and/or experience has on the ability of the equipment to perform these functions.

Uncertainty: Not applicable.

\subsubsection{Effectiveness on Various Waste Forms.}

Test Objective: Determine the capability of the end effector to handle the various objects that could be encountered in an actual operation.

Data Quality Objective: Document the various waste forms encountered and the ability of the system to move these objects through the entire excavation and transport process using photographs, videotape, and log book entries. Document the affect the waste type has on spillage, equipment jams or failure, and on the rate of retrieval for the entire system using photographs, videotape, and log book entries.

Uncertainty: Not applicable. 


\subsubsection{Effectiveness of Remote Control System.}

Test Objective: Demonstrate the effectiveness of the remote control system from measurements, observations, and operator interviews during demonstration retrieval operations.

Data Quality Objective: Document the capabilities of the remote control system (e.g., range and signal strength) and the ability of the system to effectively control the remote conveyance system by photographs, videotape, $\log$ book entries, and operator interview records.

Some data are qualitative by nature, but crucial to understanding the effectiveness of the remote control system. In particular, the ergonomics (human factors) design of the operator control station will be documented. Each operator will be interviewed to determine his/her opinion on the following:

- Is the control joystick easily within reach, does it have appropriate "feel," and are the corresponding motions of the vehicle intuitive

- Are the status indicators (lights, LCD display, and audio signal) easily understood and are warning indicators noticeable

- Are the lid and latch control switches easily within reach and adequate for the purpose

- Is the view provided by the Telerobotic Transport Vehicle (TTV)-mounted cameras adequate for the purpose of teleoperation

- Does eye strain result from continuous watching of the video monitor

- Are the camera pan, tilt, zoom, and focus controls easily within reach and intuitive.

Measure the capabilities of the remote control system by recording the following data:

- Telemetry system range: With diagnostic monitors connected to the vehicle control system and the operator station, increase the distance separating the vehicle from the base station and measure the ranges corresponding to successful telemetry throughput of $95 \%$, $90 \%, 80 \%$, and $70 \%$. Report transmitter specifications, power, antenna design, etc.

- TV system range: Using a spectrum analyzer, measure the television signal strength (in $\mathrm{dB}$ ) as a function of line-of-sight range from the base station to the TTV. Report transmitter specifications, power, antenna design, etc.

- Travel capability: In order to measure the effectiveness of the remote control joystick, verify maximum speed of the vehicle by time-to-distance measurements. Measure the smallest distance the TTV can move repeatedly in a straight line.

- Vision capability: Record by log book entries the effective viewing range of the forward and aft cameras. 
- Time/Motion Studies: In order to make comparisons between manual, telerobotic, and self-guided (future) control of the equipment, time data shall be gathered with respect to the following parameters:

- Connecting and disconnecting the ITM from the excavator.

- $\quad$ Transport time between the loading station and the waste receiving station over a fixed path of known length.

- Reliability: Record how many loading/unloading cycles can be accomplished before human intervention (other than normal teleoperation) for control or other problems is required. Record the reason for any human intervention.

Because the operational safety of the TTV is of the utmost importance, the following will be documented:

- Test and document by $\log$ book entries the function of the emergency kill switch on the control station and the conveyance vehicle.

- Test and document by log book entries, photographs, and videotape the function of the collision avoidance system (using obstacles of varying size and position), the motion alarm system, the motion indicator light, and any other safety features of the design.

- Anomalies such as the number of times the conveyance system responds differently than expected to the sent signal, the number of times the remote conveyance system receives an unintended signal, and/or the ability of the control system to regain control if such a malfunction occurs.

- $\quad$ Any other system malfunctions.

- Safeguards designed to prevent human error.

- Operator errors, the response of the system to such errors, and the procedures necessary to correct them.

Uncertainty: Not applicable or will be reported with the data.

\subsubsection{Maneuverability and Capability on Rugged Terrain.}

Test Objective: Determine the maneuverability and ability of the conveyance system to operate on rugged terrain encountered during demonstration retrieval operations. Determine the precision and accuracy of the guidance system by measuring the difference between the expected and the actual location of the TTV.

Data Quality Objective: Document the maneuverability on rugged terrain of the remote conveyance system used in the demonstration by direct measurements and photographic evidence. Determine with a $95 \%$ confidence level that for any specified target location, the average placement of the TTV was within 1 radial foot of that target location. Document the 
level of variability in the terrain and the affect these variations have on vehicle maneuverability by direct measurements and photographic evidence.

Uncertainty: The following total uncertainty specifications apply for the measurements:

- Location of reference point on TTV to target location: 0.25 in.

The 0.25 in. uncertainty was derived from engineering judgment. The uncertainties involved with this distance include the fact that the measurement using a tape measure for the location of the TTV when parked at the excavator or receiving station ignores any contribution from differences in elevation between reference marks on the TTV, excavator, and receiving station. However, the specified test site is relatively flat and the error introduced by ignoring the difference in elevation is negligible. Therefore, a 0.25 -in. uncertainty was selected because it is easy to measure and would adequately satisfy the DQO.

- Slope of TTV path on simulated hill: 10 seconds.

The 10 second slope uncertainty was derived based on the assumption that a surveyor's transit and stadia will be used to survey the simulated hill. The hill topography will be documented using this equipment.

\subsubsection{Transuranic Environment Evaluation.}

Test Objective: Estimate the capability of the system for operation in a TRU-contaminated environment (including deployment, maintenance, reparability, reliability, and operating cost).

Data Quality Objective: Determine the capability of the system to be used in a TRU contaminated environment by documenting through log book entries, photographs, and videotape the following items:

- $\quad$ Ruggedness of the equipment

- Frequency and type of maintenance required during the demonstration, both scheduled and unscheduled

- Length of time required for maintenance activities

- $\quad$ Ease and speed of deployment

- Ability of the system to easily correct for control system errors and/or operator errors.

Uncertainty: Not applicable.

\subsubsection{System Integration.}

Test Objective: Demonstrate the smooth integration of the innovative end effector and the remote conveyance system. 
Data Quality Objective: Document the level of integration of the remote conveyance and innovative end effector system and the affect that has on the smooth operation of the system using photographs videotape, and log book entries. Specific items to document include

How well the remote conveyance system receives or picks up the innovative end effector or transport container

How well the placement system (i.e., targets) work

To what extent system integration (e.g., fit and smooth operation) was built into the design of the two systems (i.e., are the designs concurrent and integral to each other so that overall system performance is improved).

Uncertainty: Not applicable.

1.3.2.8 Overall Phase II Demonstration Success. This demonstration can be deemed a success if sufficient data and operations experience are gained to assess the capability of this technology to accomplish its goals and if Environmental Restoration is provided with data to perform the feasibility studies. This determination will be made based on the following:

- Information regarding the ability of the entire system to effectively retrieve and transport waste is gathered and recorded for future use

- Sufficient data are gathered and recorded to evaluate the throughput of the system

- Sufficient data are gathered and recorded to evaluate the ability of the system to handle various waste forms and large objects

- Sufficient data are gathered and recorded to evaluate the maneuverability of the remote conveyance system on rugged terrain

- Information regarding the system integration between the remote conveyance system and the innovative end effector is gathered and recorded for future use

- Information regarding the ability of the system to operate in a TRU-contaminated environment is gathered and recorded for future use.

These objectives shall be accomplished by using the methods described in this test plan.

\subsection{Technology Agreement}

This test plan has been prepared for the BWID Waste Conveyance for Buried Waste Retrieval (TTP ID1-4-20-06) and Innovative End Effector for Dust Free Dumping (TTP ID1-4-20-07) programs. 


\subsection{Customer Needs}

The DOE has established Environmental Restoration Programs that, in part, address the remediation of buried TRU waste located at sites around the United States. The purpose of this project is to develop, with an industrial partner, a ruggedized automated guidance system, or telerobotic control system for installation on a vehicle or other conveyance apparatus capable of negotiating the terrain expected in a waste retrieval area, for the purpose of transporting retrieved waste from the point of excavation to post exhumation processing. There is an immediate need by the Environmental Restoration Program in INEL remediation projects for demonstrations of conveyance systems as production retrieval activities may start by FY-96.

As required by the Comprehensive Environmental Response, Compensation, and Liability Act (CERCLA), altemative technologies must be considered to support the formal Record of Decision (ROD) concerning removal of buried waste. The primary criteria set forth by CERCLA for evaluation of technologies include (1) perform work faster to facilitate remediation schedules and shorten development time, (2) use better technologies that reduce waste generated during remediation and allow for lower levels of decontamination, (3) reduce remediation costs, and (4) ensure that the technologies are safe by reducing personnel hazards, are in compliance with required laws and regulations, and improve environmental monitoring and assessment capabilities.

Handling of TRU waste, such as during retrieval operations, requires application of aggressive contamination control and personnel safety techniques, primarily due to the highly mobile nature of the TRU contaminants and the danger of fire and explosion from various hazardous materials interred. Remote waste conveyance systems and dust free dumping will aid in the environmental restoration of DOE buried waste sites by lowering risk to workers by minimizing exposure to radiation and hazardous materials. 


\section{ORGANIZATION AND RESPONSIBILITIES}

\subsection{Buried Waste Integrated Demonstration Program}

The mission of the BWID Program is to demonstrate, test, and evaluate technologies that are potentially faster, better, cheaper, and/or safer for restoring buried waste sites. The main personnel supporting this task are provided in Table 1.

Figure 4 shows the organizational structure for the tests to be performed as described in this test plan. The funding organization for this test is the DOE OTD. The BWID program has direct funding through OTD to evaluate and demonstrate waste management and retrieval technologies for application to current DOE Environmental Restoration Programs.

\subsection{Organizational Responsibilities}

This section describes the primary program personnel and their respective duties/responsibilities in the BWID organizational structure and for execution of the demonstration.

\subsubsection{Programmatic Responsiblities}

BWID Integrated Demonstration Coordinator-The IDC functions as the focal point for all contacts and correspondence relative to BWID. The IDC is responsible for ensuring that the BWID programmatic objectives are achieved by recommending technologies and projects to the DOE-OTD through DOE Idaho Operations Office (DOE-ID) for inclusion in BWID and to support other Integrated Demonstration and Integrated Programs. The IDC oversees technology evaluation and programmatic direction with the assistance of the BWID Program Planning Group (PPG) and the BWID Technical

Table 1. Supporting personnel for the demonstration.

\begin{tabular}{lll}
\hline \multicolumn{1}{c}{ Name } & \multicolumn{1}{c}{ Affiliation } & \multicolumn{1}{c}{ Responsibility } \\
\hline Brad Gardner & EG\&G Idaho & BWID Project Manager (PM) \\
Phil Rice & EG\&G Idaho & BWID Principal Investigator (PI) \\
Kevin Kostelnik & EG\&G Idaho & BWID Integrated Demonstration Coordinator (IDC) \\
Ann Marie Smith & EG\&G Idaho & BWID Project Engineer \\
Tamara Drake & EG\&G Idaho & Procurement Specialist \\
Lewis Rounds & EG\&G Idaho & Quality Assurance Engineer \\
John Morrison & EG\&G Idaho & BWID Support \\
Don Ord & EG\&G Idaho & BWID Safety Engineering \\
Bob Heard & EG\&G Idaho & BWID Deployment Coordinator (PM) \\
Guy Loomis & EG\&G Idaho & BWID Technical Liaison (TL) \\
David Thompson & EG\&G Idaho & Sampling Support \\
Michael Huss & RAHCO & Project Manager \\
Randy Peterson & RAHCO & Mechanical Systems Engineer \\
David Lokhorst & RSI Research & Control Systems Engineer \\
Bob Warn & RAHCO & Quality Manager \\
Randy Peterson & RAHCO & Demonstration Manager \\
Lon Gibby & Lon Gibby Productions & Video Manager \\
Charlie Stephens & RAHCO & Excavator Operator \\
Scott Schaffer & RAHCO & TTV Operator \\
TBD & RAHCO & Fork Lift Operator \\
\hline
\end{tabular}




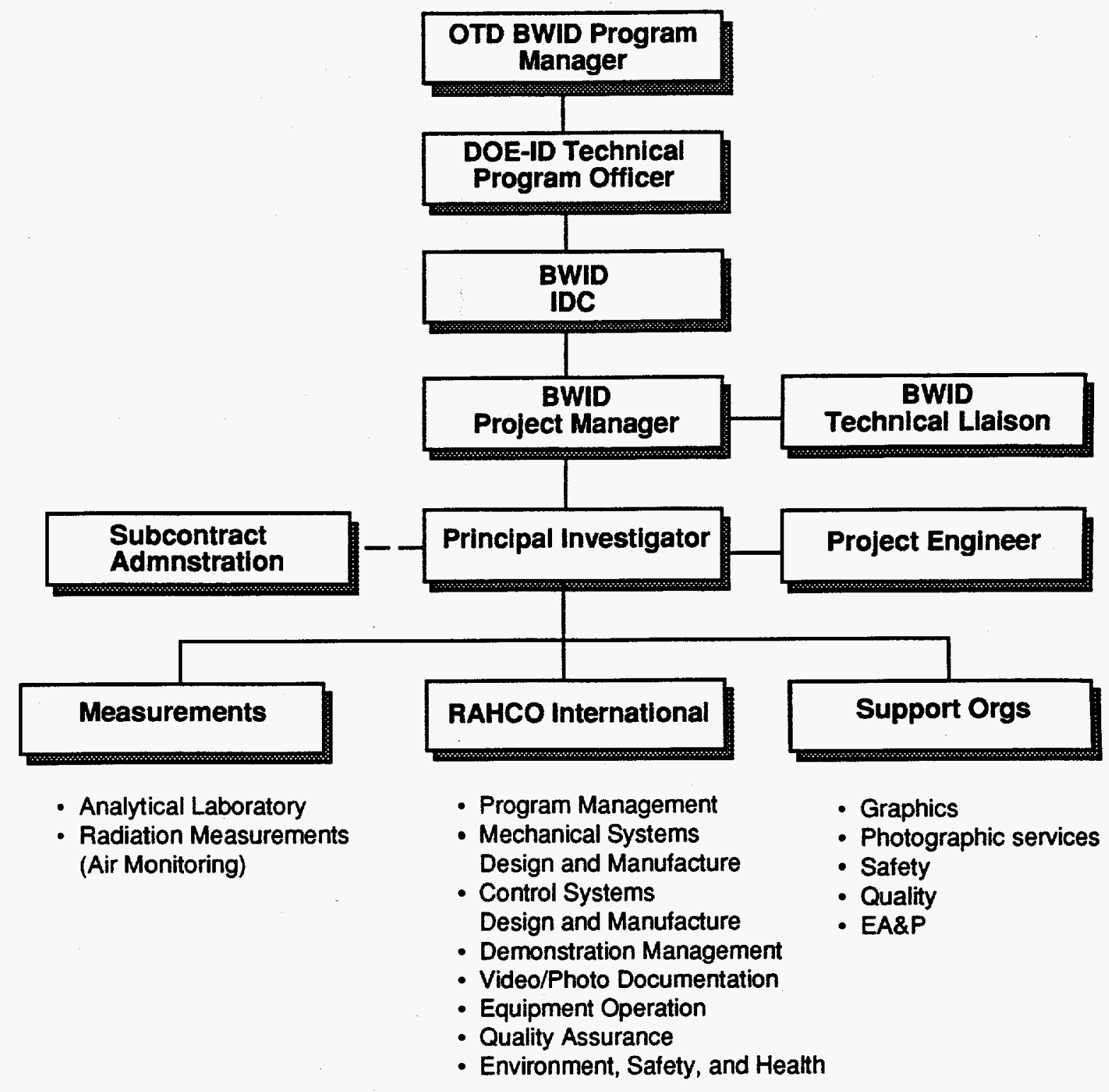

Figure 4. Innovative end effector and waste conveyance demonstration organization chart. 
Support Groups (TSG). The IDC also functions as the principal interface with other OTD-sponsored Integrated Demonstrations or Integrated Programs.

BWID Project Manager-The PM has direct responsibility for overall management of project efforts. The PM defines project work and establishes major milestones. The PM monitors program progress and provides status to the BWID Program weekly and to the DOE-ID PM monthly. The PM identifies project technical and management issues and ensures timely resolution and corrective action. The PM has primary responsibility for interfacing with the BWID Program and the DOE-ID PM.

Work Package Manager/Principal Investigator-The PI has direct responsibility for day-to-day management and coordination of project efforts. The PI schedules project work and ensures resources are available to meet the milestones established. The PI continually monitors program progress and provides status to the PM once every week and monthly. The PI identifies project technical and management issues and ensures timely resolution and corrective action. The PI has primary responsibility for interfacing with the PM and support organizations. The PI is responsible for preparing and publishing the final report.

Project Engineer-The Project Engineer has direct responsibility for day-to-day project efforts. The Project Engineer prepares technical documentation including test plans and work statements, and interfaces with subcontractors to direct their efforts. The Project Engineer monitors program progress and together with the PI provides status to the PM once every week and monthly. The Project Engineer identifies project technical and management issues and ensures timely resolution and corrective action.

BWID Technical Llaison-The BWID TL ensures the technical content of the work satisfies the high-level objectives of the program and advances the state-of-the-art. The TL works with the PI to ensure integration between BWID-sponsored projects, communicates closely with the PI to identify potential problem, and formulates corrective actions.

RAHCO International-RAHCO is responsible for the design and development of the innovative end effector system and the remote waste conveyance system, as well as overall execution of the test as specified in the statement of work and this test plan. The RAHCO PM is responsible for the day-to-day execution of the work. The RAHCO PM will be the primary interface with the BWID PI.

\subsubsection{Delegation of Authority for Conducting the Test}

The BWID PI and the RAHCO PM will jointly conduct the demonstration in accordance with this test plan. The BWID Project Engineer has the authority to act for the PI as required. If circumstances warrant it, the BWID PI and RAHCO PM will work through their respective chain of command to resolve issues or make programmatic decisions on the direction and scope of the test. Changes to the test plan shall be made in accordance with Section 6.4, "Test Plan Changes," of this document.

\subsection{Personnel Support Requirements}

The Phase I and Phase II demonstrations will require various personnel to perform the necessary activities. These personnel and their responsibilities are described in this section. Much of these 
personnel are common to both demonstrations and are discussed below. Personnel specifically required for either Phase I or Phase II are discussed in the following sections.

The PM has ultimate responsibility and authority for all of the efforts performed by the RAHCO Team. The PM will mange and control all project resources; assign units of work to project personnel; monitor their technical performance; and direct all formal reviews. The PM will be responsible for the Quality Assurance Program.

The Mechanical Systems Engineer is responsible for the design, manufacture, and performance testing of all the mechanical hardware required for the demonstrations. The mechanical hardware includes the end effector, ITM, transport container, transporter vehicle, and all remaining demonstration support equipment.

The Control Systems Engineer is responsible for the design, manufacture, and performance testing of all guidance and control systems hardware required for the demonstrations. The control systems hardware includes the TTV control unit and the remote operation control station. In addition, the control systems engineer is responsible for the integration of the control unit with the TTV.

The Demonstration Manager is responsible for the overall execution of both demonstrations including planning; setup; readiness reviews; environment, safety, and health concerns; conduct; video documentation; data collection; and reporting.

The Video Manager will be responsible for the development of the video and still photographic documentation for both demonstrations. This will include planning, lighting, video coverage, still photography, video script development, and video editing.

The Quality Manager will be the Quality Assurance Advisor to the PM. The Quality Manager will monitor and advise the PM on the effectiveness of the team's Quality Assurance and Total Quality Management programs.

The excavator operator will be responsible for the operation of the remotely controlled Hitachi EX200LC excavator.

The forklift operators will be responsible for the operation of the forklifts required to move the ITMs and waste containers.

Note: In Phase II only, the TTV operator will be responsible for the operation of the TTV.

\subsection{Personnel Qualifications and Training}

This section specifies test specific training requirements (personnel qualifications and level of training) for the demonstration. Health and Safety training requirements are specified in Section 12, "Health and Safety." 


\subsubsection{Excavator Operator}

The excavator operator will be a qualified excavator operator with at least 200 hours of operating experience. The operator will be trained to operate the excavator by remote control by Spar or RSI qualified personnel.

\subsubsection{Telerobotic Transport Vehicle Operator}

The TTV operator will be an experienced heavy equipment operator and will be trained to operate the TTV by the Control Systems Engineer.

\subsubsection{Fork Llft Operator}

The fork lift operator will be a qualified fork lift operator with at least 200 hours of operating experience. 


\section{DESCRIPTION OF TEST}

\subsection{Key Input and Output Parameters}

\subsubsection{Phase I Demonstration}

\subsubsection{Key Input Parameters-Phase I Demonstration.}

INEL Soll-The INEL soil will be provided and transported to the test facility by EG\&G Idaho. This soil is normally obtained from the "spreading area," which is a clean area containing deposited lakebed soil. It is representative of the soil used as overburden within the RWMC. The subcontractor will dry the soil, if necessary, to a 4 to $8 \%$ moisture content. The average percentage by weight of each component of the soil at the INEL is as follows: silts $=76.9 \%$, clay $=8.1 \%$, sand $=8.0 \%$, and gravel $=$ $7.0 \%$. The grain size distribution shows that $90 \%$ of the soil has a grain size finer than $100 \mu \mathrm{m}, 34 \%$ has a grain size finer than $33 \mu \mathrm{m}$, and $15 \%$ has a grain size finer than $10 \mu \mathrm{m}$. In situ soil weight is approximately $105 \mathrm{lb} / \mathrm{ft}^{3}$ per cubic foot, while the maximum compacted dry density is $110 \mathrm{lb} / \mathrm{ft}^{3}$ with an optimum moisture content of $17 \%$. The angle of internal friction is 35 degrees. The natural soil moisture is approximately $18 \%$ under normal dry conditions.

Simulated Waste-The simulated waste will include the following:

- Paper/Cloth-50\%

- Newspaper, computer paper, and rags.

- Sludge (55-gal drum filled with Portland cement)-30\%

- At least 20 55-gal drums (metal or cardboard) containing Portland cement (Portland cement simulates sludge drum density).

- $\quad$ Metal-10\%

- At least one $7 \mathrm{ft} \times 8$ in. I-beam along with other smaller pieces of metal that could fit into a 55-gal drum.

- Concrete/Asphalt-10\%

- $\quad$ An appropriate number of 2-ft diameter asphalt and concrete chunks.

Excavator-The excavator will be a telerobotically operated Spar/Hitachi EX200LC with coordinated controls. INEL.

Rare Earth Tracer-The rare earth tracer, praseodymium, will be provided and handled by the

Innovative End Effector-A specially designed end effector that features the Balderson thumb and an attachable/detachable ITM and a rugged, universal transport container capable of handling up to $9,000 \mathrm{lb}$ of waste (see Figure 5). 
2191-8

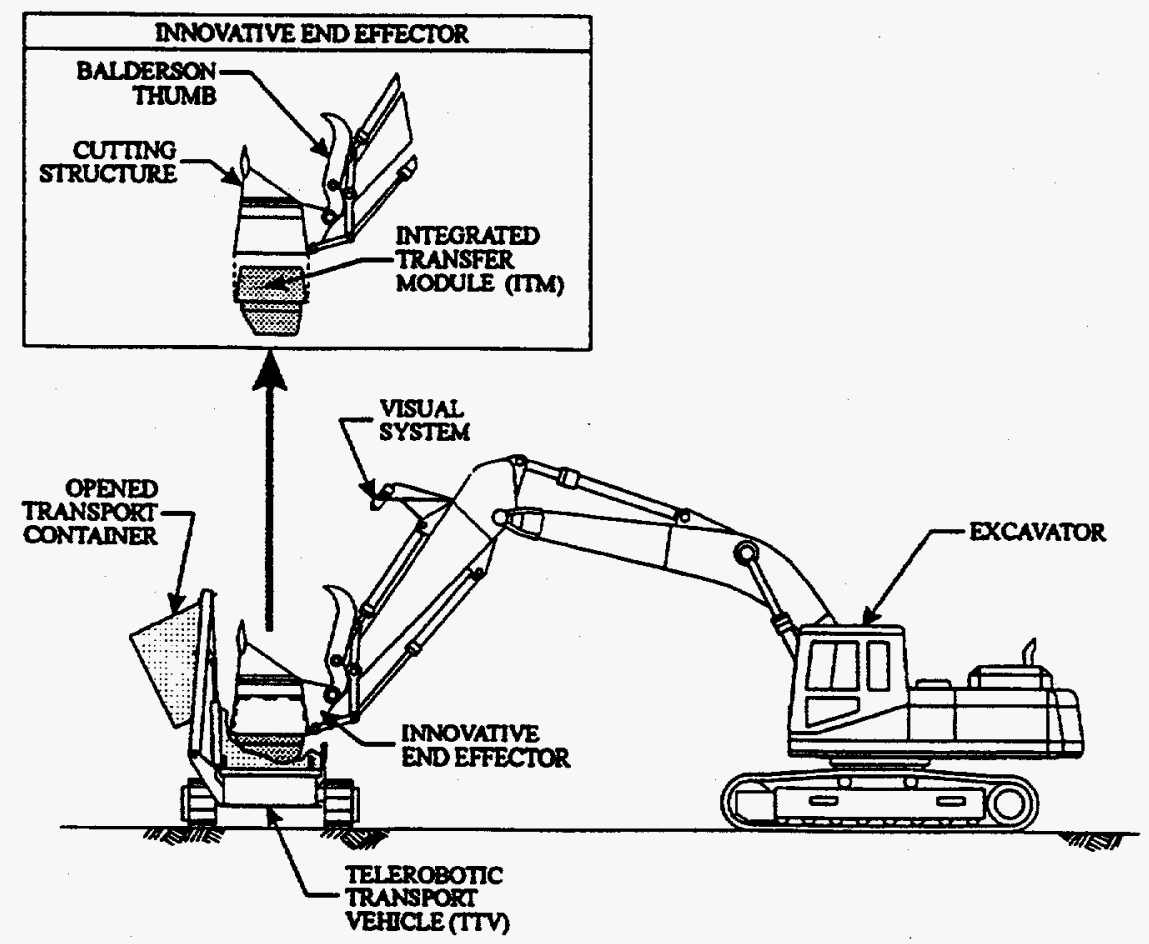

Figure 5. The innovative end effector is highly integrated with the excavator and the conveyance system.

The end effector consists of two structural assemblies: the inverted Balderson thumb and the shovel assembly, and the necessary actuating linkage and hydraulic cylinders (see Figure 6). The upper structural assembly consists of a Balderson thumb. This device has been proven to be extremely versatile, dexterous, and productive in handling the expected waste forms (Valentich, 1993). The front shovel configuration with the Balderson thumb on top was chosen to increase digging efficiency, reduce dust generation, and minimize clean up when the shovel digs into the face rather than pulling away from the face. The lower shovel assembly, consisting of digging teeth, a guide skirt, an overflow opening, and a latching mechanism, has multiple functions. When used with the Balderson thumb, it is used to retrieve large items and guide 55-gal drums into the ITM. It also acts as a shovel to scoop dirt and debris into the ITM. To prevent the ITM from overfilling, the shovel assembly has an overflow opening between the teeth and top of the ITM. The shovel assembly also has a flared skirt with a 3-in. draft to accommodate easy attachment of an empty ITM to the shovel assembly. A latch mechanism on each side of the shovel assembly secures the ITM to the assembly. Each latch is equipped with two rotating dogs that lock the ITM to the shovel assembly. This provides a positive, fail-safe connection.

The attachable/detachable ITM acts as a detachable loading, handling, and conveyance bucket when digging, handling, and conveying 55-gal drums, dirt, and small debris (see Figure 7). It is a rectangular, welded steel structure and holds approximately $1.4 \mathrm{yd}^{3}$ of soil and waste, or two 55-gal drums. A flared skirt around the upper portion is similar to that on the shovel assembly and assists the operator in mating the ITM with the shovel assembly. The tapered bottom assists the operator in placing 
$2191-4$
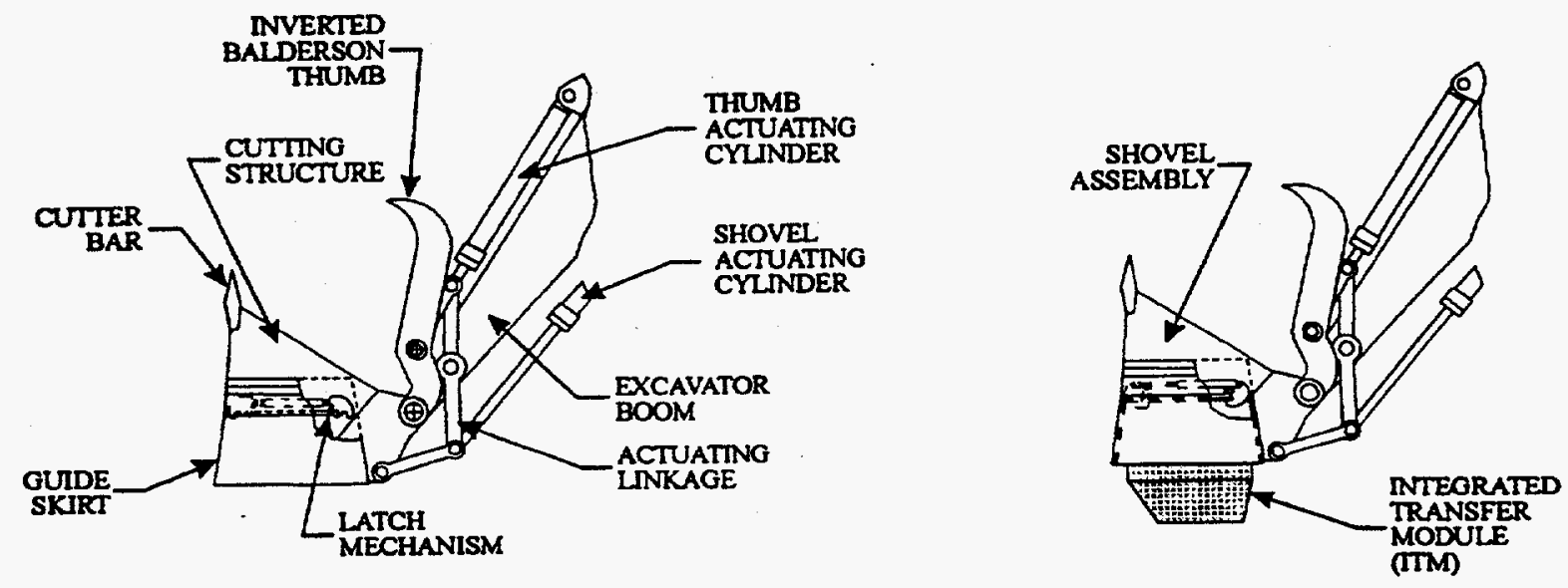

Figure 6. The multipurpose end effector integrates innovative features with proven excavation and retrieval technology.

$2191-2$
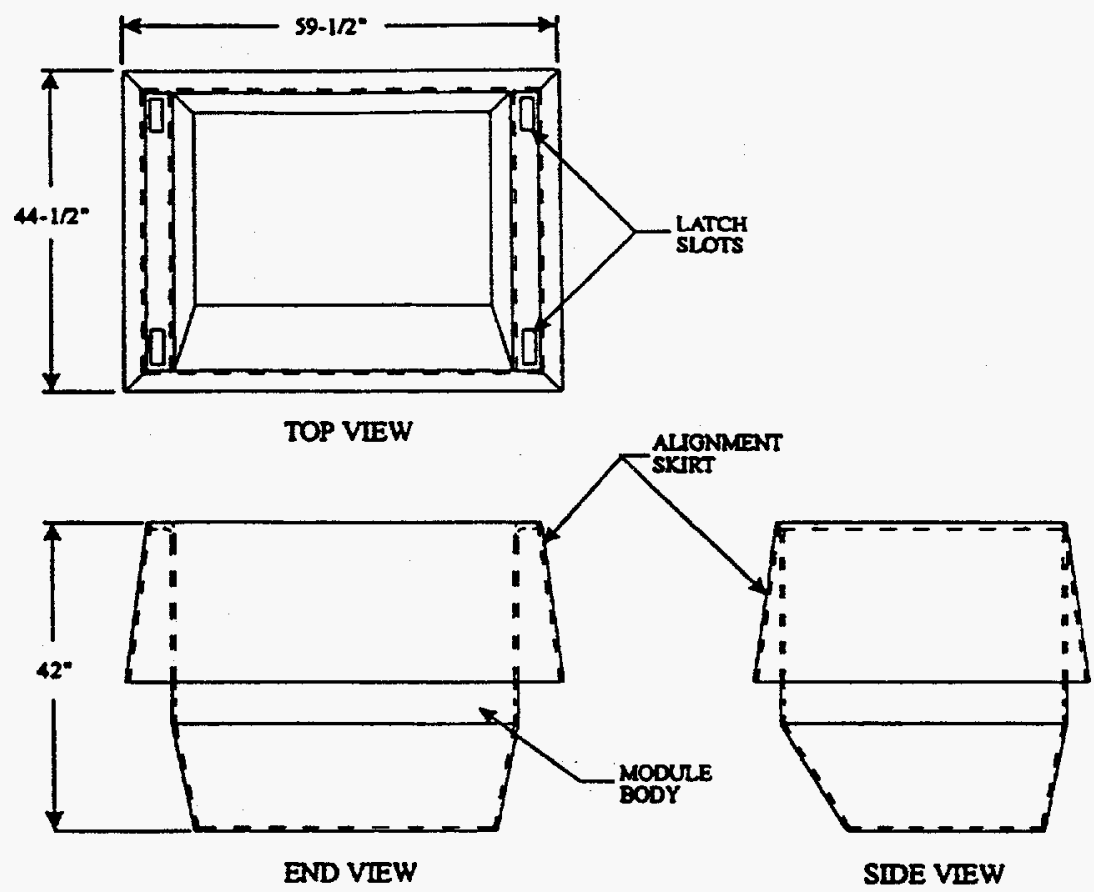

Figure 7. The ITM is a detachable loading, handling, and conveyance bucket. 
the ITM into the transport container pocket. Slots in the ITM top flanges allow the shovel assembly dogs to be engaged and lock the unit to the shovel assembly.

The 9,000-lb capacity transport container receives retrieved waste in the form of filled ITMs, $4 \times$ $4 \times 8$-ft boxes, and many other expected, irregularly shaped, large waste items (see Figure 8). After receiving the waste items directly or in an ITM, the container is closed and automatically sealed and locked to contain any dust generated during conveyance. The container is a steel structure approximately $5 \mathrm{ft}$ wide, $5 \mathrm{ft}$ high, and $9 \mathrm{ft}$ long, weighing approximately $2,800 \mathrm{lb}$ empty. The rectangular lid structure is connected to the base structure by a simple hinge assembly. The lid structure is opened by a lift mechanism to provide frontal access, thus allowing easy placement of the ITM or other waste items by the operator. A pocket, located in the bottom of the container, is configured and sized to provide an easy target for the operator and self-aligns the pocket and the ITM during loading. Dust seals, located on all sealing surfaces, are provided to contain the dust generated during conveyance. A spring-loaded, dogtype latching mechanism engages the lift bar on the lid to lock and secure the lid during handling, preventing inadvertent opening of the container. In operation, the end effector selectively retrieves the expected waste forms and places the collected waste in a 9,000-lb capacity container. For large waste items, the end effector places the item directly onto the container floor. For dirt, debris, and 55-gal drums, the excavator scoops the materials into the ITM, swings the filled ITM over the transport container, and lowers the ITM into the container pocket where it is detached. An empty ITM, staged on the TTV, is then attached to the end effector and swung back to the digface. Simultaneously, the

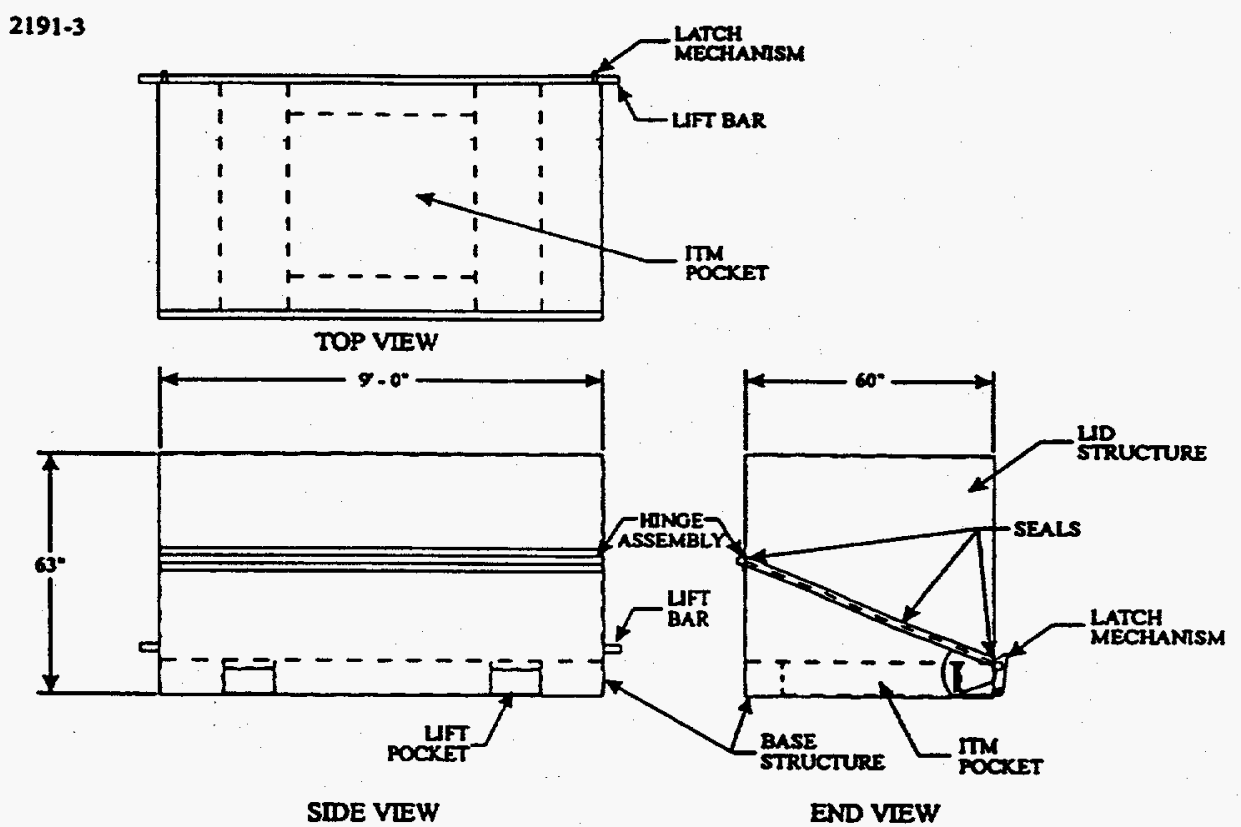

Figure 8. The waste transport container carries the ITMs and can be used to transport large objects including intact $4 \times 4 \times 8-\mathrm{ft}$ waste boxes. 
container lid is closed, and the filled ITM secured in the container. The ITM is then carried by the TTV to a storage area receiving station where the filled container and enclosed ITM are off loaded. An empty ITM, along with an empty container, are loaded onto the TTV. The TTV then travels back to the digface.

Air Monitors-The air monitors are described in Section 5.3.1 and will be supplied by the INEL. Final placement of the air monitors will be done after the waste pile is constructed and the equipment is positioned. In general, two monitors will be stationed near the digging area, two will be placed somewhere between the digging and dumping area, and the last four will be located around the dumping area. The final locations will be determined by the PI at the start of the test and recorded in the test log book. Also note that the condition of each air monitor should be considered when deciding on the final placement.

Bullding - The building will be a climate controlled structure with airflow control that is large enough to hold the demonstration and allows for adequate space between the actual dumping operation and the secondary (emptying the end effector or waste container to begin dust measurement dumping again) dumping operations so that dust measurements taken during the actual dumping are not affected by secondary dumping operations. The purpose of the building is to provide shelter out of the wind so that dust samples can be taken. No other special provisions are required.

3.1.1.2 Key Output Parameters-Phase I. The key output parameters for the Phase I demonstration are

- Dust measurements

- $\quad$ Rare earth tracer measurements

- Waste volume removal measurements

- $\quad$ Spillage measurements

- Information regarding the overall system performance.

The key output parameters will be recorded and documented in the following media:

- Photographs

- Videotapes

- Log books.

\subsubsection{Phase II Demonstration}

\subsubsection{Key Input Parameters_Phase II.}

Remote Conveyance System-The remote conveyance system will be designed and provided by RAHCO. It consists of a track-mounted, TTV, and a remote operator control station. The TTV transports the loaded/unloaded transport containers and ITMs. The remote operator control station is used for controlling the TTV, remote excavator, and video/audio systems (see Figure 9). The TTV is fully 

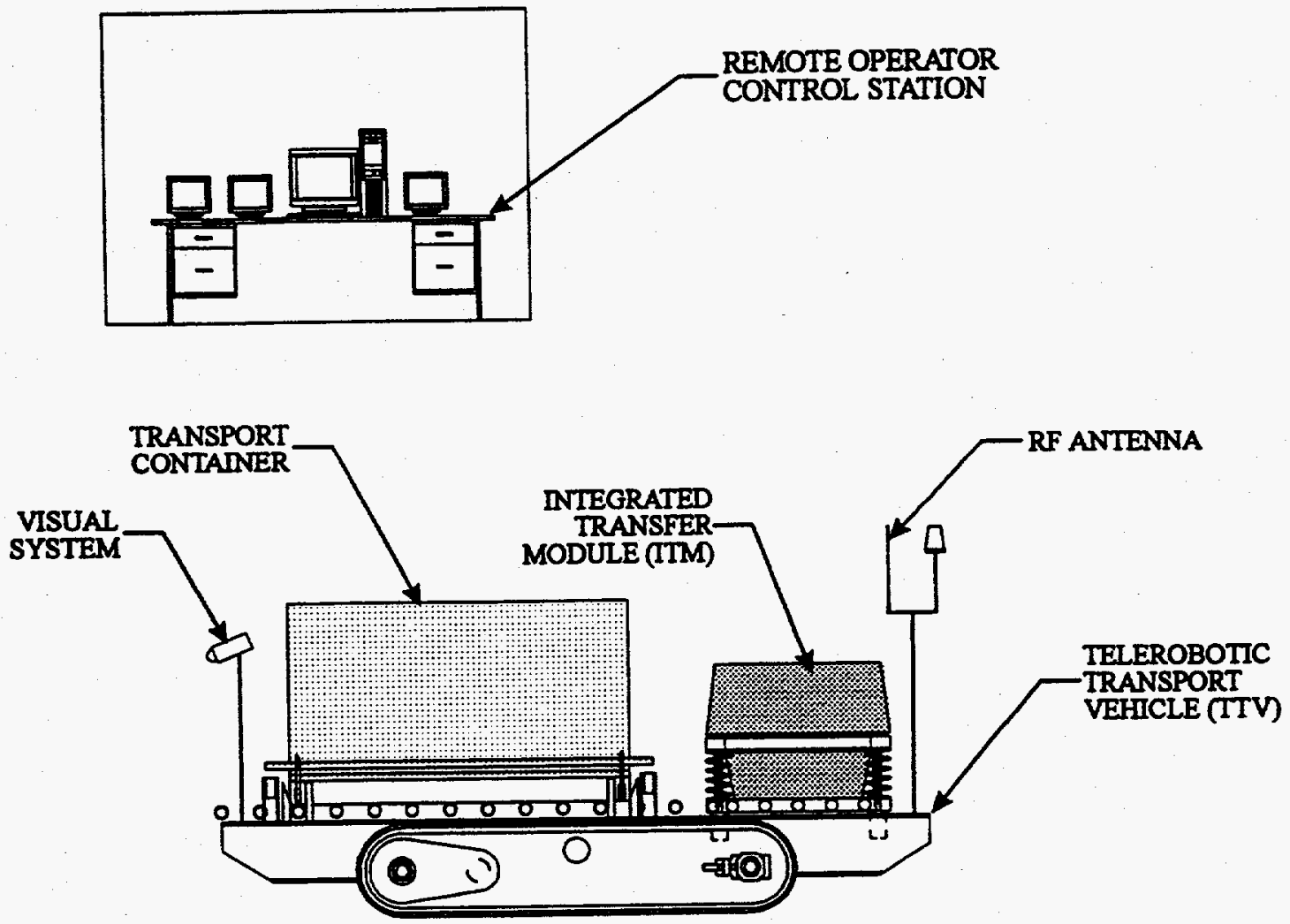

Figure 9. The TTV mechanical subsystem consists of a track assembly, main frame, diesel power plant, hydraulic system, and ITM cradle. The TTV can travel at speeds to $300 \mathrm{fpm}$ on a set of hydraulic motorpowered crawler tracks. The tracks provide stability on slopes and excellent maneuverability. Employing skid steering, the TTV can turn 360 degrees about its own center on a 14-ft wide roadway.

integrated with the end effector/waste handling system to provide a waste conveyance solution that eliminates dust generation during conveyance operations. The TTV as shown in Figure 10 is designed as a multiple function vehicle. First, it conveys full containers and ITMs from the excavation location to the dumping/unloading location. Second, it serves as a transfer station at the excavation site by (a) supporting the transport container, (b) opening, closing, and locking the container lid, and (c) providing a staging platform for the empty ITM. Third, it conveys the empty containers and ITMs from the storage area to the excavation site. The TTV consists of the mechanical and the guidance and control subsystems.

A main frame connects the tracks and supports the loads. One track is mounted rigidly to the frame while the second track is connected by horizontal pivot pin. This minimizes racking of the frame as the TTV travels over irregular terrain. 

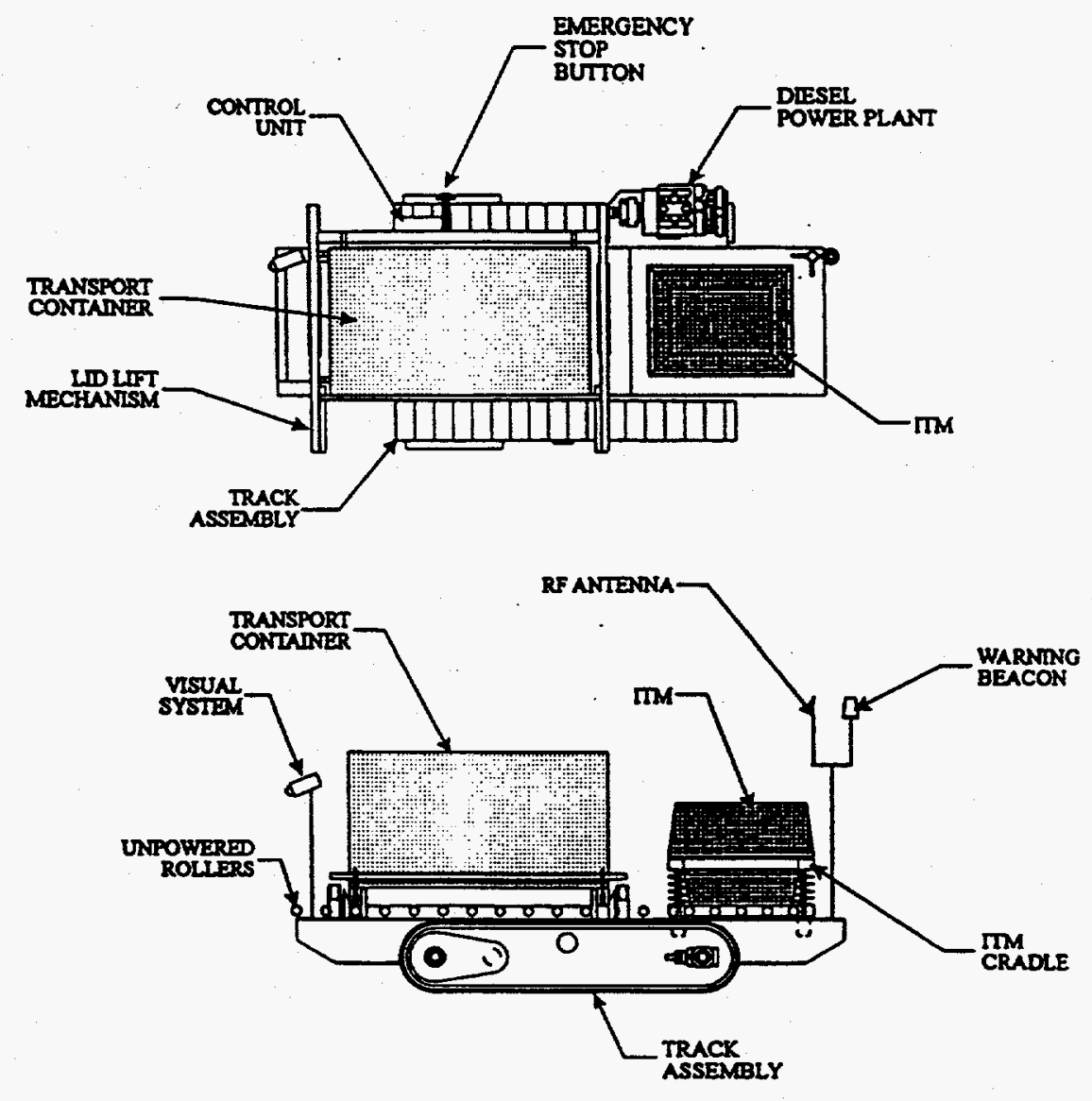

Figure 10. The mechanical subsystem uses existing, state-of-the-art, mobile equipment components.

A nonpowered roller table is located on top of the main frame. On an operational transporter, the rollers will be powered and used for rapid off loading of filled containers and on loading of empty ITMs and containers.

Located at one end of the TTV is an ITM cradle. The cradle is a three-sided steel frame supported on four large springs. This spring-mounted structure allows the ITM to self-align with the end effector during the ITM-end effector attachment operation.

A lift table, in the raised position, protrudes between the rollers and holds the transport container above the rollers. This protects the rollers from impact during the loading of waste into the containers.

Two hydraulically actuated lift mechanisms mounted to the TTV main frame release the transport container lid latches and raise the lid structure. 
The TTV is powered by a 50-hp, water-cooled, Detroit Diesel engine. A belt-driven, 24-Vdc generator will provide electrical power for the control system. The engine is directly coupled to a variable displacement hydraulic pump that powers the TTVs various hydraulic components.

The Spar-provided guidance and control systems consist of

- $\quad$ TTV Control System

- Operator Control Station

- Three radio frequency (RF) links between the TTV control system and the Operator Control Station

- $\quad$ Remote Operations Control Trailer.

The TTV control system has three separate microprocessor controllers to provide dedicated track control, waste container operation/control, and selected control of the forward and rear-mounted vehicle camera/pan and tilt units. Each microcontroller has a resident INTEL 80C196K microprocessor running proprietary software and shares a common RF link to the operator control station. These are rugged, field-proven units developed from grapple-yarders used in the logging industry.

The transporter also has on-board sensing systems to provide track speed transduction, a rate gyro for heading and noise filtering around the speed transducers, waste handling logic function switches, and a vehicle acoustic ranging system array (VARSA).

A video system, comprised of forward and rear-mounted camera/pan and tilt units, gives the remote operator visibility in forward and reverse directions. The video system is used for steering control and tracking of specially designed acousto-video targets. The targets provide the TTV operator vision tracking to the excavator to allow execution of the 90 degree turn required to align the transport container with the excavator and the receiving station.

Three vehicle control modes are provided:

\section{Mode 1: Open Loop Track Control}

Tracks are operated from the vehicle-mounted manual control or from the remote operator's joystick if the normal telerobotic control function either fails or is not required.

\section{Mode 2: Telerobotic Control}

Telerobotic control provides resolved control of tracks through a single joystick at the remote operator's station. The joystick commands provide proportional forward/reverse control and left/right directional control. The microprocessor at the operator's station resolves joystick commands into track speed commands that are sent by the RF link to the vehicle track microcontroller. The track microcontroller integrates the track speed commands with speed transducer and rate gyro feedback to control the tracks. In addition, the VARSA is interfaced 
with the track speed controls for collision avoidance. The TTV will stop at a selectable preset distance from an object that can be made proportional to speed.

\section{Mode 3: Waste Container Operation}

This mode provides for loading and unloading while the TTV is stationary. Operator commands from the remote control panel initiate individual control functions such as lid unlatch and open/close and latch. The on-board control system also monitors limit switches to ensure each function also been completed.

For teleoperated control, the transporter is operated from the remote operator control station. The control station consists of a microprocessor, control panel, RF modem, video monitor/controller, and graphical overlay controller.

The control panel includes

- One joystick providing input commands for the vehicle direction and speed in either mode 1 or 2

- $\quad$ Mode Select Switch allowing Off/Mode 1/Mode 2/Mode 3 selections

- Camera select and pan and tilt switches

- Switches for lid open/close and latching

- $\quad$ Emergency stop button with key lock

- Keypad for setting parameters including acoustic array ranging limits

- Liquid crystal display showing system health monitoring messages and status

- Spread spectrum radio modems providing RF telemetry for operator commands, emergency stop, and video signals.

Operation of the TTV can be carried out using Modes 1 and 2 at the remote operator's station or independently at the TTV itself using start, stop, and two track control levers. An emergency stop button is also provided on the TTV.

For the waste retrieval demonstration, the operator will control the vehicle in the telerobotic Mode 2 using the single joystick for travel control and the forward or rearward cameras for visibility.

As the TTV approaches the excavator, the operator tracks to an acousto-video target set on the chassis of the excavator. Within $30 \mathrm{ft}$ of the excavator, the VARSA is able to transduce range to the target and attitude.

A graphical overlay is displayed on the operator control station monitor. The overlay provides the operator with an image to track the target into. Boundary conditions on the overlay provide the 
operator with alignment and approximate ranging data, confirming the data provided by VARSA and displayed on the panel LCD. From this, the operator can determine the distance and attitude of the vehicle with respect to the targets and stop within $\pm 1 \mathrm{ft}$ of the required location.

Having reached a designated point with respect to the excavator, the operator commands the TTV to pivot 90 degrees and align to a free-standing set of targets. This positions the TTV so the ITM can be placed in the transport container. The TTV is then backed up to place the empty ITM at the correct location for attachment to the excavator and effector. The TTV now returns to the receiving station where the vehicle is docked to a single, free-standing, acousto-video target.

The Remote Operations Control Trailer is a $20-\mathrm{ft}$, air-conditioned construction trailer. Electrical power is provided from a generator set. An uninterrupted power supply unit will be provided to protect the operating system from generator failure and power surges.

Innovative End Effector System-The same system as in Phase I.

Excavator-The excavator will be a telerobotically operated Spar/Hitachi EX200LC with coordinated controls.

Simulated Waste-The same soil and waste that was used in the dust and contamination spread demonstration will be used in the Phase II demonstration.

Large Objects-A variety of large objects will be used in the demonstration, including at a minimum: a pickup truck bed, $15 \mathrm{ft}$ lengths of carbon steel pipe of varying diameter and schedule (maximum diameter 16 in. and maximum schedule 40 ), $15 \mathrm{ft}$ lengths of carbon steel structural shapes of varying weight (maximum $40 \mathrm{lb} / \mathrm{lineal}$ foot weight), and a maximum of $200 \mathrm{ft}$ of $1 \mathrm{in}$. (or less) steel cable (in maximum $50 \mathrm{ft}$ lengths), which may be randomly intertwined throughout the entire cell.

3.1.2.2 Key Output Parameters-Phase II. The key output parameters for the Phase II demonstration are

- Maneuverability measurements

- Throughput measurements

- Information regarding the overall system performance.

The key output parameters will be recorded and documented in the following media:

- Photographs

- Videotapes

Log books. 


\subsection{Test Parameters}

\subsubsection{Number of Tests}

3.2.1.1 Phase I Demonstration. Phase I of the demonstration will include four tests, each test being approximately 3 hours in duration. The subcontractor should plan on one full cycle of the $66 \mathrm{yd}^{3}$ of material total, moving approximately $15 \mathrm{yd}^{3}$ of material in each test.

3.2.1.2 Phase II Demonstration. Phase II of the demonstration will include testing to sufficiently exercise the equipment, and provide adequate opportunity to gather data. It is anticipated that during the week of testing that 4 to 6 full cycles of the $66 \mathrm{yd}^{3}$ of material (approximately 260 to $400 \mathrm{yd}^{3}$ total) will be excavated during this demonstration. A typical scenario would be to dig all $66 \mathrm{yd}^{3}$ of material and transport it to another location, relocate the excavator to where the waste was dumped, dig it up again, and return it to its original location using the remote conveyance system, then repeat the process.

\subsubsection{Location}

3.2.2.1 Phase I Demonstration. Phase I of the demonstration will be conducted at the RAHCO facility, Spokane, Washington, in the east end of RAHCO Building \#1. This building is capable of providing a controlled (especially airflow) environment conducive to collecting dust samples.

3.2.2.2 Phase II Demonstration. Phase II of the demonstration will be conducted at the RAHCO facility, Spokane, Washington. The test site will be outside to the south of Building \#1 and west of the Engineering Office Building. This test site will include a TTV path with a simulated hill for the TTV to transverse (see Figure 3). The simulated hill will include specified variable terrain including a 10 degree climb/descend slope and side slope.

\subsubsection{Duration}

3.2.3.1 Phase I Demonstration. Phase I of the demonstration is expected to take 4 days to complete, with each test taking approximately 6 hours. A dust settling time of 8 to 16 hours will be allowed between each test.

3.2.3.2 Phase II Demonstration. Phase II of the demonstration is expected to take 5 working days.

\subsubsection{Schedule}

3.2.4.1 Phase I Demonstration. The Phase I demonstration is scheduled to take place approximately 13 weeks after award of contract.

A detailed schedule for Phase I is shown in Figure 11.

3.2.4.2 Phase II Demonstration. The Phase II demonstration is scheduled to take place approximately 14 weeks after award of contract.

A detailed schedule for Phase II is also shown in Figure 11. 


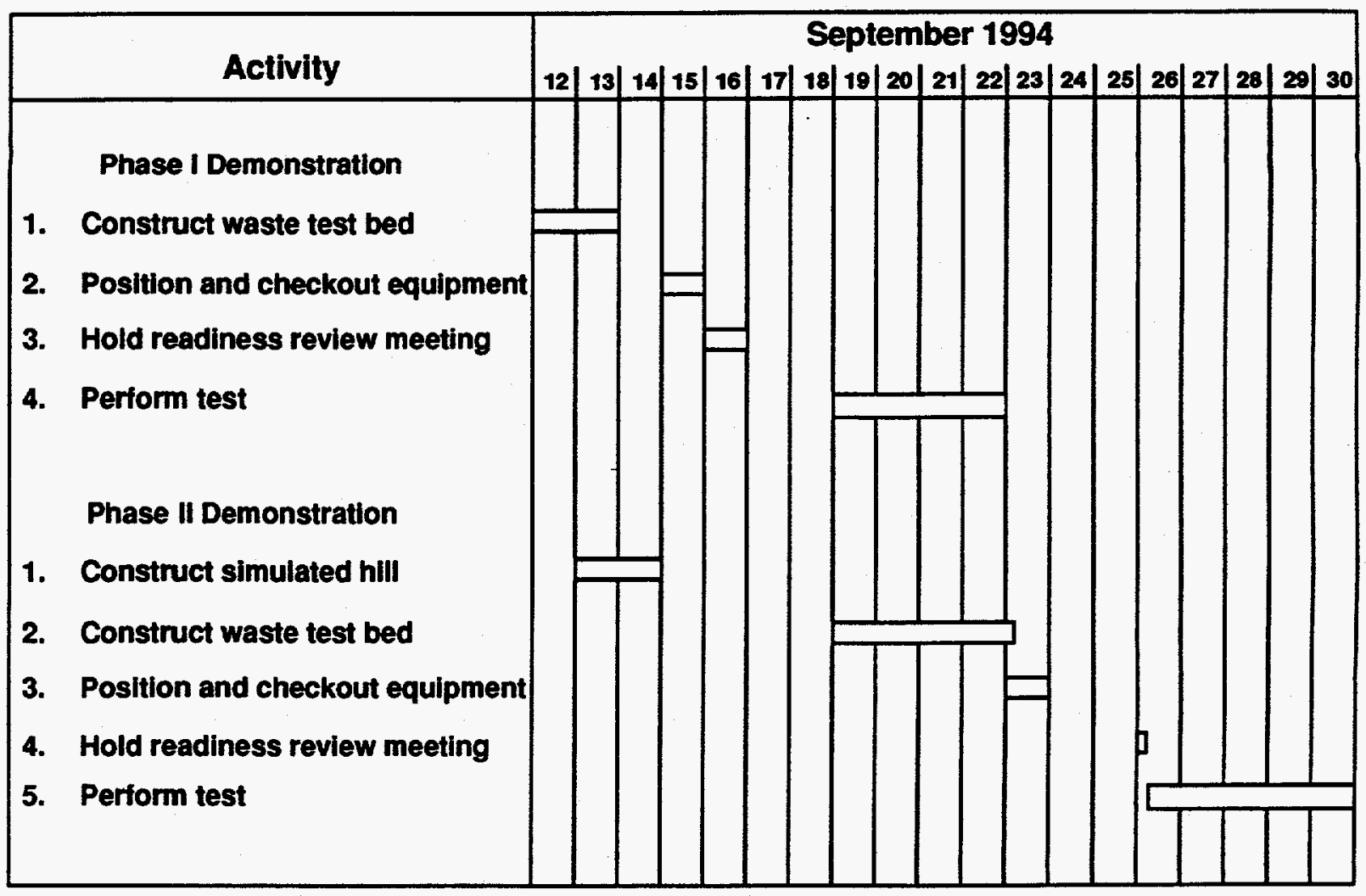

Figure 11. Detailed schedule for Phases I and II of the demonstration.

\subsection{Test Method and Uncertainties}

See Tables 2 and 3 for details of the uncertainties and risks associated with the demonstration.

\subsection{Procedures to Conduct the Test}

The details regarding the procedures to conduct the test are outlined in Appendix B.

\subsection{Contingency Plans}

See Tables 2 and 3 for details of the contingency plans associated with the demonstration.

\subsection{Performance Objectives}

\subsubsection{Innovative End Effector System Performance Objectives}

The following are performance objectives for the innovative end effector. These performance objectives are restated from the Statement of Work (SOW) and were used as the design requirements by RAHCO for development of the system. 
Table 2. Risk mitigation. Those items identified to have some risk of completion in a timely manner are identified. The magnitude of the risk, its impact, and steps to mitigate the risk are provided.

\begin{tabular}{|c|c|c|c|}
\hline Risk & Magnitude & Impact & Mitigation \\
\hline $\begin{array}{l}\text { Telerobotic Software } \\
\text { Modification and } \\
\text { Integration } \\
\text { - TTV Control System } \\
\text { - Operator Control Station } \\
\text { - Integration of Software }\end{array}$ & $\begin{array}{l}\text { Minimal } \\
\text { Moderate } \\
\text { Moderate }\end{array}$ & $\begin{array}{l}\text { Delay retrieval and } \\
\text { conveyance } \\
\text { demonstration }\end{array}$ & $\begin{array}{l}\text { - Use senior, experienced } \\
\text { Spar software engineers } \\
\text { - Assign principal staff } \\
\text { engineer to software team } \\
\text { - Perform weekly progress } \\
\text { reviews } \\
\text { - Work overtime }\end{array}$ \\
\hline $\begin{array}{l}\text { TTV Hydraulic/Control } \\
\text { System Integration }\end{array}$ & Moderate & $\begin{array}{l}\text { Delay retrieval and } \\
\text { conveyance } \\
\text { demonstration }\end{array}$ & $\begin{array}{l}\text { - Spar is purchasing TTV } \\
\text { hydraulic control valve to } \\
\text { ensure control system } \\
\text { electrical/hydraulic } \\
\text { compatibility } \\
\text { - Spar will bench test } \\
\text { electrical/hydraulic system } \\
\text { before vehicle integration } \\
\text { - Spar hydraulics engineer } \\
\text { collocated at RAHCO } \\
\text { - Work overtime during } \\
\text { integration }\end{array}$ \\
\hline $\begin{array}{l}\text { Integration of ITM on end } \\
\text { effector shovel assembly }\end{array}$ & Minimal & $\begin{array}{l}\text { Delay retrieval and } \\
\text { conveyance } \\
\text { demonstration }\end{array}$ & $\begin{array}{l}\text { Develop detailed computer } \\
\text { models to verify fit-up } \\
\text { - Build physical model prior } \\
\text { to fabrication }\end{array}$ \\
\hline $\begin{array}{l}\text { TTV hydraulic motor } \\
\text { availability }\end{array}$ & Minimal & $\begin{array}{l}\text { Delays completion of } \\
\text { TTV integration }\end{array}$ & $\begin{array}{l}\text { - Pay premium to supplier to } \\
\text { accelerate delivery } \\
\text { schedule } \\
\text { - Purchase parts immediately } \\
\text { upon award of contract } \\
\text { - Search for alternate } \\
\text { supplier } \\
\text { - Identify alternate motors } \\
\text { for system }\end{array}$ \\
\hline $\begin{array}{l}\text { Equipment Breakdown } \\
\text { - Air monitors } \\
\text { - Innovative end effector } \\
\text { - TTV } \\
\text { - Excavator }\end{array}$ & $\begin{array}{l}\text { Minimal } \\
\text { Moderate } \\
\text { Moderate } \\
\text { Moderate }\end{array}$ & $\begin{array}{l}\text { Internupt and delay } \\
\text { demonstration }\end{array}$ & $\begin{array}{l}\text { Perform preventative } \\
\text { maintenance on all } \\
\text { equipment prior to the start } \\
\text { of the demonstration } \\
\text { - Perform preventative } \\
\text { maintenance on schedule } \\
\text { during the demonstration } \\
\text { (off hours) }\end{array}$ \\
\hline
\end{tabular}


Table 3. Contingency plans for items most likely to interrupt or delay the demonstration have been identified.

\begin{tabular}{|c|c|c|c|}
\hline Problem & Magnitude & Impact & Contingency \\
\hline $\begin{array}{l}\text { Equipment Breakdown } \\
\text { - Air monitors } \\
\text { - Innovative end effector } \\
\text { - TTV Excavator }\end{array}$ & $\begin{array}{l}\text { Minimal } \\
\text { Moderate } \\
\text { Moderate } \\
\text { Moderate }\end{array}$ & $\begin{array}{l}\text { Interrupt and delay } \\
\text { demonstration }\end{array}$ & $\begin{array}{l}\text { - Identify and maintain } \\
\text { critical spare parts } \\
\text { - Obtain replacements as } \\
\text { necessary } \\
\text { - Suspend testing until } \\
\text { equipment is in working } \\
\text { order } \\
\text { - Continue testing at reduced } \\
\text { capacity }\end{array}$ \\
\hline Inclement Weather & Minimal & $\begin{array}{l}\text { Interrupt and delay } \\
\text { retrieval and } \\
\text { conveyance } \\
\text { demonstration }\end{array}$ & $\begin{array}{l}\text { Where no safety concern } \\
\text { exists and weather does not } \\
\text { pose test problems, } \\
\text { continue } \\
\text { - Delay testing until weather } \\
\text { conditions support } \\
\text { continuation } \\
\text { - Move test to indoor } \\
\text { location if sever conditions } \\
\text { prevail } \\
\text { - Work overtime during good } \\
\text { weather periods }\end{array}$ \\
\hline $\begin{array}{l}\text { Equipment Availability } \\
\text { - Excavator }\end{array}$ & Moderate & Delay demonstration & $\begin{array}{l}\text { Identify alternate } \\
\text { equipment and sources } \\
\text { early in planning }\end{array}$ \\
\hline
\end{tabular}

Dust Suppression: The dust control system shall be capable of controlling dust generation so that a maximum air particulate count of $1.1 \times \mathrm{E}-4 \mathrm{~g} / \mathrm{L}$ above background levels is achieved. For the dust and contamination spread demonstration, the soil content must simulate the worst case (driest) soil content/conditions for buried waste locations at the INEL. Although the natural soil moisture is approximately $18 \%$ under normal dry conditions, the worst case (driest) soil moisture content is 4 to $8 \%$. The soil moisture content for the demonstration shall be no greater than $8 \%$.

Waste Forms/Special Item Handling: It is the intent of this program to develop a system that is as flexible in retrieving buried waste as the Balderson thumb, while controlling dust generation and potential spread of contamination during dumping and conveyance.

The system shall be capable of handling waste materials resembling those found in actual buried waste pits and trenches, with the exception that the materials are to be nonhazardous and nonradioactive for this demonstration. Materials may include metal, wood, cloth, plastic, simulated sludge, concrete, asphalt, and cardboard. The system shall be capable of transporting waste containers or individual items weighing up to $6,000 \mathrm{lb}$. The average load of mixed soil and waste will weigh approximately $3,780 \mathrm{lb}$.

Retrieval plans may require separation of buried waste types at the digface. This will include isolation and removal of large objects. Consequently, the retrieval equipment might have to grip large 
objects individually. For example, long lengths of wire rope, electrical cables, pipe, or steel supports may be encountered. The system shall be capable of moving large objects such as steel vessels, pickup truck beds, lengths of I-beams and steel pipes, machine tools, and steel cables away from the digface and positioning them so the object does not impede excavation work. The system is not required to be capable of the post process sizing these out-sized wastes. In addition, the system must be capable of conveying intact Department of Transportation 7A 55-gal drums (drums with good structural integrity) It is not the intent of the project to develop a special end effector solely for the purpose of manipulating and conveying 55-gal drums. If a 55-gal drum is encountered during the excavation, it is acceptable to place this drum into a conveyance transport container for conveyance away from the digface. It is not acceptable to section the 55-gal drum prior to conveyance.

Throughput: The system shall be capable of excavating and conveying $80 \mathrm{yd}^{3}$ of simulated buried waste per 8-hour shift with each conveyed waste container or end effector holding a maximum of $1.4 \mathrm{yd}^{3}$ of simulated buried waste.

Spillage/Debris Limits: pillage and handling of debris are of great concern due to the dust generation and subsequent spread of contamination. The system shall be capable of moving $1,000 \mathrm{yd}^{3}$ of waste while spilling approximately $1 \mathrm{yd}^{3}$ of waste. It is a goal of the project that no spillage occur. The allowable spillage limit shall be $0.001 \mathrm{yd}^{3}$ per cycle, averaged over the entire demonstration. One cycle consists of a digging, dumping, and conveyance action. Spillage shall be measured using a visual estimate of volume.

Spillage is considered to be any material that drops from the end effector during the swing of the load from the digface to the remote conveyance system. Material that is dropped during the process of picking up the load at the digface is not considered spillage. Spillage only applies to those items dropped while moving the load from the digface to the conveyance system. Once the material has been placed in the conveyance system, no spillage shall be allowed.

Maneuverability: The system shall be easily moved or transported along the digface as excavation proceeds. In a full-scale retrieval, this may require relocation up to three times per 8-hour shift.

Environment: The system shall operate within these temperature and humidity limits.

- Temperature: $40^{\circ} \mathrm{F}$ to $110^{\circ} \mathrm{F}$

- Humidity: 0 to $100 \%$

- $\quad$ Altitude: sea level to $6,000 \mathrm{ft}$.

The working environment for the demonstration will probably be dusty and windy. Actual retrievals may include water sprays and misting for dust suppression. The equipment shall be designed to operate reliably and withstand these conditions.

\subsubsection{Performance Objectives for the Remote Waste Conveyance System}

The following are performance objectives for the design of the conveyance system. These performance objectives are restated from the SOW and were used as the design requirements by RAHCO for development of the system. 
Throughput: The system shall be capable of conveying $80 \mathrm{yd}^{3}$ of the simulated buried waste per 8-hour shift, with each conveyed waste container holding a maximum of $1.4 \mathrm{yd}^{3}$ of simulated buried waste. Large objects with a volume greater than $1.4 \mathrm{yd}^{3}$ may be conveyed individually in the transport container.

Variable Terrain: The system shall be able to accommodate variable terrain. In the final intended application, the system would be used at a buried waste location to excavate and transport mixed buried waste. The actual excavation site will have variable terrain, which may change throughout the remediation process. For this demonstration, it is necessary to demonstrate that the system will function over variable terrain rather than just in a laboratory environment. The conveyance system shall operate on a nonprepared soil surface. Conditions shall vary from rough, hard compacted soil to several inches of soft, unconsolidated dirt. Dirt clods and small rocks (up to 4 in.) shall be scattered about the area, but no large rocks or other obstacles exist. The system shall be capable of operations with a maximum capacity load on a 10 degree cross slope. The area that the conveyance system will operate in may be relatively level; however, the system shall be capable of climbing and descending a 10 degree grade.

Spillage/Debris Limits: Spillage and handling of debris are of great concem due to the dust generation and subsequent spread of contamination. The system shall be capable of moving 1,000 $\mathrm{yd}^{3}$ of waste while spilling approximately $1 \mathrm{yd}^{3}$ of waste. It is a goal of the project that no spillage occur. The allowable spillage limit shall be $0.001 \mathrm{yd}^{3}$ per cycle, averaged over the entire demonstration. One cycle consists of a digging, dumping, and conveyance action. Spillage shall be measured using a visual estimate of volume.

Spillage is considered to be any material that drops from the end effector during the swing of the load from the digface to the remote conveyance system. Material that is dropped during the process of picking up the load at the digface is not considered spillage. Spillage only applies to those items dropped while moving the load from the digface to the conveyance system. Once the material has been placed in the conveyance system, no spillage shall be allowed.

Maneuverability: The proposed equipment and process must be capable of operations within the confines of a building as demonstrated by allowing sufficient maneuverability to operate within the neat lines established for the demonstration.

The conveyance system must be capable of working around large objects (such as vehicles or transport boxes) that may be present in the immediate area.

The fully loaded conveyance system shall be capable of

- Turning a 90 degree corner on a 20 -ft wide path

- Tuming 360 degrees on a 20 -ft wide path

- Traveling on a $20-\mathrm{ft}$ wide path. 


\section{Precision and Accuracy:}

Accuracy: $\quad$ The vehicle shall be capable of locating itself within \pm 1 radial foot of the assigned position.

The vehicle shall be capable of placing a waste container within \pm 1 radial foot of the target position.

The vehicle shall be able to find and retrieve a waste container or end effector that is positioned within \pm 2 radial feet of its expected location.

Precision:

Although no specific precision requirement is specified, the precision of the system will be measured during the demonstration. Precision is defined as the standard deviation.

Waste Types: See Section 3.6.1-“Waste Forms/Special Item Handling”

Environment: See Section 3.6.1—“"Environment."

\subsection{Customer Needs}

A discussion on what customer need the technology is satisfying, and how the testing meets this need can be found in Section 1.5, "Customer Needs." The relationship between the test objectives and data quality objectives, and the CERCLA criteria are discussed in Section 5.1, "Relationship of Data to CERCLA Criteria." 


\section{SEQUENCE OF ACTIVITIES}

\subsection{Schedule}

This section presents the high-level schedule and activities for deployment and demonstration. Detail schedules for the daily activities of the tests can be found in Section 3.2 "Test Parameters."

The project level schedule beginning with award of the subcontract can be found in Figure 12 . Table 4 provides a detailed breakdown of the schedule milestones arranged by element code. Table 5 provides a detailed breakdown of the schedule milestones arranged in chronological order.

\begin{tabular}{|c|c|c|c|c|c|c|c|c|}
\hline $\begin{array}{c}\text { Element } \\
\text { Code }\end{array}$ & Reporting Element & Juase & Juy & Aeg & $\begin{array}{l}994 \\
\text { Sopp }\end{array}$ & Det & Nor & Done \\
\hline & Contraet Award & $\Delta$ & & & & & & \\
\hline 1.0 & Dust \& Contamination Spread Demo & & 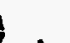 & & & & & \\
\hline 1.1 & End Eflector Design / Manufacture & & $\pi$ & & & & & \\
\hline $\begin{array}{l}1.2 \\
1.3\end{array}$ & $\begin{array}{l}\text { Iransport Container Design / Manut. } \\
\text { Pestormenea Test }\end{array}$ & & & & $\Delta$ & & & \\
\hline 1.4 & Demo Planning / Conduet / Reporting & & & & & & & \\
\hline 2.0 & Ratrieval \& Conveyance Demo & & A & & & & & \\
\hline 2.1 & TV Mechanieal & & & & & & & \\
\hline 2.2 & Vehide Control System & & & & & & & \\
\hline 2.3 & Operator Control Station & & & & & & & \\
\hline 2.4 & Integration \& Test & & & & & & & \\
\hline 2.5 & TV Pertormance Test & & & & & & & \\
\hline 2.6 & Demo Planning / Conduct / Reporting & & & & & & & \\
\hline 3.0 & Test Plan Input & $\Delta$ & & & & & & \\
\hline 4.0 & Final Report lapert & & & & & & & \\
\hline 5.0 & Reporting / Meetings & A & 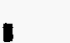 & & & & & \\
\hline 5.1 & Project Plan & & & & & & & \\
\hline 5.2 & Meotings & $\hat{\theta}$ & & 8 & g & & & \\
\hline
\end{tabular}

Figure 12. Project schedule. 
Table 4. Detailed breakdown of the schedule milestones arranged by task element code.

\begin{tabular}{|c|c|c|}
\hline Element code & Description & $\begin{array}{c}\text { Planned } \\
\text { completion date } \\
\end{array}$ \\
\hline $1.1 \mathrm{~A}$ & End Effector Design Complete & $07 / 08 / 94$ \\
\hline $1.2 \mathrm{~A}$ & Transport Container Design Complete & $07 / 15 / 94$ \\
\hline $1.3 \mathrm{~A}$ & End Effector/Transport Container Performance Test Complete & $09 / 15 / 94$ \\
\hline $1.4 \mathrm{~A}$ & Dust and Contamination Spread Demo Procedures Complete & $08 / 05 / 94$ \\
\hline $1.4 \mathrm{~B}$ & Dust and Contamination Spread Demonstration Readiness Review & $09 / 16 / 94$ \\
\hline $1.4 \mathrm{C}$ & Dust and Contamination Spread Demonstration Complete & $09 / 22 / 94$ \\
\hline 2.1A & TTV Design Complete & $07 / 15 / 94$ \\
\hline 2.1B & TTV Manufacture Complete & $08 / 16 / 94$ \\
\hline $2.2 \mathrm{~A}$ & Vehicle Control System Parts Ordered & $06 / 24 / 94$ \\
\hline $2.2 \mathrm{~B}$ & Vehicle Control System (Electronics/Hydraulics) & $07 / 15 / 94$ \\
\hline $2.2 \mathrm{C}$ & Vehicle Control System Parts Received & 07/22/94 \\
\hline $2.2 \mathrm{D}$ & Vehicle Control System Parts Tested & $07 / 29 / 94$ \\
\hline $2.3 \mathrm{~A}$ & Operator Control Station Parts Ordered & $06 / 24 / 94$ \\
\hline $2.3 \mathrm{~B}$ & Display Software Complete & $07 / 22 / 94$ \\
\hline $2.3 \mathrm{C}$ & Operator Control Station Parts Received & $07 / 22 / 94$ \\
\hline 2.3D & Software Models Complete & $07 / 29 / 94$ \\
\hline $2.3 \mathrm{E}$ & Operator Control Station Parts Tested & $08 / 05 / 94$ \\
\hline $2.3 \mathrm{~F}$ & Bench Test Complete & $08 / 12 / 94$ \\
\hline $2.4 \mathrm{~A}$ & Vehicle and Manual Controls Integrated & $08 / 23 / 94$ \\
\hline $2.4 \mathrm{~B}$ & Vehicle Controller and Work Station Integrated & $09 / 07 / 94$ \\
\hline $2.5 \mathrm{~A}$ & TTV Performance Test Complete & $09 / 23 / 94$ \\
\hline $2.6 \mathrm{~A}$ & Retrieval and Conveyance Demo Procedures Complete & $08 / 26 / 94$ \\
\hline $2.6 \mathrm{~B}$ & Mobilization Complete & $09 / 23 / 94$ \\
\hline $2.6 \mathrm{C}$ & Readiness Review/Safety Kick-Off & $09 / 26 / 94$ \\
\hline $2.6 \mathrm{D}$ & Retrieval and Conveyance Demonstration Complete & $09 / 30 / 94$ \\
\hline $2.6 \mathrm{E}$ & Demobilization Complete & $10 / 07 / 94$ \\
\hline $2.6 \mathrm{~F}$ & Video Script Submittal & $08 / 19 / 94$ \\
\hline $2.6 \mathrm{G}$ & Video Documentation Submittal & $11 / 25 / 94$ \\
\hline $3.0 \mathrm{~A}$ & Test Plan Input & $06 / 24 / 94$ \\
\hline $4.0 \mathrm{~A}$ & Final Report Draft Input & $10 / 07 / 94$ \\
\hline $4.0 \mathrm{~B}$ & Final Report Final Input & $10 / 28 / 94$ \\
\hline $5.1 \mathrm{~A}$ & Project Plan Draft & $6 / 24 / 94$ \\
\hline $5.1 \mathrm{~B}$ & Project Plan Final & $07 / 08 / 94$ \\
\hline $5.2 \mathrm{~A}$ & Kick-Off Meeting & $06 / 06 / 94$ \\
\hline $5.2 \mathrm{~B}$ & Technical Interchange Meeting No. 1 & 08/08/94 \\
\hline $5.2 \mathrm{C}$ & Technical Interchange Meeting No. 2 & $09 / 07 / 94$ \\
\hline $5.2 \mathrm{D}$ & BWID Technology Expo & $08 / 08 / 94$ \\
\hline $5.3 \mathrm{~A}-\mathrm{G}$ & Monthly Reports & Last day of each month \\
\hline
\end{tabular}


Table 5. Detailed breakdown of the schedule milestones arranged in chronological order.

Element code

Description

Planned completion date
06/06/94

$06 / 24 / 94$

$06 / 24 / 94$

06/24/94

$06 / 24 / 94$

$07 / 08 / 94$

07/08/94

$07 / 15 / 94$

07/15/94

$07 / 15 / 94$

07/22/94

$07 / 22 / 94$

$07 / 22 / 94$

$07 / 29 / 94$

07/29/94

$08 / 05 / 94$

08/05/94

$08 / 08 / 94$

08/08/94

$08 / 12 / 94$

$08 / 16 / 94$

08/19/94

$08 / 23 / 94$

$08 / 26 / 94$

$09 / 07 / 94$

09/07/94

$09 / 15 / 94$

$09 / 16 / 94$

$09 / 22 / 94$

$09 / 23 / 94$

$09 / 23 / 94$

$09 / 26 / 94$

09/30/94

$10 / 07 / 94$

$10 / 07 / 94$

$10 / 28 / 94$

$11 / 25 / 94$

Last day of each month 


\section{SAMPLING AND DATA}

\subsection{Relationship of Data to CERCLA Criteria}

This section describes how the data collected address the criteria identified in the CERCLA.

\subsubsection{Overall Protection of Human Health and the Environment}

Handling of TRU waste, such as during retrieval operations, requires application of aggressive contamination control and personnel safety techniques, primarily due to the highly mobile nature of the TRU contaminants and the danger of fire and explosion from various hazardous materials interred. Remote waste retrieval and conveyance systems will aid in the environmental restoration of DOE buried waste sites by lowering risk to workers by minimizing exposure to radiation and hazardous materials.

Dust and rare earth tracer data will be collected and analyzed to determine the effectiveness of the system to reduce or eliminate the spread of contamination during buried waste retrieval efforts. The dumping operation is the main mechanism for spreading dust and therefore airbome contaminants, and no sufficient dust control method or mechanism has been demonstrated to date. Due to the extremely hazardous nature and small particulate size of the contaminants, there is a need for a system that reduces dust generation and eliminates the potential spread of airbome contaminants especially during dumping operations. The innovative end effector is intended to operate remotely in a containment building. However, even for remote operations, there will be a need for bubble suited entry for maintenance and repairs. Studies have shown that bubble suited entry into areas with high levels of loose contamination can lead to uptake during removal of the bubble suits. Therefore, it is imperative that the contamination level in the containment structure be maintained as low as possible.

\subsubsection{Long-Term Effectiveness and Permanence}

Data on overall performance (especially as relates to remote operations) will be used to evaluate the long-term effectiveness of the system.

\subsubsection{Reduction of Toxicity, Mobility, and Volume Through Treatment}

There is no treatment (per se) involved in the system. Reduction of toxicity, mobility, and volume (of waste) is accomplished via active contamination control. As was discussed in Section 5.1.1, collection and analysis of dust and rare earth tracer data are the primary means of determining these parameters.

\subsubsection{Short-Term Effectiveness}

Data on overall performance (especially as it relates to remote operations) will be used to evaluate the short-term effectiveness of the system. 


\subsubsection{Implementability}

Aside from data to determine the dust and rare earth tracer quantities, virtually all the remaining data are being gathered to support the assessment of the implementability of the system. Examples include:

- Data to determine the rate of waste removal using the selected end effector and/or dust free dumping system

- Data to determine the capability of the end effector and/or dust free dumping system to handle the various objects that could be encountered in an actual operation

- Data to establish the rate for conveyance of waste from the digface

- Data to determine the effectiveness of the remote control or automated control system

- Data on the maneuverability and ability of the conveyance system to operate in rugged terrain

- Data gathered to generally evaluate the capability of the system for operation in a TRUcontaminated environment (including deployment, maintenance, reparability, reliability, and operating cost)

- Data regarding the integration of the innovative end effector to the remote conveyance systems.

\subsubsection{Cost}

Cost data will be gathered/generated in three ways: (1) data on the cost of design and development, and procurement of hardware will be collected during the development phase and used in the cost analysis to be presented in the technology evaluation report, (2) during the demonstration, data on the reliability, maintainability, operating costs, etc., of the system will be collected, and (3) an analysis will be provided in the technology evaluation report that will define estimated capital procurement costs, operating costs, and operating and maintenance costs based on data gathered during the test, and lessons learned from the testing. This analysis will be predicated on an actual retrieval of "hot" waste in a production environment.

\subsection{Data Collection Techniques}

\subsubsection{Particulate Sample Filters}

Air sampling will be performed using HI-VOL particulate air samplers. The HI-VOL samplers (see Figure 13) contain a 4-in. air particulate filter held in the sampler by a screw-in retaining ring. The sampler unit is self-contained with the pump, filter, and flow monitor. Airflow through the sampler is set to run at 10 to $20 \mathrm{cfm}$.

\subsubsection{Mass Measurements}

Sample weights (of the air filters) will be obtained using a four-place analytical balance. This balances weighs to the nearest 0.1 of a milligram. 


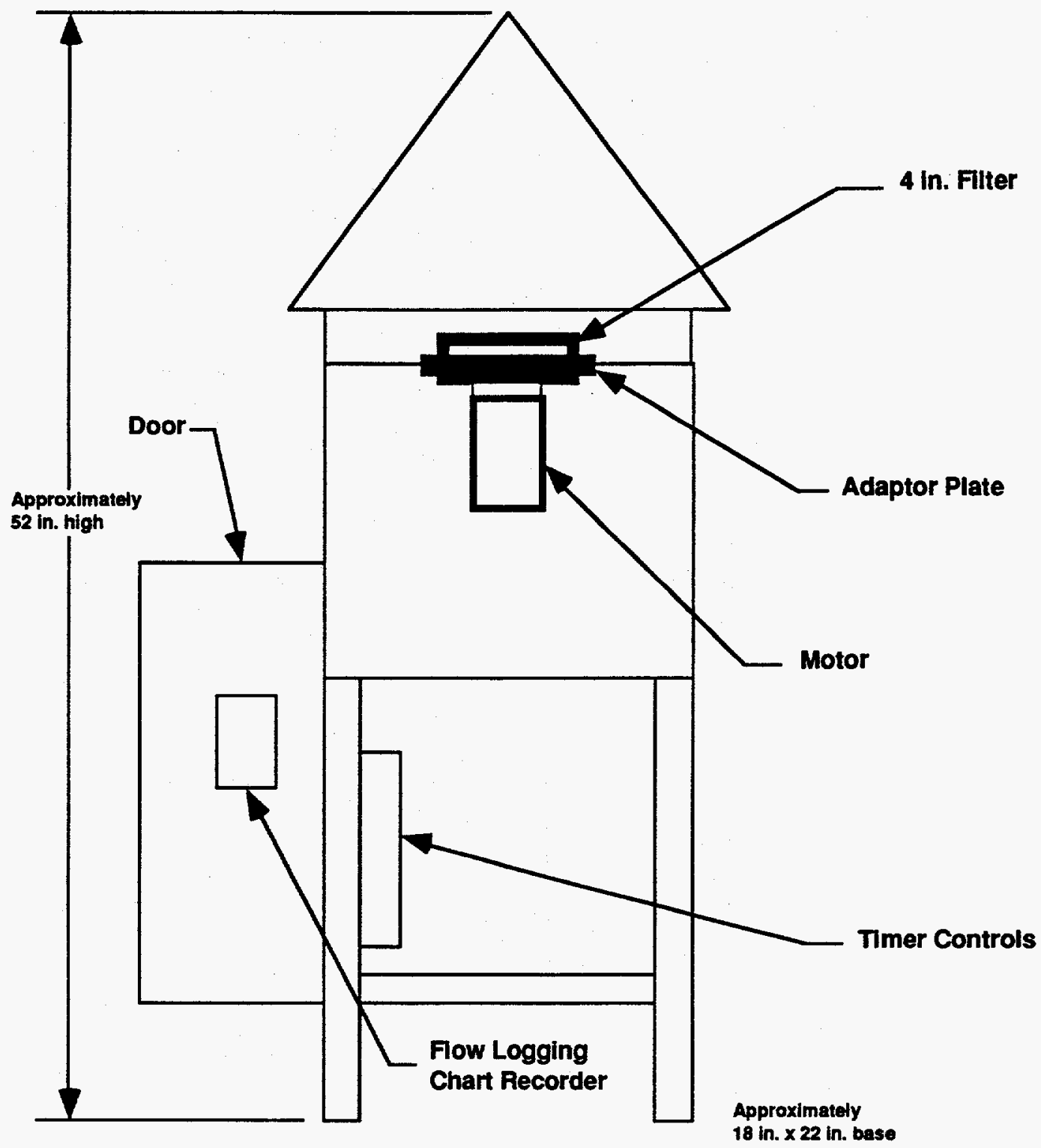

Figure 13. Cross-sectional view of the HI-VOL air sampler. HI-VOL particulate air samplers will be used to determine background dust levels and monitor dust and contamination spread during the demonstration.

\subsubsection{Maneuverability (Precision and Accuracy) Evaluation}

Data concerning the maneuverability of the equipment (especially as relates to precision and accuracy of placement) will be gathered using a standard measuring tape; reference location markings on the TTV, the excavator, and the receiving station; TTV path marking posts; a TTV path marker, and simple geometrical calculations. Maneuverability precision and accuracy will be measured by establishing the actual location of the TTV and comparing this position to the expected location. The details of this approach are described below. 
Reference location markings will be established on the front and sides of the TTV, the sides of the excavator, and on the front of the receiving station. Two reference marks will be placed on each of these surfaces. The reference marks on the front of the TTV will be positioned near the front corners. The reference marks on the excavator will be placed on the excavator chassis (nonrotating portion) and positioned to align with the marks on the front of the TTV. The excavator markings will be located so that when the TTV is positioned with its reference marks aligned to those on the excavator chassis, the distance between the marks on the TTV and the excavator reference marks will be identical as shown in Figure 14. The reference marks on the receiving station will be positioned similarly (to align with those on the front of the TTV). The reference marks on the side of the TTV will be placed so that when the TTV rotates 90 degrees with respect to the excavator these side TTV marks will align with those on the excavator chassis (see Figure 14). Each time the TTV is positioned at the excavator or the receiving station, the four measurements shown in Figure 14 will be made with a measuring tape and recorded for later analysis. Simple geometrical analysis will be performed to determine the distance from the actual TTV location to the desired TTV location.

The maneuverability of the TTV during movement will also be measured. The actual path that the TTV travels will be compared to the desired path using path marking posts and a TTV path marker. Path marking posts will be placed at several locations along the intended TTV path. These posts will be positioned to guide the operator and to provide a reference location to measure the actual path to the desired path. A TTV path marker will mark the actual path that the TTV travels. This marker will consist of a spring that is placed at the TTV center of rotation and will be positioned so that it scores a line into the ground as the TTV travels its path. The distance from the travel path line to each marking post will be measured and compared to the expected distance in order to perform the TTV maneuverability evaluation (see Figure 14).

Other maneuverability data will be gathered by "exercising" the equipment through a series of maneuverability demonstrations designed to verify operating envelopes. Data will be gathered using direct measurements, photography, video, and field notes. The measurements will be made using the methodology described above. The maneuverability operating envelopes that will be verified include

- Tuming a 90 degree comer on a 20 - $\mathrm{ft}$ wide path

- Tuming 360 degrees on a 20 - $\mathrm{ft}$ wide path

- $\quad$ Traveling on a 20 -ft wide path.

\subsubsection{Operational Evaluation}

Data concerning the operations of the equipment will be recorded in the test log book, on videotape taken during the demonstration, and with still photography. Data to be considered include the ability of the end effector to handle simulated waste objects, visual dust generation, reliability of the hardware, rate of use of consumables, any other operational parameters deemed noteworthy, and measured (Phase I only) dust and contamination spread.

\subsection{Sampling and Data Collection Procedures}

\subsubsection{Particulate Sample Filters}

The particulate air samplers will be positioned at several locations around the test area as discussed in Section 3. The preweighed particulate filters will be removed from their petri dish, placed in 


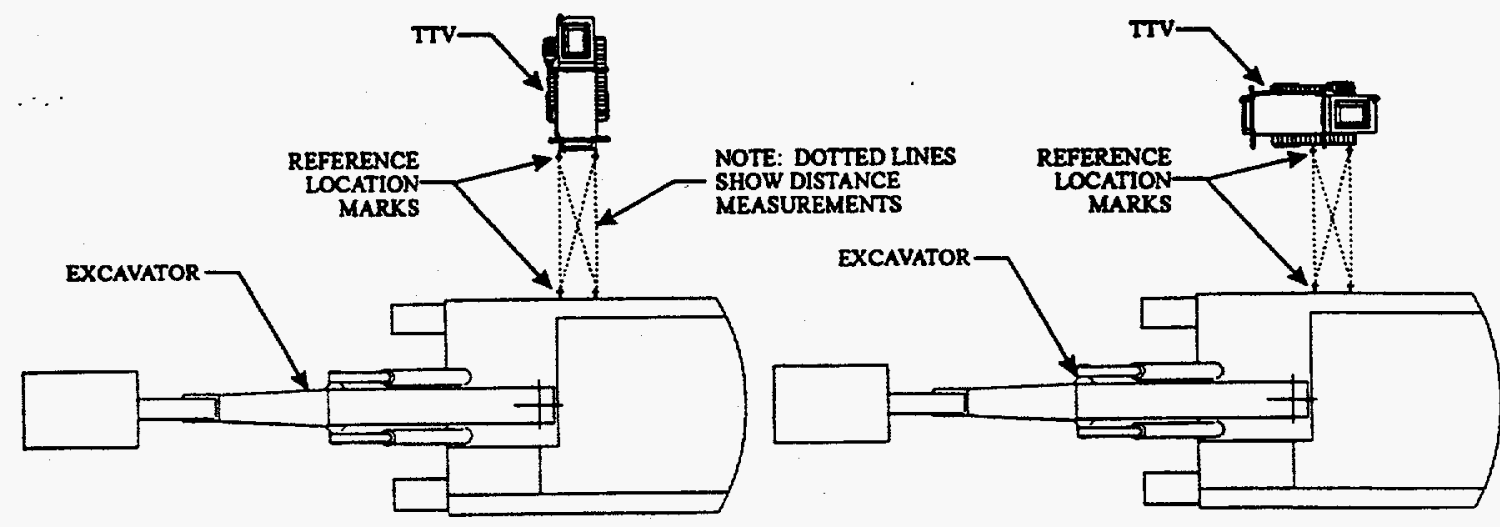

TTV PARKED AT EXCAVATOR

BEFORE TURNING $90^{\circ}$ NOTE: RECIEVING STATION PARKING LOCATION IS SIMILAR)
TTV PARKED AT EXCAVATOR AFTER TURNING $90^{\circ}$

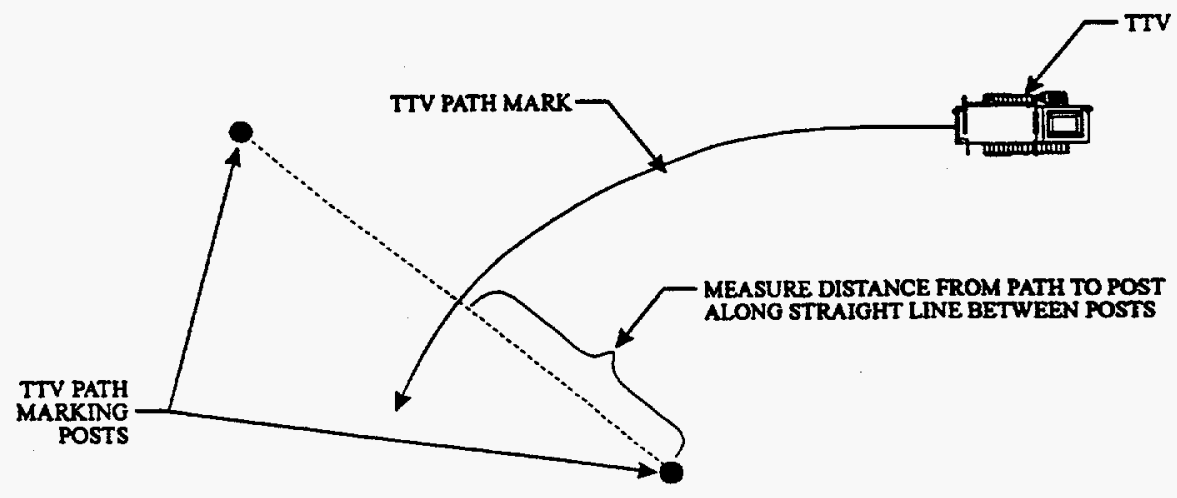

Figure 14. TTV maneuverability evaluation measurements.

the filter holder, and the retaining ring will be attached. The sampler filter shall be handled using tweezers to minimize contamination of the filter from moisture or natural skin oils from the hand. The filter number will be noted in the log book along with the sampler location and number (see Section 5.4.2, "Management of Samples"). After the test run is completed, the particulate filters will be removed from the air monitors using the same procedures to install them and placed in their original petri dish. The filters will be kept together and protected from damage or contamination. A total of five complete test runs are planned for Phase I of the demonstration. Each test will use 15 4-in. filters as follows:

3 filters for background measurements

8 filters for test samples

4 filters for laboratory blanks

15 total filters for each test run

$15 \times 5=75$ filters total 
Two extra sets (total of 30 filters) will be prepared as backup for use if a test has to be scrubbed for some reason.

During the test, each HI-VOL shall be monitored and data recorded on a form similar to that shown in Figure 15. The date, time, manometer reading, and a record of what action was taken (e.g., turning the monitor on/off or taking a manometer reading) shall be recorded on the form and kept with the log book. The airflow calculated value will be computed at a later date.

\subsubsection{Precision and Accuracy of Remote Operations}

The TTV position will be recorded several times during each excavation cycle performed in the Phase II demonstration. Three "parked" positions will be documented including the position when the excavator places a loaded ITM in a waste container on the TTV, the position when the TTV pulls forward to the provide the excavator access to an empty ITM (after placing the full ITM into the waste container), and the position when the TTV parks next to the receiving station to off-load the full ITM and receive an empty waste container and ITM. Also, the position of the actual TTV path will be recorded at approximately six locations each time the TTV travels between the excavator and the receiving station. The maneuverability evaluation methodology described in Section 5.2.3 will be used in making these TTV position measurements. For the parked TTV positions, four measurements will be taken. For the TTV path locations, one measurement will be taken for each position. These measurements are illustrated in Figure 14. All measurements will be recorded in the log book.

\subsection{Sampling and Analysis Plan}

\subsubsection{Chain of Custody}

A Chain of Custody (COC) for each filter will be initiated at the time when the presampling weight for the filter is taken. The COC will be tracked by the project's PI and Project Engineer.

\subsubsection{Management of Samples}

Sample control will be maintained by placing all filters and smears in an numbered petri dish after the initial weight is recorded using the system indicated below:

Sample ID $=\mathbf{P}-\mathbf{X}$

where

$\mathrm{P} \quad=\quad$ particulate air filter

$\mathrm{X}=$ alpha numeric sample number.

When that sample is used during testing, all pertinent data for that sample will be noted in the log book. A sample data sheet showing the method of logging the filter specific data is provided in Figure 15. In addition, plot plans will be used to give a reference to each sample location to note the location and test parameters of each sample taken. These plots will be included as inserts in the log book. Each insert will be signed and dated. A sample data sheet showing the method of logging the filters for 


\begin{tabular}{|c|c|c|c|c|}
\hline $\begin{array}{c}\text { Sample ID } \\
(\mathrm{P}-\mathrm{XXX})\end{array}$ & $\begin{array}{c}\text { Preweight } \\
(\mathrm{g})\end{array}$ & $\begin{array}{c}\text { Post-weight } \\
(\mathrm{g})\end{array}$ & $\begin{array}{c}\text { Test number } \\
\text { and location ID }\end{array}$ & $\begin{array}{c}\text { Background } \\
\text { (BG), test (T), } \\
\text { or blank (BL) }\end{array}$ \\
\hline P-001 & 0.00000 & 0.00000 & $1-1$ & BG \\
\hline & & & & \\
\hline & & $\begin{array}{c}\text { Manometer } \\
\text { reading } \\
\text { (in) }\end{array}$ & Action & $\begin{array}{c}\text { Airflow } \\
\text { (calculated } \\
\text { value) (l/m) }\end{array}$ \\
\hline Date & Time & & & \\
\hline & & 6.30 & Power on & \\
\hline $08 / 23 / 94$ & 800 & 6.10 & Reading & \\
\hline $08 / 23 / 94$ & 815 & 5.50 & Reading & \\
\hline $08 / 23 / 94$ & 830 & 5.00 & Reading & \\
\hline $08 / 23 / 94$ & 845 & 5.00 & Reading & \\
\hline $08 / 23 / 94$ & 900 & 5.00 & Reading & \\
\hline $08 / 23 / 94$ & 915 & 1.00 & Reading & \\
\hline $08 / 23 / 94$ & 930 & 4.80 & Power off & \\
\hline $08 / 23 / 94$ & 945 & & & \\
\hline
\end{tabular}

Figure 15. Sample dust measurement collection sheet. HI-VOL air monitor data shall be recorded on a form similar to the one shown above. Each filter will have its own form and will be tracked separately.

tracking purposes is provided in Figure 16. The test number refers to the test series, and the location ID will coordinate with the identity of the HI-VOL air monitor (e.g., HI-VOL numbers 1 through 8).

In addition, to control for rare earth tracer contamination on the raw (unused) filters, the filters shall be chosen from single lots, and identified by lot number.

The sampler filter shall at all times be handled using tweezers to minimize contamination of the filter from moisture or natural skin oils from the hand.

\subsubsection{Analysis of Samples}

For gravimetric and chemical analysis of the filters, see Section 7, "Analytical Procedures," of this document.

\subsubsection{Data Reduction, Validation, and Verification}

For data reduction, validation, and verification, see Section 8, "Data Reduction, Validation, and Verification," of this document.

\subsubsection{Data Analysis}

5.4.5.1 Dust Measurement Analysis. To assess whether the dust detected on the air sample filters exceeds the background level of dust in the air by $1.1 \times 10^{-4} \mathrm{~g} / \mathrm{L}$, a statistical t-test will be employed. The procedure tests the hypothesis of equality of the mean dust detected during operations to 


\begin{tabular}{|c|c|c|c|c|}
\hline $\begin{array}{c}\text { Sample ID } \\
(\mathrm{P}-\mathrm{XXX})\end{array}$ & $\begin{array}{c}\text { Preweight } \\
(\mathrm{g})\end{array}$ & $\begin{array}{c}\text { Post-weight } \\
(\mathrm{g})\end{array}$ & $\begin{array}{c}\text { Test number } \\
\text { and location } \\
\text { ID }\end{array}$ & $\begin{array}{c}\text { Background (BG), } \\
\text { test (T), } \\
\text { or blank (BL) }\end{array}$ \\
\hline & & & & \\
\hline P-001 & & & $1-1$ & BG \\
\hline P-002 & & & $1-2$ & BG \\
\hline P-003 & & & $1-3$ & BG \\
\hline P-004 & & & $1-1$ & T \\
\hline P-005 & & & $1-2$ & T \\
\hline P-006 & & & $1-3$ & T \\
\hline P-007 & & & $1-4$ & T \\
\hline P-008 & & & $1-5$ & T \\
\hline P-009 & & & $1-6$ & T \\
\hline P-010 & & & $1-7$ & T \\
\hline P-011 & & & $1-8$ & T \\
\hline P-012 & & & $1-B L$ & BL \\
\hline P-013 & & & $1-B L$ & BL \\
\hline
\end{tabular}

Figure 16. Sample filter weight data collection sheet. Data sheets similar to that shown will be used in the management of air filter samples. Data will include pretest and post-test filter weights, test number and location ID, and the designation of what the filter was used for (e.g., background, test, or blank).

the background dust plus the target level of $1.1 \times 10^{-4} \mathrm{~g} / \mathrm{L}$ (e.g., is the amount of dust detected on the air sample filters equal the background level of dust in the air plus $1.1 \times 10^{-4} \mathrm{~g} / \mathrm{L}$ ?).

Null Hypothesis: $\quad H_{0}: \quad$ Mean Dust Detected $\leq$ Background Dust $+1.1 \times 10^{-4} \mathrm{~g} / \mathrm{L}$ or

Null Hypothesis: $\quad H_{o}: \quad \mu_{d}>\mu_{b}+1.1 \times 10^{-4}$

Alternate Hypothesis: $\quad H_{1}: \quad$ Mean Dust Detected $>$ Background Dust $+1.1 \times 10^{-4}$ or

Alternate Hypothesis: $\quad H_{i}: \quad \mu_{d}>\mu_{b}+1.1 \times 10^{-4}$

where

$$
\begin{aligned}
& \mu_{d}=\text { the mean of the dust detected on the filters } \\
& \mu_{b} \quad=\quad \text { the mean of the background dust measurements taken during the test. }
\end{aligned}
$$

Because the two means are unknown, a pooled t-test or two-sample t-test will be used in the analysis. The assumption is that both distributions are normal.

The test statistic is therefore:

$$
t=\frac{\bar{x}_{d}-\left(\bar{x}_{b}+1.1 \times 10^{-4}\right)}{S_{p} \sqrt{1 / n_{d}+1 / n_{b}}}
$$


where

$$
\begin{aligned}
& t \quad=\quad \text { the critical value } \\
& \bar{x}_{d}=\text { the observed mean of the dust detected } \\
& \bar{x}_{b}=\quad \text { the observed mean of the background dust detected } \\
& n_{d} \quad=\quad \text { the number of test filters } \\
& n_{b} \quad=\quad \text { the number of background filters } \\
& S_{p} \quad=\quad \text { the pooled standard deviation } \\
& S_{p}=\sqrt{\frac{s_{d}^{2}\left(n_{d}-1\right)+s_{b}^{2}\left(n_{b}-1\right)}{n_{d}+n_{b}-2}}
\end{aligned}
$$

where

$$
\begin{aligned}
& s_{d}^{2} \quad=\quad \text { the variance of the dust detected } \\
& s_{b}^{2} \quad=\quad \text { the variance of the background dust. }
\end{aligned}
$$

The equation chosen for the pooled standard deviation assumes homogeneous variances (i.e., $s_{b}^{2}=s_{d}^{2}$ ). This assumption will be checked when the data are available, and an adjustment to the analytical procedure made if necessary.

The null hypothesis $\left(H_{o}\right)$ is not rejected when

$$
t<t\left(\alpha, n_{d}+n_{b}-2\right)
$$

where

$$
\alpha \quad=\quad \text { level of significance }
$$

The null hypothesis $\left(H_{o}\right)$ is rejected in favor of the alternate hypothesis $\left(H_{1}\right)$ when

$$
t>t\left(\alpha, n_{d}+n_{b}-2\right) \text {. }
$$

5.4.5.2 Rare Earth Tracer Analysis. To assess whether the rare earth tracer (praseodymium) detected on the air sample filters exceeds the background level of praseodymium in the air, a statistical t-test will be employed. The procedure tests the hypothesis of equality of the mean praseodymium detected during operations to the background praseodymium (e.g., is the amount of praseodymium detected on the air sample filters equal to the background level of praseodymium in the air in units of $\mu \mathrm{g}-\mathrm{Pr} / \mathrm{L}$-air?).

Null Hypothesis: $\quad H_{o}: \quad$ Mean Praseodymium Detected $=$ Background Praseodymium or

Null Hypothesis: $\quad H_{o}: \quad \mu_{d}=\mu_{b}$ 
Altemate Hypothesis:

$H_{1}$ : $\quad$ Mean Praseodymium Detected $>$ Background Praseodymium or

Altemate Hypothesis:

$$
H_{1}: \quad \mu_{d}>\mu_{b}
$$

where

$$
\begin{aligned}
& \mu_{d} \quad=\quad \text { the mean of the praseodymium detected on the filters } \\
& \mu_{b} \quad=\quad \text { the mean of the background praseodymium measurements taken during the test. }
\end{aligned}
$$

Because the two means are unknown, a pooled t-test or two-sample t-test will be used in the analysis. The assumption is that both distributions are normal.

The test statistic is therefore:

$$
t=\frac{\bar{x}_{d}-\bar{x}_{b}}{S_{p} \sqrt{1 / n_{d}+1 / n_{b}}}
$$

where

$$
\begin{aligned}
& t \quad=\quad \text { the critical value } \\
& \bar{x}_{d} \quad=\quad \text { the observed mean of the praseodymium detected } \\
& \bar{x}_{b} \quad=\quad \text { the observed mean of the background praseodymium detected } \\
& n_{d} \quad=\quad \text { the number of test filters } \\
& n_{b} \quad=\quad \text { the number of background filters } \\
& S_{p} \quad=\quad \text { the pooled standard deviation } \\
& S_{p}=\sqrt{\frac{s_{d}^{2}\left(n_{d}-1\right)+s_{b}^{2}\left(n_{b}-1\right)}{n_{d}+n_{b}-2}}
\end{aligned}
$$

where

$$
\begin{aligned}
& s_{d}^{2}=\text { the variance of the praseodymium detected } \\
& s_{b}^{2}=\text { the variance of the background praseodymium. }
\end{aligned}
$$

The equation chosen for the pooled standard deviation assumes homogeneous variances (i.e., $s_{b}^{2}=s_{d}^{2}$ ). This assumption will be checked when the data are available and an adjustment to the analytical procedure made if necessary. 
The null hypothesis $\left(H_{o}\right)$ is not rejected when

$$
t<t\left(\alpha, n_{d}+n_{b}-2\right)
$$

where

$$
\alpha \quad=\quad \text { level of significance }
$$

The null hypothesis $\left(H_{o}\right)$ is rejected in favor of the alternate hypothesis $\left(H_{1}\right)$ when

$$
t>t\left(\alpha, n_{d}+n_{b}-2\right) \text {. }
$$

5.4.5.3 Other Analysis. Qualitative data taken during the demonstration will not be subject to analysis, but will be recorded and documented through log book entries, photographic evidence, and videotapes.

Analysis of the throughput of the system will include calculations of the mean and standard deviation for the entire Phase II demonstration and each excavation cycle. Time-outs will occur during the testing for maneuverability measurements. Time-outs may also be directed by the Demonstration Manager as a result of any anomalous conditions that occur during testing. These time-outs will be recorded in the log book and will be deducted from the excavation cycle time for the throughput analysis.

The amount of spillage per unit volume will be calculated by taking the total amount of spillage and dividing it by the total volume of waste processed during the demonstration.

The precision and accuracy with which the TTV is capable of maneuvering will be determined by simple geometrical analysis of the measurements between the reference marks. The methodology of how these measurements will be taken is described in Section 5.2.3. This geometrical analysis will provide the distance between the actual and intended TTV location. The mean and standard deviation will be calculated for all the maneuverability data collected in the Phase II testing. Calculations for determining precision and accuracy are as follows:

Precision (Standard Deviation): Average deviation of the observations from each other.

$$
S=\sqrt{\frac{\sum_{i=1}^{n}\left(X_{i}-\bar{X}\right)^{2}}{n-1}}
$$

where

$$
\begin{array}{lll}
X_{i} & = & \text { an observation } \\
\bar{X} & = & \text { the mean of the observations } \\
\mathrm{S} & = & \text { the standard deviation (precision) } \\
n & = & \text { the number of observations. }
\end{array}
$$


Accuracy (Bias): Average deviation from the value expected.

Bias $=\frac{\sum_{i=1}^{n}\left(\mu_{0}-X_{i}\right)}{n}$

where

$$
\begin{array}{lll}
X_{i} & = & \text { an observation } \\
\mu_{o} & = & \text { the target cut depth } \\
n & = & \text { the number of observations. }
\end{array}
$$




\section{DOCUMENT CONTROL}

This section discusses document control. EG\&G Idaho and BWID procedures for control shall be followed for this project.

\subsection{BWID Requirements}

Data shall be managed in the manner that best protects the credibility of the data and is in compliance with the BWID Program Directives. BWID Program Directive 4.4 establishes the requirements for configuration management. Engineering Project Files shall be prepared by design participants as required by BWID Program Directive 4.4, Project Files, and EG\&G Idaho Company Procedures 9.13 and 2.20. Project file numbers (WTD-CONVEY-082-94 and WTD-BUCKET-083-94) have been obtained for the Waste Conveyance and Innovative End Effector demonstration from the BWID program office. BWID Program Directive 4.7, Change Control, provides instruction on the process of change control. In addition, the PI shali comply with the following BWID data management policy. Data collected during BWID approved testing and demonstrations shall be managed according to BWID Program Directive 4.3, Data Management and as specified in this test plan.

\subsubsection{Management of Electronic Data}

The PI shall define the format, acquire the data, back up the data on a daily basis, control the configuration of the data, technically document the data, generate processed data, and archive the data.

The PI shall submit to BWID a copy of all configuration controlled data (raw and processed) and appropriate technical documentation acquired during the course of the demonstration testing. The project shall submit complete copies of final configuration controlled raw and processed data with appropriate technical documentation to BWID with the final report.

\subsubsection{Management of Reports}

The PI shall draft reports, obtain and incorporate review comments, obtain approvals, archive, and control the configuration of data via a project Engineering Design File.

Copies of all draft reports shall be submitted to BWID. Copies of all final reports shall be submitted to BWID with an electronic copy.

\subsubsection{Management of Log Books}

Data shall be recorded in log books in accordance with BWID guidelines from past demonstrations. A data log book will be kept during set-up and conduct of experiments. As a minimum, specific data that shall be included in the log book for the work performed under this test plan are listed below:

- Locations of samplers and filter numbers during all tests

- Flow meter calibration information

- $\quad$ Filter and smear preweight and post-weight 
- Changes made in experimental or electronic presets

- Test abnormalities observed

- Date and negative numbers of any photographs taken

- Dates and information on all quality assurance samples (standards, blanks, and duplicates)

- Maneuverability measurements

- Excavation process parameters (e.g., time, volume)

- Unusual events

- Any other pertinent information that the experimenter feels is necessary.

In addition, each page and entry into the log book shall be dated and coded with the name of the person making the entry. All log book entries shall be photocopied at the end of each day of the demonstration and copies delivered to BWID.

\subsection{Video Production}

RAHCO shall provide two videotapes of the demonstrations. The first videotape (in color) shall include all key aspects of the dust and contamination spread demonstration and the retrieval and conveyance demonstration. This videotape will be used as the basis for the second 7 to 10 minutes long videotape. It is recommended that a minimum of 1 to 2 hours per day of videotape be shot to ensure that all key demonstration activities are preserved on film. RAHCO shall video the preparation of the demonstration soils and pit, the set-up and deployment of the equipment, and the resultant demonstrations. Additional areas for video taping may include close-up shots of the equipment, slow motion operations of the equipment, and shots emphasizing how dust generation and spread are minimized by the equipment. Other filming, particularly anomalous conditions, equipment malfunctions, or other unusual occurrences shall be captured. RAHCO shall maintain the capability to, at the direction of EG\&G Idaho, take video footage of certain aspects of the work in progress. Video taken from any cameras on-board the remote conveyance system shall be included.

The first video (deliverable) shall be produced from footage taken during videotaping of the demonstrations. The video shall be 1 to 3 hours long. It shall include a full record of the Phase I dust control demonstration, and the Phase II retrieval/conveyance demonstration shall be professionally produced (professional narration is not a requirement) and will be used primarily as a historical record of the demonstrations. Narration of the videotape shall include a statement of the objectives of the demonstrations, an emphasis on the positive aspects of the demonstrations, a statement on the overall results of the demonstrations, and a commentary of how well the demonstrations met the project objectives. A second video (deliverable) approximately 7 to 10 minutes in length shall be provided. It shall be professionally produced and narrated, and shall be a condensation of the essential information included in the first video. This shorter version will be used for presentations to the DOE, internal 
management, seminars, and symposiums. Sample videos of a previous demonstration that show the quality level required for the videos will be provided by EG\&G Idaho to RAHCO for review.

RAHCO shall be responsible to produce scripts for each of the videos described above. These will be furnished to EG\&G Idaho for review and approval prior to the completion of the videotapes.

RAHCO shall provide negatives and still photos of the demonstrations.

EG\&G Idaho may take additional video and still photographs of the demonstrations. This photography will be limited to the subject demonstrations, facilities, and equipment covered under this test plan.

\subsection{Data Reporting}

To ensure that the demonstration results are reported to interested parties, the following methods of data reporting will be used:

- Technology Evaluation Report-The data generated by the demonstration as well as the information on the planning and conducting of tests will be assembled and documented in a Technology Evaluation Report. The Technology Evaluation Report will summarize the tests, test results, and lessons learned and provide recommendations for further development. The Technology Evaluation Report will be issued as an EG\&G Idaho informal report.

- Publications-Information on the demonstrations and results will be submitted for publication to the Waste Management '95 conference and other waste management or environmental restoration related journals, conferences, and meetings.

- $\quad$ BWID Open House-A public open house will be held by BWID in late summer, 1994, to display BWID projects.

- Video-A professionally produced and narrated video, 7 to 10 minutes in length shall be provided. It will be used for presentations to the DOE, internal management, seminars, and symposiums.

\subsection{Test Plan Changes}

Change requests to this plan may be initiated by any person participating in the remote conveyance and innovative end effector demonstration, but they must be approved by the PI and/or the BWID PM and the RAHCO PM. Changes that are determined by the PI and PM to be minor will be approved and incorporated immediately. These changes shall be clearly documented by red-lining the procedures to match the procedure that is actually followed, initialing the procedure, recording the changes in the daily log book, and photocopying the procedure to be sent to BWID. Changes that are deemed to be significant by the PI and PM shall be documented and approved by the BWID IDC or designate. The Environmental Support Group of EG\&G Idaho shall be notified if the project is modified (depending on the scope of the change) to determine what (if any) follow-up actions are required with regard to environmental documentation. 


\section{ANALYTICAL PROCEDURES}

\subsection{Gravimetric Analysis of Filters}

All filters shall be dried by desiccation before weighing to ensure that there is no excess moisture in the filter. All filters shall be weighed on a five-place analytical balance that has been calibrated and approved by the EG\&G Idaho Standards and Calibrations Laboratory. All filters shall be preweighed before transport to the test site to establish a baseline weight. The filter will then be placed in a petri dish and sealed until used at the sampling location. The sampler filter shall be handled using tweezers to minimize contamination of the filter from moisture or natural skin oils from the hand. The filter will be placed on the balance, and the initial weight recorded in the project log book.

After sampling, the particulate filters shall be dried to remove any excess moisture trapped in the filter during sampling. The samples will then be taken to the weighing area and the filter placed on the balance. The weight will then be recorded in the project $\log$ book. This procedure will be repeated for all filters. After all the filters have been weighed, the samples will then be transported for tracer analysis.

\subsection{Chemical Analysis of Filters}

The digestion method used for glass microfiber filters for lanthanide elements is fully described in the Analytical Chemistry Environmental Chemistry Laboratory (ECL) Standard Operating Procedure (SOP) IP-1.3. The filters are digested on a hot plate using nitric acid and hydrogen peroxide. The method is a hot acid leaching procedure and not a total digestion. While the method does not result in total dissolution of the glass microfibers, previous studies have shown that rare earths are fully dissolved by this method. After digestion, the samples are analyzed by Inductively Coupled Plasma-Mass Spectrometry (ICP-MS). The determination of lanthanide elements by ICP-MS is described in the Analytical Chemistry ECL SOP IM-6.1. The specific rare earth element tracer analyzed for will be praseodymium. 


\section{DATA REDUCTION, VALIDATION, AND VERIFICATION}

\subsection{Data Reduction}

During the Phase I test, the total airborne dust collected with the air samples will be used to compare the amount of dust generated and contamination spread with the background levels. The amount of dust collected on each filter will be determined by subtracting the presampling weight of the filter from the post-sampling weight of the filter. The total mass of dust on each sampler filter will be divided by the total volume of air sampled to determine airborne dust concentrations. The digestion method described in Section 7.2, "Chemical Analysis of Filters," will be used to determine the amount of rare earth tracer in the filter samples.

\subsubsection{Dust Measurement Data Reduction}

The HI-VOL air filters will be weighed using the procedures outlined in Section 7.1, "Gravimetric Analysis of Filters," by the ECL. The data will be reported by the lab using their standard forms and procedures and published in the technology evaluation report. Figure 17 shows a sample of a graph that may be used to display the dust measured for the test background and the test samples. The raw data and calculation of the mean, standard deviation, and t-test analysis will be presented in a table similar to that shown in Table 6 . The procedures used to calculate the statistical results can be found in Section 5.4.5, "Data Analysis."

\section{Dust Measurement - Test \#X}

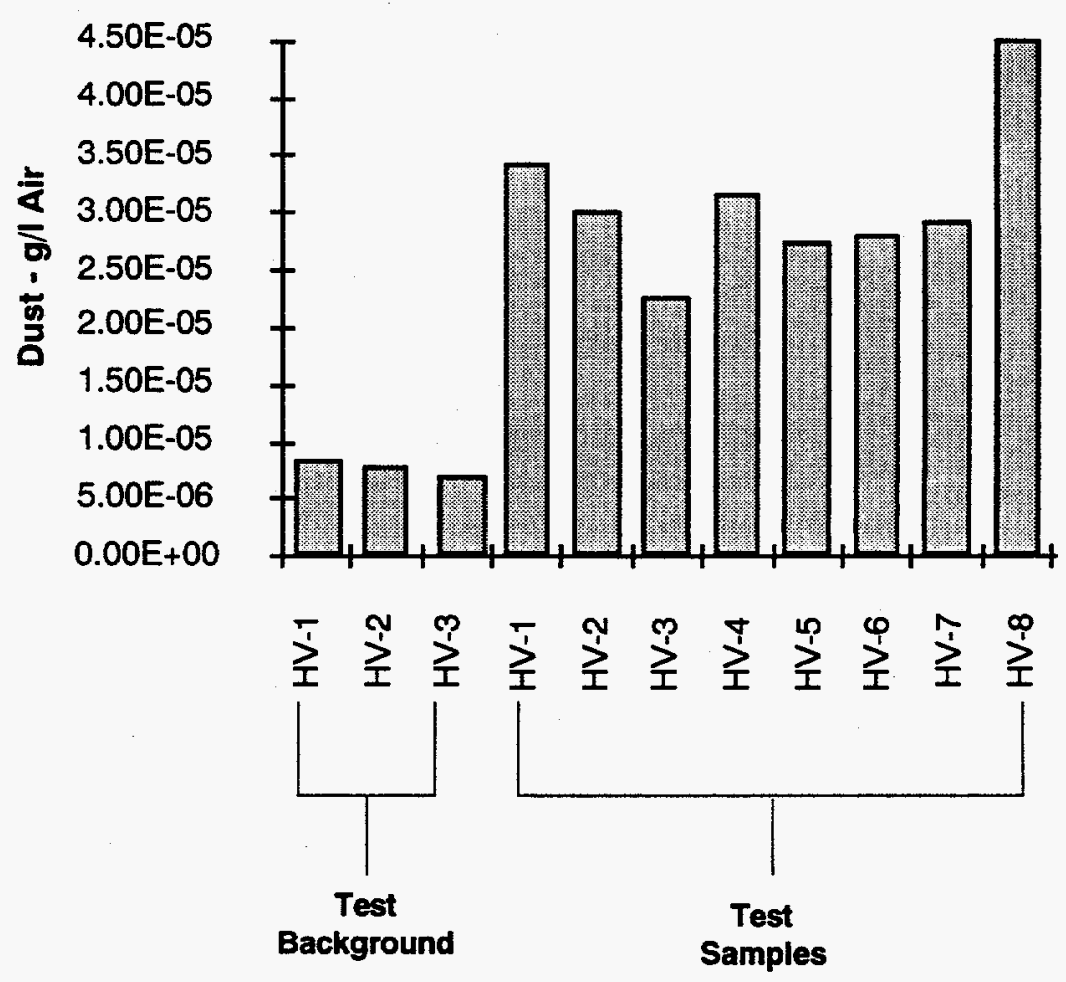

Figure 17. A simple bar chart will be used to display the dust measurement data. 
Table 6. The data and analysis for dust measurement will be published in tabular form for each test run similar to the table shown.

\begin{tabular}{|c|c|c|}
\hline \multirow{4}{*}{ Description } & Monitor & $\begin{array}{c}\text { Dust loading } \\
\text { g/L air }\end{array}$ \\
\hline \multirow{3}{*}{ Test Background } & HV-1 & \\
& HV-2 & \\
\hline & HV-3 & \\
\hline \multirow{5}{*}{ Test Samples } & HV-1 & \\
\hline & HV-2 & \\
\hline & HV-3 & \\
\hline & HV-4 & \\
\hline & HV-5 & \\
\hline & HV-6 & \\
\hline & HV -7 & \\
\hline
\end{tabular}

$\begin{aligned} \text { Test Mean } & = \\ \text { Test Std Dev } & = \\ n_{d} & = \\ v=\left(n_{d}+n_{b}-2\right)= & \\ \text { Critical 1-Sided }(.95, v) & = \\ \text { Pooled Std Dev } & = \\ \text { Calculated t Statistic } & = \\ \text { Calculated P-value } & \\ \text { Background Mean } & = \\ \text { Background Std Dev } & = \\ n & \\ n_{b} & = \\ & \end{aligned}$

a. HV\# = High-Volume Air Sampler

\subsubsection{Rare Earth Tracer Data Reduction}

The HI-VOL air filters will be analyzed for the rare earth tracer using the procedures outlined in Section 7.2, "Chemical Analysis of Filters," by the ECL. The data will be reported by the lab using their standard forms and procedures and published in the technology evaluation report. Figure 18 shows a sample of a graph that may be used to display the rare earth tracer analysis for the test background and the test samples. The raw data and calculation of the mean, standard deviation, and t-test analysis will be presented in a table similar to that shown in Table 7. The procedures used to calculate the statistical results can be found in Section 5.4.5, "Data Analysis."

The following is an example calculation showing how instrument solution concentrations are derived. The sample data are from HI-VOL air filter samples taken in FY-93.

Dust load weight on filter: $0.0011-0.0714 \mathrm{~g}$ 


\section{Rare Earth Tracer Quantities - Test \#X}

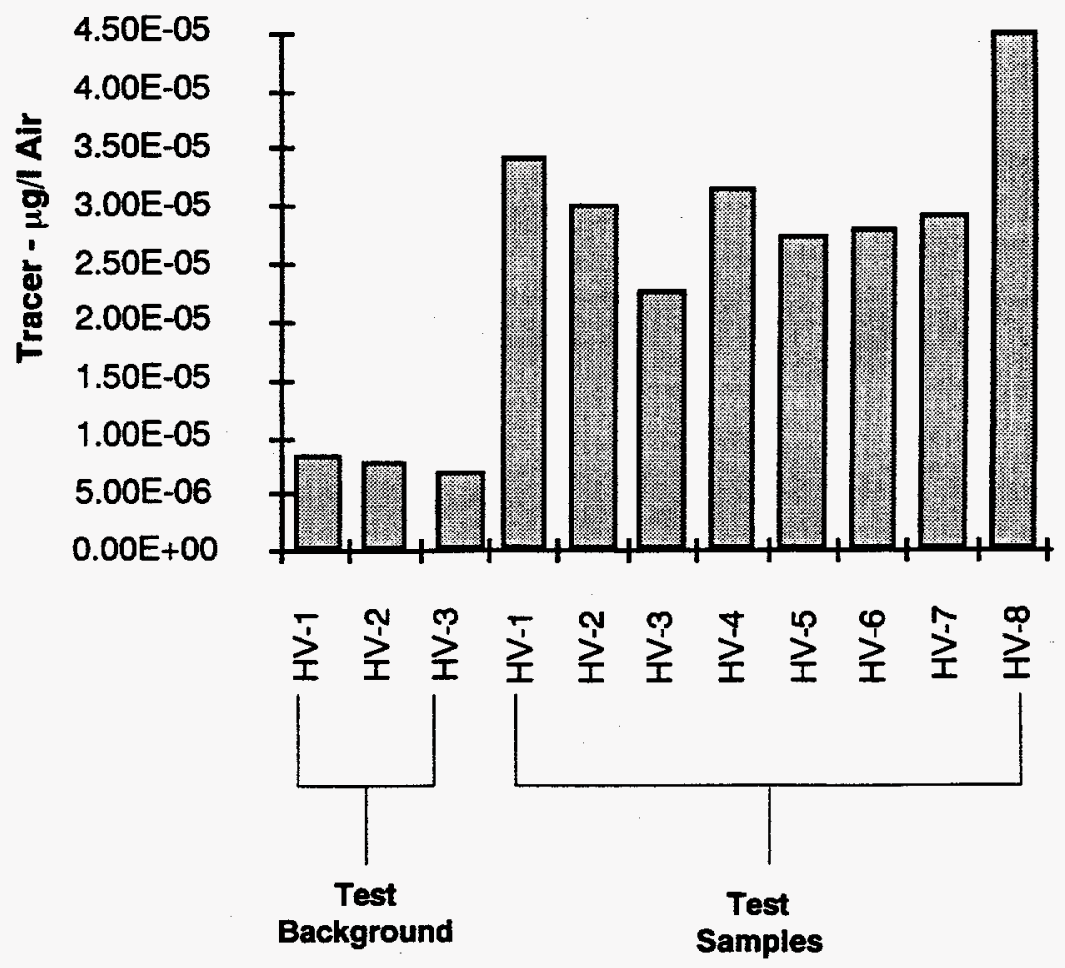

Figure 18. A simple bar chart will be used to display the rare earth tracer data. 
Table 7. The data and analysis for rare earth tracers will be published in tabular form for each test run similar to the table shown.

\begin{tabular}{|c|c|c|}
\hline \multirow{4}{*}{ Description } & & $\begin{array}{c}\text { Tracer loading } \\
\mu \mathrm{g} / \mathrm{L} \text { air }\end{array}$ \\
\hline \multirow{3}{*}{ Test Background } & Monitor $^{\mathrm{a}}$ & \\
\hline \multirow{5}{*}{ Test Samples } & HV-1 & \\
\hline & HV-2 & \\
\hline & HV-1 & \\
\hline & HV-2 & \\
\hline & HV-3 & \\
\hline & HV-4 & \\
\hline & HV-5 & \\
\hline & HV-6 & \\
\hline & HV-7 & \\
\hline
\end{tabular}

$\begin{aligned} \text { Test Mean } & = \\ \text { Test Std Dev } & = \\ n_{d} & = \\ \mathrm{v}=\left(n_{d}+n_{b}-2\right) & = \\ \text { Critical 1-Sided } \mathrm{t}(.95, \mathrm{v}) & = \\ \text { Pooled Std Dev } & = \\ \text { Calculated } \mathrm{t} \text { Statistic } & \\ \text { Calculated P-value } & = \\ \text { Background Mean } & = \\ \text { Background Std Dev } & = \\ n_{b} & = \\ & \\ \text { Test Mean /Background Mean) } & =\end{aligned}$

a. HV\# = High-Volume Air Sampler

Assume $\quad \sim 6.0 \mu \mathrm{g} / \mathrm{g}$ praseodymium background then the lowest dust weight

$6.0 \mu \mathrm{g} / \mathrm{g} \times 0.0011 \mathrm{~g}=0.0066 \mu \mathrm{g}$ praseodymium $/ 250 \mathrm{~mL}$

$0.026 \mu \mathrm{g} / \mathrm{L}$ praseodymium in solution for instrument.

Assume $\quad \sim 6.0 \mu \mathrm{g} / \mathrm{g}$ praseodymium background then the lowest dust weight

$6.0 \mu \mathrm{g} / \mathrm{g} \times 0.0714 \mathrm{~g}=0.4284 \mu \mathrm{g}$ praseodymium $/ 250 \mathrm{~mL}$

$1.71 \mu \mathrm{g} / \mathrm{L}$ praseodymium in solution for instrument. 
The example calculations do not address levels of praseodymium present in the air filter material, which would have to be subtracted from the total praseodymium $\mu \mathrm{g}$ value before calculating the parts per million $(\mu \mathrm{g} / \mathrm{g})$ result in dust. The filter background will have to be determined for each lot of filters chosen for the test. The expected value of background praseodymium in the filter is approximately $0.8 \mu \mathrm{g}$ of praseodymium per 4-in. filter.

\subsubsection{Other Data Reduction Methods}

The data regarding the overall system performance, including system integration, effectiveness on large objects and various waste forms, reliability, and maintainability etc., will be recorded to document the system capabilities and will not be subject to data reduction techniques.

The data regarding the throughput and maneuverability of the system will be recorded and analyzed by calculating the mean, range, bias, and standard deviation, as appropriate.

\subsection{Data Collection and Validation}

Data validation requires a systematic process for reviewing data against a set of criteria to provide assurance that the data are adequate for their intended use. The criterion for the filter data is that the location and test case recorded with the sample number is correct and documented so that the data cannot be lost. When necessary, other data will be validated by cross checking between the RAHCO and EG\&G Idaho log books. The PI and RAHCO test conductor will review the field log books.

The data will be assembled, analyzed, and documented in EG\&G Idaho informal reports. Specific data to be reported include

- Measurement of mass of dust collected on filters

- Measurement of the amount of rare earth tracer collected on filters

- Time/volume analysis of removal and conveyance rates

- Ambient environmental conditions during testing (wind velocity, temperature, and humidity)

- Length of time between current measurement and previous background or test measurement

- Dimensions for determining maneuverability of the equipment

- Soil moisture

- Visual estimate of spillage

- Ability of equipment to operate within the designated maneuverability path

- Throughput of the system

- Effectiveness of the equipment to handle various waste forms and large objects. 
Analytical results for the rare earth tracer will be validated by the use of prepared standards, use of duplicate samples, and submission of blanks with each sample set. The standards, duplicates, and blanks will be submitted as a blind to the analytic laboratory (see Section 9.2, "Quality Control Methods and Procedures," for a more complete discussion.

\subsection{Data Validation Responsibility}

Qualification of the data will be conducted by the analysis team and approved by the analysis team leader. The analysis team leader will be one of the BWID retrieval technical liaisons. The analysis team leader will not be directly involved in the data collection or analysis activities, but instead will review the data and analysis to ensure it meets the requirements stated herein.

In addition, the data will be validated during collection by the personnel performing the demonstration. This review is primarily to determine if the data collected are meaningful and within the bounds expected. If this review determines that there are suspect data, a review of the test procedures and test plan will be made to determine if there is a problem.

\subsection{Acceptance Criteria}

All of the filter samples taken during the demonstration will be recorded and forwarded to the ECL for analysis. Once the data on all of the filters are analyzed, the task manager will review the log book to determine if any of the data on the filters or other data should be rejected due to gross abnormalities during the demonstration. If there are major equipment malfunctions during a portion of

the demonstration, the task manager, PM, and field team leader may concur that the analysis of some data will be futile and cancel the analyses of that data. 


\section{QUALITY ASSURANCE}

A review of the requirements of BWID Program Directive 9.5, Quality Plan indicates that a project specific Quality Program Plan (QPP) is not required. All work associated with this task shall be performed in accordance with the Engineering Research and Applications Department QPP-044 and applicable sections of the EG\&G Idaho Quality Manual.

\subsection{Quality Level}

The quality level for this work scope will be Quality Level B. Quality of acquired data will be verified using a quick look review by the responsible EG\&G Idaho site representative, RAHCO Project Engineer or PM, project scientist, and or other BWID Program personnel who are knowledgeable of data, assumptions, methodology, and individual measurements analysis to verify that data are within the performance specification as detailed in this test plan.

\subsection{Quality Control Methods and Procedures}

All testing shall be done in accordance with an approved test plan, approved test procedures, and with qualified personnel (as defined in the procedures). The test procedures shall specify sensor and measurement systems to be used (e.g., model number, make, and calibration). Measurement uncertainty for data taken against the test objectives shall be documented.

Routine monitoring will be needed during the time that the samplers are operational in the field. During this check, the person will ensure that each sampler is operational and running within operational limits of the flow. Any changes made to the sampler shall be noted in the field log book, along with any other information such as temperature, humidity, and weather conditions. In addition, the person shall conduct a routine safety inspection of the equipment and general area to ensure that no unsafe conditions occur.

Data quality shall be verified using peer review by a person knowledgeable of data, assumptions, methodology, and individual measurement analysis to verify that data are within the performance specifications detailed in this test plan.

Quality assurance of samples collected will be verified using several methods. All filters used for sampling will be weighed on a balance having a current calibration certification from the Standards and Calibrations Laboratory. HI-VOL air monitors will have current calibrations and calibration data from the Standards and Calibrations Laboratory before use. The calibration information will be referenced in the project log book, and the reference data will be kept in the project file. Analytical results will be verified by the use of prepared standards, use of duplicate samples, and submission of blanks with each sample set. The standards, duplicates, and blanks will be submitted as a blind to the analytic laboratory.

The quality level for this work scope will be Quality Level B, as described in ERA QPP-044. The analytical quality control will consist of the preliminary interference study to determine if other interfering elements or polyatomic species present problems during ICP-MS analysis for the rare earth tracer. Included in each batch of samples will be a minimum of four blank filters from the same batch used for sampling, two of which will be spiked with known quantities of rare earth tracer and a reagent blank for a reagent impurity check. 
Previously the laboratory has participated in analyses of rare earth tracers in support of the cryogenic retrieval demonstration during the summer of 1992 and the overburden removal demonstration in the summer of 1993. The analytical methodology is described in existing laboratory SOPs for this work; the only change to the SOPs for this work scope is the identity of the tracer analytes. In 1992, this laboratory was approved by EG\&G Idaho Environmental Restoration Department, Sample Management Office for analytical support of the cryogenic retrieval demonstration using these specific analyses.

\subsection{Precision and Accuracy of Measured Data}

\subsubsection{Dust and Rare Earth Tracer Data}

Instrument batch quality control samples will consist of an independent calibration standard check and continuing calibration standard and blank checks every 10 samples. A post-digestion spike also will be included in every instrument batch. These quality control samples will provide precision and accuracy estimates for the analytical methodology.

\subsubsection{Maneuverability (Precision and Accuracy Data)}

The use of standard measuring tapes for the measurement of distances between reference marks will provide data sufficient to meet the data quality objective.

\subsection{Change Control}

See Section 6.4, "Test Plan Changes."

\subsection{Internal Audits}

Self or independent audits of project activities shall be performed in accordance with BWID Program Directive 4.2, Audit Planning. 


\section{EQUIPMENT AND INSTRUMENTS}

\subsection{Equipment and Instrument List}

Table 8 provides a list of equipment and supplies needed to conduct sampling during the Phase I demonstration. Table 9 lists primary equipment to be used for this demonstration. Table 10 lists primary equipment to be used for the Phase II demonstration. The equipment noted as rental may be substituted with an equal or better depending on availability at the time of the demonstration.

Table 8. Air sampling equipment, laboratory equipment, and consumables (filters) are required to determine the contamination spread and dust generation for Phase 1 of the demonstration.

Description

HI-VOL samplers

Four-place analytical balance (or equivalent)

4-in. glass fiber particulate filters
Required

8

1

Approximately 150

Table 9. Primary equipment needed to support the Phase I demonstration.

Description

Spar-Hitachi remote operated hydraulic excavator

Remote operation system control trailer with operator control station

Innovative end effector assembly

Integrated Transfer Module

Transport container

Rough terrain forklift

Transport container stand

Table 10. Primary equipment needed to support the Phase II demonstration.

Description Required

Spar-Hitachi remote operated hydraulic excavator

Innovative end effector assembly 1

Integrated Transfer Module 3

Transport Container

2

Receiving Station

Telerobotic Transport Vehicle

Remote operation system control trailer with operator control station

Rough terrain forklift 


\subsection{Instrument Requirements}

The Phase I demonstration does not require any instrumentation other than that described in Table 8 for air sampling. The Phase II demonstration requires a calibrated surveyor's transit and stadia to survey the topography of the simulated hill.

\subsection{Calibration and Standardization}

Air monitor calibration is performed by the EG\&G Idaho Standards and Calibration Laboratory on a biannual basis. All non-INEL instruments requiring calibration shall be calibrated by the responsible party prior to deployment to the field.

\subsection{Maintenance}

Because of the short duration of this demonstration, only the following maintenance should be performed. All of the following shall be performed each morning before starting the equipment:

- Check lubricant and coolant levels on the conveyance vehicle, excavator, generators, etc.

- Check diesel fuel levels on all of the above

- Check battery levels. 


\section{SUPPLIES, UTILITIES, AND FACILITIES}

\subsection{Subcontractor Supplied Items}

RAHCO will provide all utilities and services, such as water, power, phone, and sanitary, at the work location. The HI-VOL particulate air samplers, which will be provided by EG\&G Idaho, will require ac power for their operation. RAHCO will provide ac power to meet this and any other EG\&G Idaho power needs.

Any other necessary equipment (such as an excavator for performing the demonstration) to be used in conjunction with the demonstration or area general maintenance will be supplied by RAHCO.

RAHCO will be responsible for providing operators for the machines. The operators designated for the excavator at the start of the test will be available throughout the duration of the demonstration. This is to ensure continuity of operation and consistency of comments and feedback. RAHCO is responsible for all transporting, fuel, maintenance, and operation of all machines.

RAHCO will provide approximately $16 \mathrm{yd}^{3}$ of simulated waste forms in the following proportions:

- $\quad$ Paper/Cloth-50\%

- Sludge (55-gal drum filled with Portland cement)-30\%

- $\quad$ Metal-10\%

- $\quad$ Concrete/Asphalt-10\%.

RAHCO shall also include a variety of large objects for the Phase II test, including at a minimum: a pickup truck bed, $15 \mathrm{ft}$ lengths of carbon steel pipe of varying diameter and schedule (maximum diameter $16 \mathrm{in}$. and maximum schedule 40 ), $15 \mathrm{ft}$ lengths of carbon steel structural shapes of varying weight (maximum $40 \mathrm{lb} /$ lineal foot weight), and a maximum of $200 \mathrm{ft}$ of 1 -in. (or less) steel cable (in maximum $50 \mathrm{ft}$ lengths), which may be randomly intertwined throughout the entire cell.

RAHCO will supply a means to move the transfer containers or receptacles as necessary during the demonstration.

Still photos and videotape of the demonstration at RAHCO's facility will be taken by RAHCO.

\subsection{EG\&G Idaho Supplied Items}

EG\&G Idaho shall maintain project management responsibility for the project. EG\&G Idaho personnel shall provide timely approval of necessary project documentation, witness portions of the fabrication and testing of the equipment, and witness all performance tests, and demonstrations. No other materials, services, personnel, equipment, or other items necessary to conduct the test will be furnished by EG\&G Idaho except as stated herein. 
EG\&G Idaho will provide approximately $50 \mathrm{yd}^{3}$ of INEL soil. The soil will be placed in transport boxes and shipped to RAHCO's testing site.

The soil will be spiked with rare earth tracer (praseodymium) by EG\&G Idaho personnel in conjunction with RAHCO. The rare earth tracers will be provided by EG\&G Idaho. The rare earth tracer (praseodymium) is a nonradioactive, nonhazardous (refer to the material safety data sheets) material. 


\section{HEALTH AND SAFETY}

Safety is of utmost concem with all experiments. It is the policy of EG\&G Idaho to take every practical precaution to protect the health of the employees. Three types of safety and training concerns are emphasized: radiological, laboratory, and waste management.

\subsection{Radiological Safety Training}

No work involving radioactive materials will be conducted during this demonstration.

\subsection{Laboratory Safety Training}

Laboratory safe practices are described in the EG\&G Idaho Science and Technology Standard Practices Manual, Safety Manual, Industrial Hygiene Manual, and the ECL SOPs. The subsections covered by each document that apply to this test plan include:

EG\&G Idaho Science and Technology Standard Practices Manual:

- Section 2.1.8-Laboratory Hood Use

- $\quad$ Section 1.4.4-Housekeeping Standard

- Section 2.1.6—Chemical Laboratory Safety

- $\quad$ Section 1.1.3-Training.

EG\&G Idaho Safety Manual:

- Section 7-Personal Protective Equipment: Eye Protection and Clothing.

EG\&G Idaho Industrial Hygiene Manual:

- Section 18-Personal Protective Equipment.

ECL SOPs:

- Section 1.1.3-Personnel Training

- Section 1.4.1-Safety And Health Management.

\subsection{Waste Management Practices and Training}

Waste management practices are prescribed in the EG\&G Idaho Science and Technology Standard Practices Manual, ER\&A Department Standard Practices Manual, EG\&G Idaho Company Procedures Manual, Safety Manual, and the ECL SOPs. The subsections covered by each document that apply to this test plan include:

EG\&G Idaho Science and Technology Standard Practices Manual:

- Section 2.1.4 Chemical Spill Control. 
ER\&A Department Standard Practices Manual:

- Section 5-Chemical Management.

EG\& G Idaho Company Procedures-Volume II:

- Section 8.2-Satellite Accumulation Area.

ECL SOPs:

- $\quad$ Section 3.0-Waste Management

- $\quad$ Section 3.4.1-Satellite Accumulation Area Operation

- $\quad$ Section 3.4.1-Spill Contingency Plan.

EG\&G Idaho Safety Manual:

- Section 15.1-Routine Solid Waste Collection and Handling.

\subsection{Field Safety}

The BWID safety engineer and/or RAHCO's safety engineer shall conduct a safety walk-down of the test area periodically but at least once a week. Safety discrepancies and concerns shall be reported to the RAHCO field supervisor and BWID representative. Together, they shall correct any safety concems that arise in a timely manner.

The following safety training is required:

- Safety meeting (safety kick-off meeting on first day).

The following safety equipment will be required:

- $\quad$ Steel-toed safety shoes

- Leather gloves for handling and moving equipment

- Hard hats

- Hearing protection

- $\quad$ Filter face masks

- $\quad$ Eye protection with side shields

- No contact lenses will be allowed.

\subsubsection{Environmental Conditions}

During periods of inclement weather or strong winds, retrieval may (at the discretion of the field personnel from both EG\&G Idaho and RAHCO) be temporarily suspended. 


\subsubsection{Telerobotic Transport Vehicle}

The TTV is a diesel powered remotely-controlled tracked vehicle. Personnel shall avoid the TTV tracks, both when the TTV is moving or not moving. Everyone onsite will be reminded at each moming's safety meeting that when the TTV's diesel engine is running, it can move in any direction at any time without warning. Access to the test area will be administratively controlled.

\subsubsection{Excavation}

The most prominent personnel safety hazard during this demonstration is being in the vicinity of the excavator during operation. It is extremely important that personnel avoid:

- Tracks of the excavator, both with the machine moving or not moving

- Boom and swing arc of the boom

- Swing arc of the excavator cab body

- End Effector-No adjustments or other work shall be performed on the bucket unless the excavator is turned off and the operator's cab is empty.

Everyone onsite will be reminded at each moming's safety meeting that when the excavator's diesel engine is running, it can move in any direction at any time without waming. Access to the test area will be administratively controlled.

\subsubsection{Lockout and Tagout}

Lockout and tagout procedures will be followed in accordance with the project specific Environmental, Safety, and Health Plan. These procedures should be followed during any maintenance, repair, or adjustment for all engine or electrical equipment.

\subsubsection{Radiological}

No radioactive waste by-products are generated from the work described in this plan. No radioactive materials are involved in this demonstration. No work will be conducted in a radiation environment.

\subsubsection{Electrical}

Electrical power for the TTV control system will be provided by a 24 Vdc generator belt-driven by the TTV diesel engine. Personnel will not access the TTV control system for any reason while the TTV engine is operating.

Electrical power for the Remote Control Operations Trailer is provided by RAHCO Building 4 power outlets or a mobile generator. The power will be tumed on only for the time that power is needed during the testing. Access to the area around the generator set and the power lines will be administratively controlled. Power lines will be routed away from personnel pathways. 


\subsubsection{Dust Inhalation}

During Phase I, any person working when dust is high will wear a filter mask to prevent excessive dust inhalation. No contact lens will be allowed in the immediate area during Phase I testing.

The rare earth tracer to be used in the Phase I demonstration (praseodymium) is an irritant and can be irritating to eyes, respiratory system, and skin. Because the concentrations to be used in the demonstration are significantly greater than natural background, certain precautions shall be taken. Depending on potential level of exposure, the following personal protection equipment, use, and procedures shall be required:

- Chemical safety goggles

- Compatible chemical-resistant gloves

- National Institute of Occupational Safety and Health/Mine Safety and Health Administration-approved respirator

- Safety shower and eye bath

- Mechanical exhaust required

- Avoid inhalation

- Avoid contact with eyes, skin, and clothing

- Avoid prolonged or repeated exposure

- Wash thoroughly after handling

- No contact lenses will be allowed.

Personnel applying the praseodymium to the waste pile or supervising the application shall require the highest level of protection. Others may only require a dust mask during the demonstration when direct contact and exposure are limited. 


\section{RESIDUALS MANAGEMENT}

\subsection{Phase I Demonstration-Dust and Contamination Spread}

The only waste stream from the Phase I portion of the demonstration is the INEL soil and simulated waste mixture. Approximately $66 \mathrm{yd}^{3}$ total volume of this waste will require disposal at the completion of the demonstration. The waste will consist of a heterogeneous mixture composed of approximately $50 \mathrm{yd}^{3}$ of INEL dry soil and $16 \mathrm{yd}^{3}$ of simulated waste forms in the following proportions:

- Paper/Cloth-50\%

- Newspaper, computer paper, and rags.

- Sludge (55-gal drum filled with Portland cement)-30\%

- At least 20 55-gal drums (metal or cardboard) containing Portland cement (Portland cement simulates sludge drum density).

- $\quad$ Metal-10\%

- At least one $7 \mathrm{ft} \times 8$ in. I-beam along with other smaller pieces of metal that could fit into a 55-gal drum.

- $\quad$ Concrete/Asphalt-10\%

- $\quad$ An appropriate number of 2-ft diameter asphalt and concrete chunks.

The soil and waste from Phase I of the demonstration shall be recycled for use in the second phase of the demonstration.

\subsection{Phase II Demonstration-Retrieval and Conveyance}

The Phase II demonstration will use the same soil and waste that was used in the dust and contamination spread demonstration.

In addition, the Phase II demonstration will include a variety of large objects including at a minimum: a pickup truck bed, $15 \mathrm{ft}$ lengths of carbon steel pipe of varying diameter and schedule (maximum diameter 16 in. and maximum schedule 40 ), $15 \mathrm{ft}$ lengths of carbon steel structural shapes of varying weight (maximum $40 \mathrm{lb} /$ /ineal foot weight), and a maximum of $200 \mathrm{ft}$ of $1 \mathrm{in}$. (or less) steel cable (in maximum $50 \mathrm{ft}$ lengths), which may be randomly intertwined throughout the entire cell.

All solid waste (including the simulated buried waste and INEL soil) generated by RAHCO in conjunction with this demonstration shall be disposed of in a manner that complies with local ordinances and environmental law. This may include direct disposal of material at a municipal or private landfill, segregation of the material and recycling, or other means of disposal as determined by RAHCO. The RAHCO shall be responsible to dispose of all equipment, end effectors, funnel, storage boxes, or any other tools and items associated with this project. The excavated area shall be reclaimed with clean fill dirt. 


\section{REFERENCES}

Arrenholz, D. A., Knight, J. L., A Brief Analysis and Description of Transuranic Wastes in the Subsurface Disposal Area of the Radioactive Management Complex at INEL, EGG-WTD-9438, EG\&G Idaho, Inc., February 1991.

Bonnenberg, R. W., R. E. Heard, L. M. Milam, and L. R. Watson, Buried Waste Integrated Demonstration FY-93 Deployment Plan, EGG-WTD-10539, EG\&G Idaho, Inc., February 1993.

Meyer, L. C., Transuranic Contamination Control Using Electrostatic Curtains (Proof-of-Principle Experiments), EGG-WTD-9336, EG\&G Idaho, Inc., November 1990.

Meyer, L. C., et al, La-oxides as Tracers for $\mathrm{PuO}_{2}$ to Simulate Contaminated Aerosol Behavior, EGG-WTD-11161, EG\&G Idaho, Inc., April 1994.

Valentich, D. J., Full Scale Retrieval of Simulated Buried Transuranic Waste, EGG-WTD-10895, EG\&G-Idaho, Inc., September 1993. 
Appendix A

Basis for Dust Level

A-1 
A-2 


\section{Appendix A}

\section{Basis for Dust Level}

Revision 1, March 22, 1994

This is a description of the data and process used to develop the dust level requirement for the Innovative End Effector/Dust Free Dumping Demonstration.

Given the following average* contamination level expected for RWMC remediation activities:

$450 \mathrm{nCi} / \mathrm{g}: \quad$ Plutonium/Americium/mass soil. Based on calculations done by Guy Loomis that showed a level of $150 \mathrm{nCi} / \mathrm{g}$; this number was increased by a factor of 3 when Hazel OLeary announced (1993) the factor of 3 increase in the amount of plutonium at the RWMC. Local hot spots may have higher contamination levels.

To allow for bubble suit entry, it is necessary to have an airborne exposure level of $<10 \mathrm{nCi} / \mathrm{g}$. [Based on Maximum Permissible Concentration (MPC) values and calculated by Burt Baldwin and Wayne Scofield.] Bubble suited entry into areas of higher airbome exposure levels has been shown to lead to uptake during doffing of bubble suits.

Problem: Need to reduce the amount of aerosolized dust so that the airbome exposure level is $<10 \mathrm{nCi} / \mathrm{g}$.

If we completely aerosolized the dust, we would see airborne exposure levels of $450 \mathrm{nCi} / \mathrm{g}$. (In actuality, this is not possible, because some particles are too heavy to become/remain airborne. To be conservative, we will use this worst case number.) To achieve an airborne contamination level of $<10 \mathrm{nCi} / \mathrm{g}$, we need to remove $98 \%$ of the dust $(10 \mathrm{nCi} / \mathrm{g} / 450 \mathrm{nCi} / \mathrm{g}=.02$, or $2 \%)$.

The next step is to identify a number (mass per unit volume, i.e., $g / L$ ) that represents a worst case (100\% aerosolized) dust measurement. A study done at the INEL (Menkhaus, 1991) regarding shower effectiveness included a test that aerosolized dust to simulate a worst case scenario. In the test, dust was aerosolized continuously and air particulate filters were used to measure the amount of airbome dust. The amount (mass) of airborne dust per unit volume of air seen was $5.5 \mathrm{E}-3 \mathrm{~g} / \mathrm{L}$, as shown below.

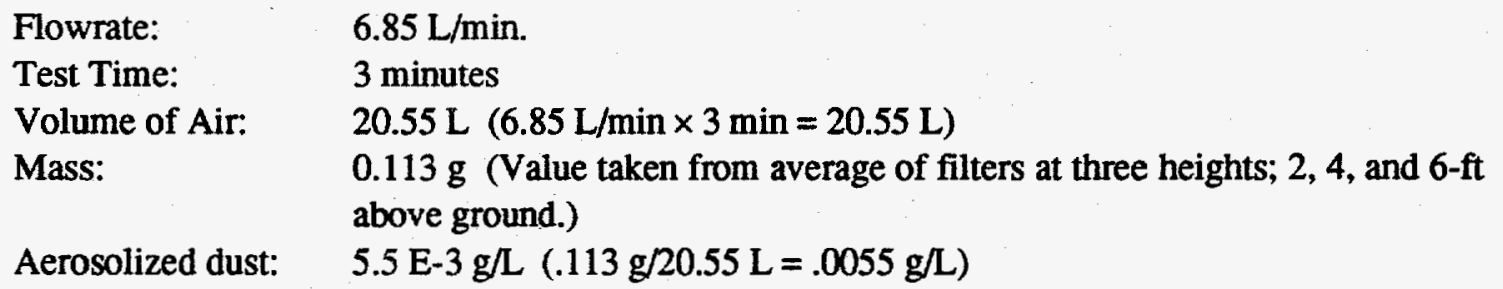

This number, $5.5 \mathrm{E}-3 \mathrm{~g} / \mathrm{L}$, represents worst case aerosolized dust. To achieve the required airbome exposure levels, we need to achieve a $98 \%$ improvement over this value. The maximum dust level allowed is therefore:

$1.1 \mathrm{E}-4[.0055 \mathrm{~g} / \mathrm{L} \times .02=.00011 \mathrm{~g} / \mathrm{L}]$ 
This number $(1.1 \mathrm{E}-4 \mathrm{~g} / \mathrm{L})$ will be used as the goal for the dust level to be achieved by the Innovative End Effector/Dust Free Dumping Demonstration to be conducted in FY-94.

* Note: Much higher values could be encountered for regions containing waste containers with the maximum amount of allowable plutonium/americium, i.e., $200 \mathrm{~g} /$ container. These areas constitute local hot spots.

\section{References}

Menkhaus, Daniel E., Personnel Protective Equipment Total-Encapsulating Suit Decontamination Study Using Shower Systems, EGG-WTD-9475, EG\&G Idaho, Inc., January 1991. 
Appendix B

Test Procedures

B-1 
B-2 


\section{Appendix B}

\section{Test Procedures}

\section{B-1. PHASE I DEMONSTRATION}

\section{Test Set-Up}

1. Construct simulated waste test bed.

2. Attach end effector and ITM to excavator boom.

3. Position test equipment including excavator, transport container stand, ITMs, transport containers, and remote operations control trailer. The excavator will be positioned near the test bed. The transport container stand will be placed 180 degrees from the test bed with respect to the excavator boom rotation. A waste container and an ITM will be positioned on this stand. The other waste container and ITM will be placed on the floor at the west door of the building. The remote operations control trailer will be positioned between the test bed/excavator and the building's west door.

4. Start the generator for the remote operations control trailer and verify power to operator control station.

5. Start the excavator and check out all movements and operations.

6. Confirm that all fuel tanks and lubricant levels are full and ready for operation.

7. Close east door of building. Seal any large cracks in building walls with duct tape.

8. Set up the particulate air samplers. The air samplers will be positioned as follows: two will be placed near the simulated waste pile, two will be placed near the excavator chassis, and four will be placed around the test stand where the ITM is transferred to the transport container.

9. Position video cameras and lights.

10. Hold Test Readiness Review meeting. Review test set-up, test procedures, safety issues, etc.

Test

1. Start the remote operations control trailer generator.

2. Obtain 30 minutes worth of background data from the HI-VOL samplers, then pull the background sample filters and replace with new filters.

3. Start the excavator. 
4. Start the HI-VOL samplers.

5. Start video cameras.

6. Begin excavating test bed and place full ITM into transport container.

7. Record volume of waste in ITM and spillage during transfer.

8. Excavator mates end effector with empty ITM, attaches, and lifts ITM up from stand.

9. Building 4 overhead crane closes transport container lid and transports it to west end of building.

10. Forklift outside building opens transport container and removes full ITM.

11. Forklift empties ITM at designated location outside of building.

12. Wipe excess dust from ITM.

13. Forklift places empty ITM into transport container (on floor at west end) and closes lid.

14. Overhead crane returns transport container (with empty ITM inside of it) and places transport container on stand near excavator.

15. Overhead crane opens transport container lid and places ITM on stand for excavator to pick up.

16. Repeat steps 6 through 15 until end of day, time to remove air sampling filters, or until testing is completely excavated.

17. This completes the Phase I demonstration. 


\section{B-2. PHASE II DEMONSTRATION}

Test Set-Up

1. Construct simulated hill.

2. Construct simulated waste test bed. This is built as the Phase I demonstration is performed by simply dumping the excavated waste into a pile at a designated location.

3. Attach end effector and ITM to excavator boom.

4. Position test equipment including excavator, TTV, ITMs, transport containers, receiving stations, and remote operations control trailer (see Figure 3). The excavator will be positioned near the test bed. The TTV will be placed 180 degrees from the test bed with respect to the excavator boom rotation. A waste container and an ITM will be positioned on the TTV. The receiving station will be positioned at the end of the TTV path (see Figure 3). The other waste container and ITM will be placed on this receiving station. The remote operations control trailer will be positioned next to the Engineering Office Building.

5. Attach all TTV, excavator, and receiving station reference marks.

6. Position TTV path marking posts.

7. Start the generator for the remote operations control trailer and verify power to operator control station.

8. Start the excavator and check out all movements and operations.

9. Confirm that all fuel tanks and lubricant levels are full and ready for operation.

10. Position video cameras and lights.

11. Hold Test Readiness Review meeting. Review test set-up, test procedures, safety issues, etc.

Test

1. Start the remote operations control trailer generator.

2. Start the excavator.

3. Start video cameras.

4. Begin excavating test bed and place full ITM into transport container on TTV. Record time at start of excavating.

5. Record volume of waste in ITM and spillage during transfer. 